\title{
IntechOpen
}

\section{Modern Medical Genetics and Genomics}

\author{
Edited by Israel Gomy
}





\title{
Modern Medical Genetics and Genomics
}

\author{
Edited by Israel Gomy
}



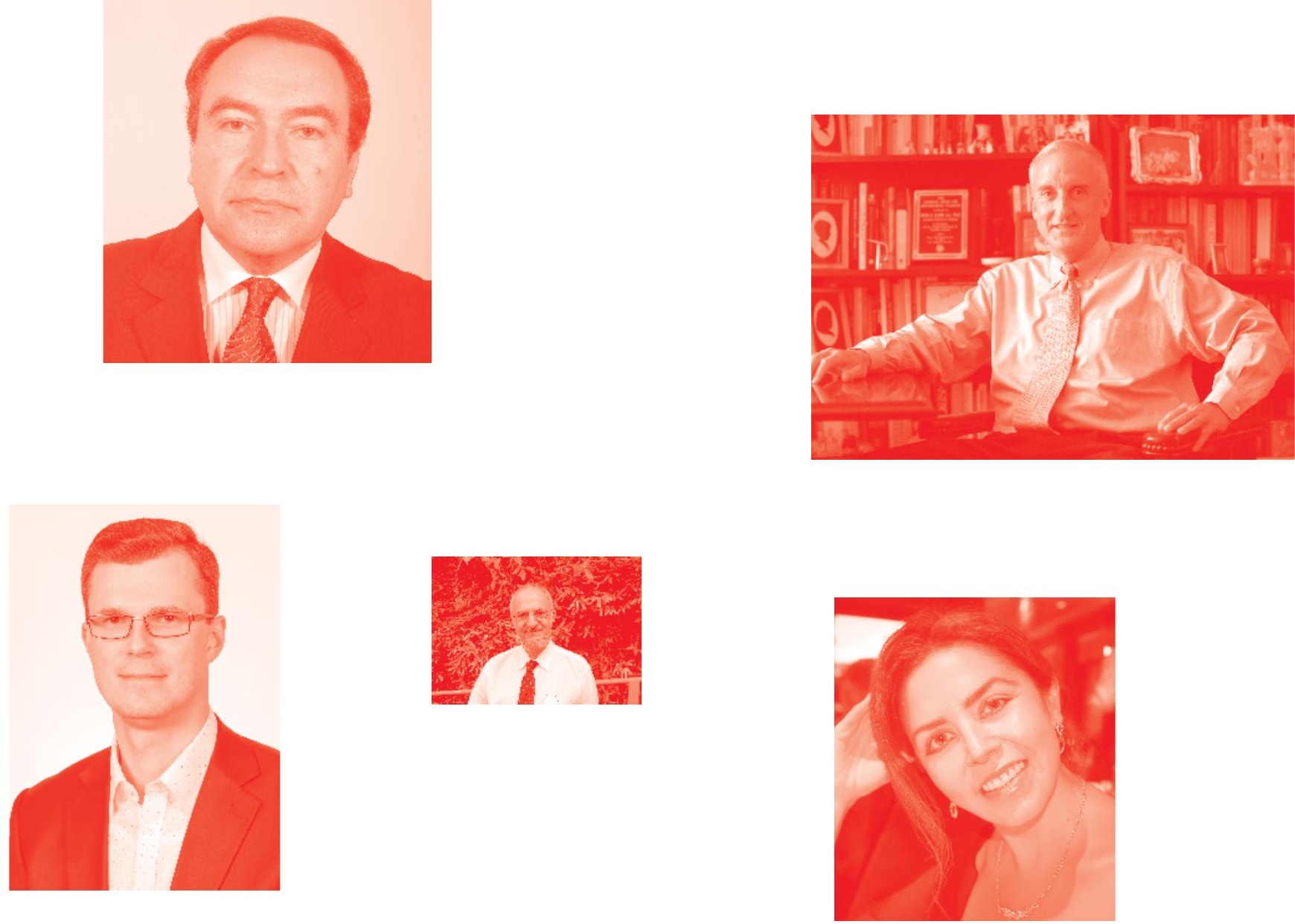

Supporting open minds since 2005
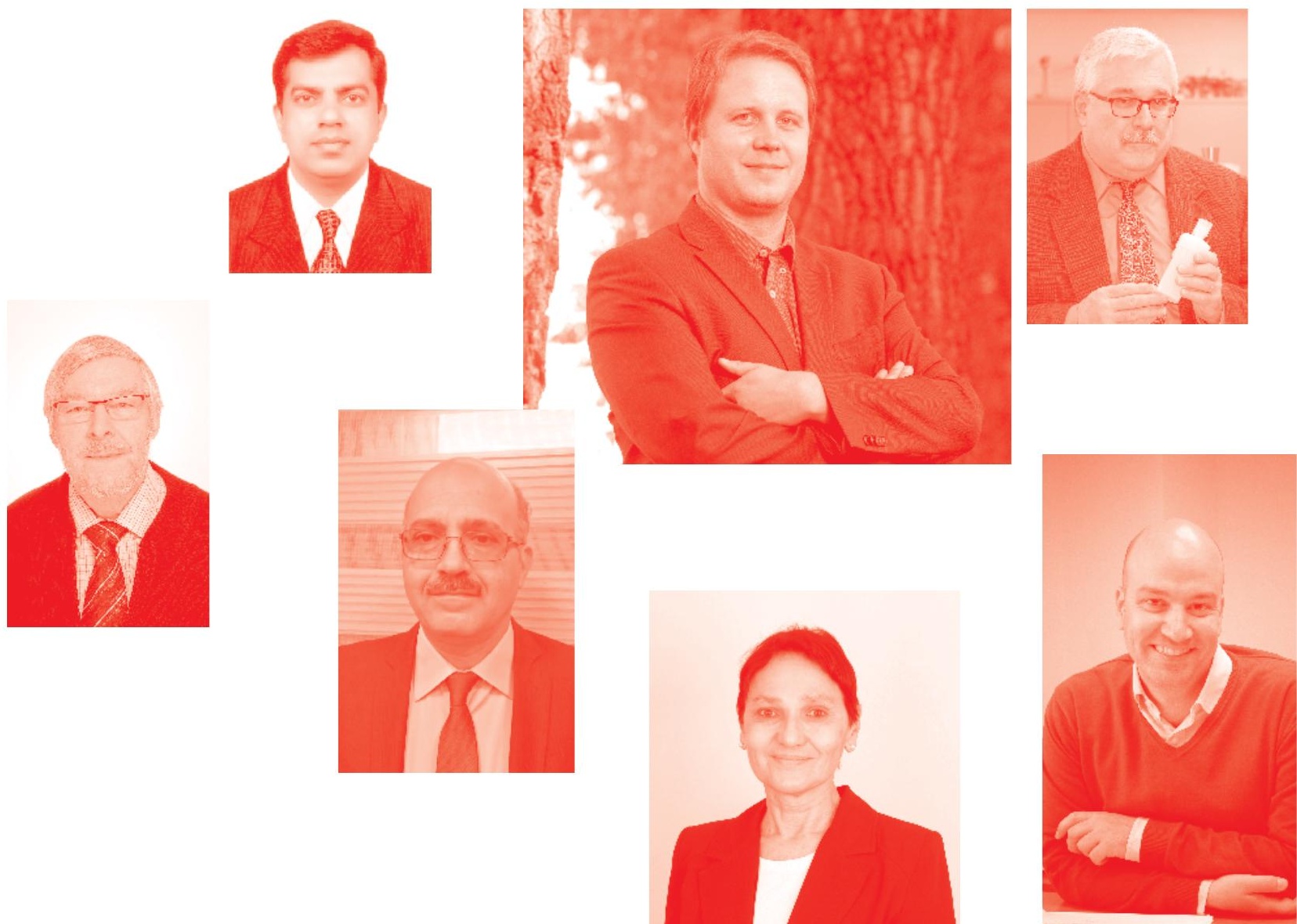
Modern Medical Genetics and Genomics

http : //dx. doi. org/10.5772/intechopen. 76597

Edited by Israel Gomy

\section{Contributors}

Esther Lopez-Bayghen, Almena Lopez-Luna, Dinorah Hernandez-Melchor, Leticia Ramirez, Rodney Scott, Tom Nolis, Isam Al Jashi, Al Jashi Cristina Gladys, Leonardo Porchia, Elizbeth Schaeffer, Israel Gomy

( ) The Editor(s) and the Author(s) 2019

The rights of the editor(s) and the author(s) have been asserted in accordance with the Copyright, Designs and Patents Act 1988. All rights to the book as a whole are reserved by INTECHOPEN LIMITED. The book as a whole (compilation) cannot be reproduced, distributed or used for commercial or non-commercial purposes without INTECHOPEN LIMITED's written permission. Enquiries concerning the use of the book should be directed to INTECHOPEN LIMITED rights and permissions department (permissions@intechopen.com).

Violations are liable to prosecution under the governing Copyright Law .

\section{(cc) BY}

Individual chapters of this publication are distributed under the terms of the Creative Commons Attribution 3.๑ Unported License which permits commercial use, distribution and reproduction of the individual chapters, provided the original author(s) and source publication are appropriately acknowledged. If so indicated, certain images may not be included under the Creative Commons license. In such cases users will need to obtain permission from the license holder to reproduce the material. More details and guidelines concerning content reuse and adaptation can be found at http : //www . intechopen . com/copyright-policy . html .

\section{Notice}

Statements and opinions expressed in the chapters are these of the individual contributors and not necessarily those of the editors or publisher. No responsibility is accepted for the accuracy of information contained in the published chapters. The publisher assumes no responsibility for any damage or injury to persons or property arising out of the use of any materials, instructions, methods or ideas contained in the book.

First published in London, United Kingdom, 2019 by IntechOpen IntechOpen is the global imprint of INTECHOPEN LIMITED, registered in England and Wales, registration number: 11086078 , 7th floor, 10 Lower Thames Street, London,

EC3R 6AF, United Kingdom

Printed in Croatia

British Library Cataloguing-in-Publication Data

A catalogue record for this book is available from the British Library

Additional hard and PDF copies can be obtained from orders@intechopen.com

Modern Medical Genetics and Genomics

Edited by Israel Gomy

p. $\mathrm{cm}$.

Print ISBN 978-1-83968-142-4

Online ISBN 978-1-83968-143-1

eBook (PDF) ISBN 978-1-83968-144-8 


\section{We are IntechOpen, \\ the world's leading publisher of Open Access books}

\section{Built by scientists, for scientists}

\section{$4,500+$}

Open access books available

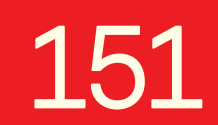

Countries delivered to

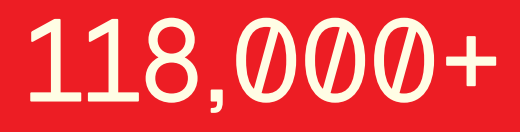

International authors and editors
$130 \mathrm{M}+$

Downloads

Our authors are among the

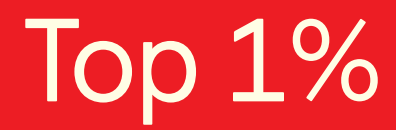

most cited scientists

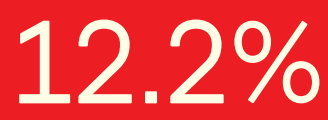

Contributors from top 500 universities

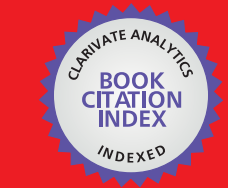

WEB OF SCIENCE ${ }^{\text {MM }}$

Selection of our books indexed in the Book Citation Index in Web of Science ${ }^{\mathrm{TM}}$ Core Collection (BKCI)

\section{Interested in publishing with us? \\ Contact book.department@intechopen.com}

Numbers displayed above are based on latest data collected.

For more information visit www.intechopen.com 



\section{Meet the editor}

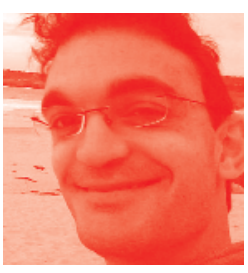

Dr. Israel Gomy graduated in Medicine at Pontificia Universidade Católica do Paraná, Curitiba, Brazil. He received his Master's degree in Biomedical Research at Universidade de São Paulo, Ribeirão Preto, Brazil, and his $\mathrm{PhD}$ in Oncology at Fundação Antônio Prudente, São Paulo, Brazil. Dr. Gomy is an assistant professor at Faculdades Pequeno Príncipe, Curitiba, Brazil, and an assistant physician at Hospital de Clínicas da Universidade Federal do Paraná, Curitiba, Brazil. He is also a postdoctoral researcher in medical oncology at Dana-Farber Cancer Institute, Boston, USA. 



\section{Contents}

Preface

Section 1

Introduction

Chapter 1

Modern Medical Genetics and Genomics in the Era of Personalized/Precision

Medicine

by Israel Gomy

Section 2

Reproductive and Prenatal Genetics

Chapter 2

The Genetic and Biochemical Blueprint of Endometrial Receptivity: Past, Present, and Future Factors Involved in Embryo Implantation Success

by Almena López-Luna, Dinorah Hernández-Melchor, Leticia Ramírez-Martínez and Esther López-Bayghen

Chapter 3

Aneuploidy Rates Inversely Correlate with Implantation during In Vitro

Fertilization Procedures: In Favor of PGT

by Elizabeth Schaeffer, Leonardo Porchia, Almena López-Luna,

Dinorah Hernández-Melchor and Esther López-Bayghen

Chapter 4

Screening (Bi Test, Triple Test, Panorama Test) and Amniocentesis for Early

Diagnosis of Congenital Malformations

by Gladys Cristina Al Jashi and Isam Al Jashi

Section 3

Cancer Genetics

Chapter 5

Genetic Contributors to Hereditary Cancer Predispositions: Do We Have Enough Information?

by Tom Nolis and Rodney J. Scott 



\section{Preface}

The field of medical genetics and genomics is undergoing a constant revolution based on new breakthroughs that bring increasing insights into the etiology of rare and common diseases, which help improve the health care of individuals with these disorders.

The development of high-throughput technologies such as next-generation sequencing (NGS) has enabled the detection of inherited susceptibilities and actionable mutational profiles of tumors for tailored therapies and management. Additionally, the generation of such massive amounts of data has prompted advances in the field of bioinformatics, with regard to complex tools and numerous databases to guide the interpretation of such big data, and to deal with noninformative results such as the notorious variants of uncertain significance. Besides these technical challenges, important ethical issues must also be considered: for example, the disclosure of results from prenatal and newborn screening through NGS, and findings from population-level screening of asymptomatic individuals. Addressing such challenges is not easy. We propose that investigators must provide tentative answers for one vital question: What is the analytic validity, clinical validity, and clinical utility of genetic testing?

This book aims to depict some of the myriad applications of genetics and genomics in the practice of medicine. We present the material in three sections: (1) an introductory landscape of medical genetics and genomics and portraits of personalized genomic medicine; (2) the field of reproductive genetics and prenatal screening: the first two chapters of this section deal with the most critical factors involved in the success of embryo implantation through assisted reproductive technology, including endometrial receptivity and rates of embryonic aneuploidy; the third chapter evaluates the accuracy of invasive and noninvasive prenatal screening for predicting the risk of fetal malformations; and (3) the area of hereditary cancer genetics, wherein is presented an updated review of the clinical utility of genetic testing, as exemplified by the description of hereditary breast and ovarian cancers.

Even though the information presented here offers a very limited look at the modern-day developments and breakthroughs of the centenarian field of medical genetics, this book nevertheless provides an important glimpse of the fascinating and challenging era of personalized or precision medicine. 

Section 1

\section{Introduction}





\section{Modern Medical Genetics and Genomics in the Era of Personalized/Precision Medicine}

Israel Gomy

\section{Introduction}

Modern medical genetics as a well-defined field of medicine has developed so fast since its origins half a century ago that we cannot bear in mind how long time ago its roots and beginnings came from.

It can be argued that genetics overall was based on measuring the problems of human hereditary features and inherited diseases, since before the twentiethcentury acceptance of Mendelian laws of heredity. Thus, medical genetics, viewed from its broadest perspective, is perhaps the oldest area of genetics and not a recent area that it is sometimes believed.

\section{Modern genomics in medicine}

During the years, with developments in cellular and molecular biology, the field of medical genetics expanded from a small clinical subspecialty focused at describing a few rare hereditary disorders to a recognized medical specialty whose principles and approaches are essential parts of the diagnosis and management of many disorders, both common and rare. These genetic concepts and approaches are not restricted to any one medical specialty or subspecialty, as they permeate many, and perhaps all areas of medicine.

The medical geneticist is usually a physician who works as part of a team of clinical providers, including many other physicians, nurses, and genetic counselors, to evaluate patients and their relatives for possible hereditary diseases. They characterize the patient (or proband) through analyses of personal and family history and physical examination; assess risk and possible modes of inheritance; indicate diagnostic testing; manage prevention, treatment, and surveillance; and participate in communicating to other family members at risk for the disorder.

During the twentieth century, it gradually became clear that hereditary factors were implicated in many conditions and that different genetic mechanisms were involved. Virtually, any disease is the result of the interaction of genes and environment, but the relative influence of the genetic component may be large or small. Traditionally, genetic conditions have been classified into three categories: monogenic, chromosomal, and multifactorial disorders. However, it is becoming increasingly evident that the interplay of different genes (polygenic inheritance) is essential in disease and that an additional category-acquired somatic genetic disease-should also be included.

Improvements in all areas of medicine, mainly public health and therapeutics, resulted in modifying patterns of diseases, with improving recognition of the role 
of genetic factors for most of common disorders or even for the susceptibility to infectious diseases. For complex chronic degenerative diseases of adult onset, their overall contribution of heritability has been identified, as life expectancy increases and high-throughput technologies improve. These provide the opportunity for understanding the interactions between the genetic and environmental factors of diseases such as cancer, Alzheimer's disease, diabetes mellitus, macular degeneration, and cardiomyopathy.

In recent years, we have been facing the applications of modern genomics to the practice of medicine. With robust molecular biology technologies, one can identify the actionable mutations present in a tumor and establish the profile of its pattern of RNA expression, which are currently being used for determining prognosis and choosing appropriate targeted therapies for individual cancer patients. Another application is how modern genomic approaches are increasing our abilities in risk assessment and helping provide more accurate genetic counseling to patients and families affected with hereditary diseases as well as advances in prenatal diagnosis.

There are further examples of applications of genomics to individualized health care: screening asymptomatic individuals for genetic predisposition to various diseases in order to improve health care, population-based newborn screening for preventable and treatable genetic diseases, identifying couples that are carriers for autosomal recessive or X-linked diseases that could affect their children before conception, prenatal screening of the fetus for aneuploidy by maternal cell-free DNA, and applications of pharmacogenomics on the detection of individual variation affecting drug therapy, which can be used to improve therapeutic efficacy and reduce adverse events.

At the beginning of the twenty-first century, the Human Genome Project (HGP) provided a virtually complete sequence of human genome from which now derives the efforts to catalog all human genes, understand their structure and regulation, determine the extent of their variation in different populations, and uncover how genetic variation contributes to susceptibility. The whole genome of any individual can now be sequenced rather than sequencing one gene at a time. These achievements are making possible the practice of genomic medicine, which aims at applying a wide analysis of the human genome and its products, including the epigenetic regulation of gene expression, gene variation, and their interactions with the environment, to medical care.

The HGP has now been succeeded by the Human Variome Project, which seeks to compile and share the huge variation in human DNA sequence worldwide. This is potentially possible since whole exome sequencing (WES) and whole genome sequencing (WGS) have been increasingly performed in several population studies. For example, the 100,000 Genomes Project in the United Kingdom have recently achieved its goal of 100,000 genomes sequenced [1].

The study of genetics and its role in causing human disease is now widely acknowledged as being among the most exciting and influential areas of medical research. Certainly, their valuable discoveries have benefited patients and families dramatically, but this achievement will be measured by translating them into both treatment and prevention of disease.

\section{Diagnostic advances}

Advances over the past few years in mutation identification have provided many improvements in risk assessment, carrier detection, and prenatal diagnosis, allowing the detection of particular mutations with almost $100 \%$ accuracy. Laboratory testing for pathogenic (disease-causing) mutations is available for more than 4,500 genes associated to over 11,000 genetic conditions [2]. The better knowledge of the genes involved in hereditary disease and the rapidly 
cheaper cost of DNA sequencing have permitted the identification of mutations in a patient or family member, and, therefore, the molecular diagnosis has become the standard of care for many conditions. DNA samples for testing are available not only from readily accessible tissues, such as a buccal scraping or blood sample, but also from tissues obtained by more invasive testing, such as chorionic villus sampling or amniocentesis.

For many hereditary disorders (including retinal degeneration, deafness, hereditary breast and ovarian cancer, Lynch syndrome, congenital myopathy, mitochondrial disorders, and hypertrophic or dilated cardiomyopathies), there is a substantial locus heterogeneity, that is, numerous genes are known to be mutated in different families with these disorders. When a patient with one of these highly heterogeneous disorders seeks for testing, recent advances in DNA sequencing make it possible to analyze large panels of dozens to more than 100 genes simultaneously and cost-effectively for mutations in every gene in which mutations have been seen previously to cause the disorder.

In those conditions for which even a large panel of relevant genes cannot be formulated for a particular phenotypically defined disorder, or for those genetically heterogeneous entities (e.g. intellectual disability, autism spectrum disorder) genetic diagnosis still can be achieved by analyzing all the coding exons of every gene (by WES) or by sequencing the entire genome (by WGS) to identify pathogenic mutations.

The use of large gene panels and, even more so, WGS or WES raises special issues for sequence interpretation and risk assessment. As there are more genes being tested, the number of sequence differences between a patient's DNA and that of an arbitrary reference sequence also increases; consequently, many previously undescribed variants will be found whose pathogenicity is unknown. These are so-called variants of uncertain significance (VUSs). This is the case, for example, of a missense mutation that results in the substitution of one amino acid for another in the encoded protein.

Thus, the interpretation of variants is a challenging and demanding area for all professional geneticists who provide molecular diagnosis. The American College of Medical Genetics and Genomics has recommended that variants be categorized into one of five classes: pathogenic, likely pathogenic, of uncertain significance, likely benign, and benign variants [3] Specialists in molecular diagnostics, human genomics, and bioinformatics have developed a series of criteria for addressing the mutation status. In most cases, none of these criteria is absolutely definitive but must be considered together to provide an overall assessment of the pathogenicity of a variant. Only those variants with a high probability of being pathogenic are communicated to the health professional and patient. It is arguable whether the testing laboratory should disclosure all VUSs, at the same time remaining available for updating as new information allow reclassification as either benign or pathogenic.

Despite all the time and effort put into interpretation, it is still impossible to ensure any clinical significance to the vast majority of all variants found through next-generation sequencing (NGS). There is a general concern that individuals and their clinical providers, when confronted with VUSs, will require additional unnecessary testing, with the potential for finding results with even more VUSs, thereby increasing patient's uncertainty and anxiety. Moreover, there is the additional concern that even when a variant is known to be pathogenic and highly penetrant in families with multiple affected individuals, the true penetrance of a variant when it is found in individuals with a negative family history may be much lower.

Therefore, risk assessment and genetic counseling in this context are challenging processes and depend on continually addressing recently available information and communicating it properly to healthcare providers and patients. 


\section{Ethical dilemmas}

Each new advance in genetic technology has simultaneously brought new ethical concerns and raised new dilemmas about how science will be applied and utilized in medicine. At the center of this is the recognition that an individual's genetic background is fundamental to both their identity and possible disease susceptibility. The most controversial field is prenatal genetics and reproductive choice, though national legal frameworks and cultural practices vary widely worldwide. The debate surrounding the early ability to perform prenatal diagnosis for Down syndrome through invasive procedures in the mid-1960s is compared to the new technology that makes it possible to perform detailed genetic screening of the fetus on cell-free fetal DNA in the maternal blood or on embryos created through in vitro fertilization for preimplantation genetic diagnosis (PGD). Great controversy has taken place, and will go on, regarding the disclosure of unexpected but significant "incidental findings" from WES or WGS carried out for specific clinical purposes [4]. Furthermore today there is the technical feasibility of all newborns having their genome sequenced and screened for either childhood disorders or adult-onset conditions [5].

Advances in genetics attract great media attention, and this has brought the ethical debate to a wide public scenario. Issues about insurance, forensic science and DNA databases, patenting, gene therapy, population screening, cloning, stem cell research, and hybrids are considered to have major societal, commercial, and political importance and therefore impact clinical and laboratory practice in medical genetics. On a global scale, it is essential to safeguard fundamental principles such as privacy, confidentiality, and respect for human life at all stages and ages.

Many of the questions raised do not have easy or definitive answers, which means that there will be a great need for both public awareness and properly trained clinicians and counselors to balance the needs of their patients and families with these ethical challenges for the foreseeable future.

\section{Personalized and precision medicine}

The aim of personalized or individualized medicine is to use knowledge of an individual's genetic (or genomic) background relevant to the maintenance of health, prevention, and treatment of diseases as a routine part of medical care.

During the past 10 years, many examples of stratified medicine have blossomed, where the therapy of a particular disease is dependent on the germline or somatic variants patients may carry. These examples include monogenic rare diseases where a different treatment is recommended for patients with some types of germline mutations in a specific gene, such as CFTR gene mutations that cause cystic fibrosis, and the molecular therapy targeted on an actionable somatic mutation of a specific tumor, such as the $B R A F$ V600E mutation in malignant melanoma. The genetic (or genomic) diagnosis is therefore a crucial step toward the most appropriate treatment and/or prevention, what is so-called clinical utility or actionability [6, 7]. Recent initiatives are focusing on improving health outcomes through precision medicine especially in Oncology [8] (Table 1). This is a multidisciplinary integrated approach that analyzes human samples and personal data to improve health care through increased precision in the knowledge of mechanisms of both disease and drug response.

Personalized genomic medicine (PGM) is only one component of precision medicine, which means, in a broadest sense, it requires clinical care providers to combine genomic information with other types of information, such as biochemical or physiological testing results, neurodevelopmental history, environmental exposures, and psychosocial experiences. The most important goal is provide more 
Modern Medical Genetics and Genomics in the Era of Personalized/Precision Medicine DOI: $h$ ttp://dx.doi.org/10.5772/intechopen. 84578

\begin{tabular}{lll}
\hline Tumor(s) & Genes & Clinical application(s) \\
\hline Melanoma & $B R A F, C D K N 2 A, K I T$ & $\begin{array}{l}\text { Therapy; risk assessment; inherited } \\
\text { susceptibility }\end{array}$ \\
\hline Breast and ovarian cancer & $B R C A 1, B R C A 2$ & Therapy; inherited susceptibility \\
\hline Colorectal cancer & $M L H 1, M S H 2, M S H 6$, PMS2, \\
& $E P C A M, B R A F$, KRAS, NRAS & Therapy; inherited susceptibility \\
\hline Non-small-cell lung cancer & $\begin{array}{l}\text { EGFR, BRAF, KRAS, ERBB2, RET, } \\
\text { MET, ALK, ROS1 }\end{array}$ & Therapy \\
\hline Myelodisplastic syndrome & $\begin{array}{l}\text { TP53, GATA2, JAK2, ASXL1, ETV6, } \\
\text { RUNX1, SF3B1, EZH2 }\end{array}$ & Diagnosis; risk stratification \\
\hline Acute myeloid leukemia & KIT, CEBPA, FLT3, NPM1 & Risk stratification \\
\hline
\end{tabular}

Table 1.

Genetic/genomic profiling for selected malignancies (adapted from [8]).

precise diagnosis, genetic counseling, management, prevention, and therapy. This effort has already got started, but plenty of work still needs to be done before PGM becomes integrated into medicine itself.

\section{Conflict of interest}

The author declares no conflict of interest.

\section{Author details}

Israel Gomy

Universidade Federal do Paraná, Curitiba, Brazil

*Address all correspondence to: israel.gomy@hc.ufpr.br

\section{IntechOpen}

(C) 2019 The Author(s). Licensee IntechOpen. This chapter is distributed under the terms of the Creative Commons Attribution License (http://creativecommons.org/licenses/ by/3.0), which permits unrestricted use, distribution, and reproduction in any medium, provided the original work is properly cited. (cc) BY 


\section{References}

[1] Genomics England. Available from: https://www.genomicsengland.co.uk. [Accessed 01/31/19]

[2] Genetic testing registry. Available from: https://www.ncbi.nlm.nih.gov/gtr [Accessed: 01/31/19]

[3] Richards S, et al. Standards and guidelines for the interpretation of sequence variants: A joint consensus recommendation of the American College of Medical Genetics and Genomics and the Association for Molecular Pathology. Genetics in Medicine. 2015;17:405-424. DOI: 10.1038/gim.2015.30

[4] Kalia SS, Adelman K, Bale SJ, et al. Recommendations for reporting of secondary findings in clinical exome and genome sequencing, 2016 updated (ACMG SF v2.0): a A policy statement of the American College of Medical Genetics and Genomics. Genetics in Medicine. 2017;19:249-255. DOI: 10.1038/gim.2016.190

[5] Anderson, J. et al. Parents perspectives on whole genome sequencing for their children: qualified Qualified enthusiasm? Journal of Medical Ethics. 2017;43(8):535-539. DOI: $10.1136 /$ medethics-2016-103564

[6] Chakravaty D et al. OncoKB: A precision oncology knowledge base JCO precision Oncology. 2017. Available from: https://oncokg.org. DOI: 10.1200/ PO.17.00011. [Accessed: 01/31/19]

[7] ClinGen. Actionability Working Group. Evidence-based Summaries. Available from: https://clinicalgenome. org/working-groups/actionability/ projects-initiatives/actionabilityevidence-based-summaries [Accessed: 01/31/19]
[8] National Comprehensive Cancer Network. Biomarker compendium. Available from: https://www.nccn. org/professionals/content/ [Accessed: 01/31/19] 
Section 2

Reproductive and Prenatal

Genetics 



\title{
The Genetic and Biochemical Blueprint of Endometrial Receptivity: Past, Present, and Future Factors Involved in Embryo Implantation Success
}

\author{
Almena López-Luna, Dinorah Hernández-Melchor, \\ Leticia Ramírez-Martínez and Esther López-Bayghen
}

\begin{abstract}
In the field of assisted reproductive technology, endometrial receptivity is a crucial aspect that affects implantation rates in in-vitro fertilization procedures; in fact, impaired endometrial receptivity has been identified as the rate-limiting step for favorable pregnancy outcomes once factors regarding embryo quality have been optimized. The endometrium is a dynamic tissue that undergoes proliferative and secretory changes in each menstrual cycle, acquiring a short and transient period of embryo receptivity known as the Window of Implantation. Precise embryo-endometrial synchrony is necessary to achieve a successful pregnancy, and it involves complex and multifactorial processes related to morphological, biochemical, and genetic changes. On that behalf, defining the receptive window of each patient for personalized embryo transfer is a current goal. Here, we review different indicators of endometrial receptivity throughout the menstrual cycle, spotlighting the opening of the window of implantation: classical histological and biochemical markers, genetic factors, leading-edge transcriptomic signatures and miRNA profiles, and novel features such as the microbiome and secretome. Understanding the molecular mechanisms behind endometrial receptivity will facilitate the optimization and improvement of infertility treatments.
\end{abstract}

Keywords: endometrial receptivity, embryo implantation, menstrual cycle, window of implantation, decidualization

\section{Introduction}

The field of assisted reproductive technology (ART) has grown significantly in use and understanding over the past few decades, nevertheless, the rates of successful pregnancies in in-vitro fertilization (IVF) procedures are still relatively low. Impaired endometrial receptivity (ER) has been identified as the rate-limiting step for favorable pregnancy outcomes once all other factors, including the acquisition and selection of the best quality embryo(s), have been optimized. Correct and synchronized maturation of the endometrial tissue is essential for embryo 


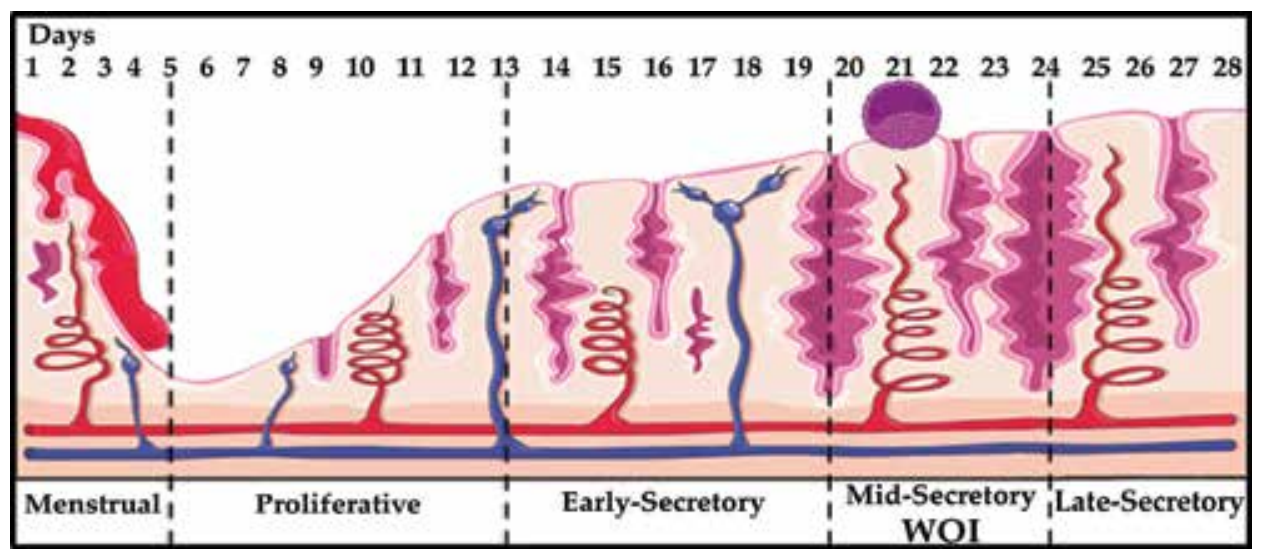

Figure 1.

Endometrial dynamics throughout the menstrual cycle. This picture was modified from Servier Medical Art under the Creative Commons License 2018.

implantation $[1,2]$. The endometrium is a dynamic tissue that undergoes proliferative and secretory changes in each menstrual cycle. Throughout most of this cycle, the endometrium remains "non-adhesive" to embryos and it only acquires a short and transient period of embryo receptivity known as the "window of implantation" (WOI) $[3,4]$. In humans, during a natural cycle, the endometrium becomes receptive 6 to 8 days after ovulation and it remains receptive for approximately 24-48 $\mathrm{h}$, this time is assumed to occur between days 20 and 24 of a regular menstrual cycle $[2,5]$ (Figure 1). The cyclic fluctuations of the endometrium are coordinated by the ovarian hormones estrogen (E2) and progesterone (P4); a finely balanced signaling process mediated by these hormones defines the WOI. The menstrual cycle is divided in two phases: proliferative or follicular, and secretory or luteal [6]. During the proliferative phase (PP), E2 from the maturing follicle allows the elongation of the spiral arteries and the proliferation of endometrial stromal cells (EnSCs) and glands [7]. Afterwards, during the secretory phase (SP), P4 from the corpus luteum induces secretory changes; the endometrium thickens and it acquires a receptive phenotype that will support blastocyst attachment [8-10]. During the Mid-Secretory Phase (MSP) circulating P4 induces EnSCs to undergo decidualization [11]. Decidualization is the transformation of the endometrial stroma into a dense cellular matrix known as the decidua, this process initiates during the SP in the stroma and, if pregnancy occurs, it progresses into the development of the decidua which will in turn form the maternal placenta [12]. The optimization of the endometrium to support embryo implantation is a complex and multifactorial process that involves morphological, biochemical, and genetic changes [13]. ER is a key aspect that affects implantation rates in IVF procedures considering that a precise embryo-endometrial synchrony is completely necessary to achieve a successful pregnancy $[4,14]$. Thus, understanding the molecular mechanisms behind ER will facilitate the optimization and improvement of infertility treatments.

\section{Factors involved in endometrial receptivity}

\subsection{Evaluation of endometrial morphology for receptivity assessment}

Morphological changes during the endometrial cycle generate markers that have been used over decades to assess receptivity, such as histological evaluation of a biopsy and ultrasound examination of the endometrium. Endometrial biopsies are now 
considered to provide little clinically relevant information $[15,16]$. Additionally, the formation of pinopodes was thought to show potential as a clinical marker to assess ER [17]. However, the presence of pinopodes was demonstrated not only during the WOI but also in the post-receptive endometrium, precluding in this way its use as a marker of ER $[17,18]$. On the other hand, ultrasound examination is a routinely used technique in IVF procedures $[9,19]$. This non-invasive technique is based on the interpretation of a medical ultrasound of the endometrium. Various ultrasonographic parameters have been proposed as pregnancy predictors, such as endometrial thickness, volume, and blood flow patterns. The most commonly used is endometrial thickness [20,21]. Due to differences in stimulation protocols, sonographic approaches, and difficulties in obtaining a standard sagittal view of the uterus, discrepancies in the cut-off value of endometrial thickness to achieve pregnancy arise [22]. Generally, it is considered that a minimum of 6-8 mm in endometrial thickness is necessary for a successful pregnancy [23-25]. Nevertheless, case reports have described pregnancy establishment despite an endometrial thickness of no more than $4 \mathrm{~mm}[26,27]$. Threedimensional (3D) sonography assesses ER by considering endometrial thickness, volume, and angiogenic dynamics. The endometrial volume of fewer than $2 \mathrm{ml}$ has been shown to decrease pregnancy rates significantly [19, 28, 29]. Another evaluated criterion is an endometrial pattern, which can be classified as triple-line, intermediate, or homogenous [30]. Among these, the triple-line pattern has been suggested to reflect ER $[24,31]$ broadly. Finally, the impact of ovarian stimulation on ER has yet to be determined. Abnormal hormone concentrations the due to stimulation protocols during IVF might affect endometrial morphology and thereby ER [32]. Comprehensively, although morphological elements are important components of receptivity, there is still no consensus on the extent in which they can be used as WOI predictors.

\subsection{Genetic factors involved in ER}

Endometrial genetic abnormalities can lead to implantation failure due to dysregulation of critical processes such as trophoblast invasion and angiogenesis. Here, we discuss common genetic abnormalities that have been analyzed to determine their role in implantation failure (Table 1). Parental chromosomal abnormalities such as mutations and translocations should be considered relevant in the efficacy of improving reproductive outcome.

\subsubsection{Angiogenetic factors: vascular endothelial growth factor (VEGF), endothelial nitric oxide synthase (eNOS), TP53 tumor suppressor (TP53), murine double minute 2 (MDM2), herpes virus-associated ubiquitin-specific protease (HAUSP)}

Successful pregnancy is dependent on adequate placental circulation and fetal vasculature. The development of a normal vascular network during implantation, embryo development, and placentation requires cooperation between different cell types and various growth factors. VEGF is a potent angiogenic factor that plays an essential role in embryo implantation/development. Four VEGF polymorphisms have been reported to affect VEGF activity and expression increasing aberrations in vascular formation and/or function. The polymorphism -1154G/A located in the promoter region has been associated with RPL [33], RSA [34, 35], and RIF [36, 37]. Moreover, a meta-analysis showed that genotypes $-2578 \mathrm{C} / \mathrm{A},-634 \mathrm{G} / \mathrm{C}$, and 936C/T increase the risk of RSA as well [38]. Furthermore, $e N O S$, which is expressed in the terminal chorionic villous vessels, is important for vascular nitric oxide (NO) production to supply nutrients to the fetus. Only the eNOS Glu298Asp polymorphism has been shown to be significantly associated with RPL [39]. Additionally, successful trophoblast invasion requires the induction of paracrine apoptotic reactions to 


\begin{tabular}{|c|c|c|c|c|}
\hline Gene & Polymorphism & rs code & Relevance & References \\
\hline$A P O E$ & & & $\begin{array}{l}\text { Heterozygous genotype is more frequent } \\
\text { in women with RPL }\end{array}$ & [33] \\
\hline \multirow[t]{3}{*}{ eNOS } & \multirow[t]{2}{*}{ VNTR (B/A) } & & Association to the risk of RPL & [77] \\
\hline & & & No associated & [78] \\
\hline & Glu298Asp & & $\begin{array}{l}\text { Homozygote genotype } \mathrm{T} / \mathrm{T} \text { is associated } \\
\text { with risk of IRM }\end{array}$ & [39] \\
\hline \multirow[t]{2}{*}{ ESR1 } & IVS1-397T>C & rs2234693 & \multirow{2}{*}{$\begin{array}{l}\text { Related to unknown thin endometrium in } \\
\text { which } \mathrm{P} \text { allele may be the risk and } \mathrm{X} \text { allele } \\
\text { its guard factor }\end{array}$} & \multirow[t]{2}{*}{ [44] } \\
\hline & IVS1-351A>G & rs9340799 & & \\
\hline \multirow[t]{2}{*}{$F 2$} & \multirow[t]{2}{*}{ G20210A } & \multirow[t]{2}{*}{ rs1799963 } & No association & $\begin{array}{l}{[58,60,62,} \\
\quad 63]\end{array}$ \\
\hline & & & $\begin{array}{c}\text { Heterozygous genotype is more frequent } \\
\text { in women with RSA in the first trimester } \\
\text { [57] and women with RPL [42] }\end{array}$ & {$[42,57]$} \\
\hline \multirow[t]{4}{*}{ F5 } & \multirow[t]{2}{*}{ G1691A, Leiden } & \multirow[t]{2}{*}{ rs6025 } & No association & $\begin{array}{l}{[57,58,62,} \\
63]\end{array}$ \\
\hline & & & More frequent in women with RIF & {$[60]$} \\
\hline & H1299R (R2) & & No association & {$[58,62,63]$} \\
\hline & Y1702C & & No association & {$[58,62,63]$} \\
\hline \multirow[t]{2}{*}{ F8 } & \multirow[t]{2}{*}{ V34L } & & More prevalent in women with RPL & {$[42,58]$} \\
\hline & & & No association & {$[62,63]$} \\
\hline$F G B$ & G-455A & rs1800790 & No association & $\begin{array}{l}{[57,58,62,} \\
\quad 63]\end{array}$ \\
\hline GPIIIa & C1565T & & No association & [57] \\
\hline HAUSP & rs1529916 G/A & rs1529916 & Allele $\mathrm{A}$ is associated with RIF & {$[40]$} \\
\hline HPA1 & $\begin{array}{l}\text { HPA1 a/b } \\
(\mathrm{L} 33 \mathrm{P})\end{array}$ & & No association & {$[58,62,63]$} \\
\hline \multirow[t]{4}{*}{$L I F$} & C715A & & No associated & [72] \\
\hline & G3400A & & More frequent in nulligravid women & {$[72,73]$} \\
\hline & G3424A & & No associated & [72] \\
\hline & T1414G & rs929271 & G/G genotype is associated with RIF & {$[40,74]$} \\
\hline$M D M 2$ & T309G & rs2279744 & Allele $\mathrm{G}$ is associated with RIF & {$[40]$} \\
\hline \multirow[t]{3}{*}{ MTHFR } & A1298C & rs1801131 & No association & {$[58,62-64]$} \\
\hline & \multirow[t]{2}{*}{ C677T } & \multirow[t]{2}{*}{ rs1801133 } & $\begin{array}{l}\text { More frequent in women with } \\
\text { unexplained infertility [64], RPL [42, } \\
58 \text { ], and RSA [60] }\end{array}$ & {$[42,58-60]$} \\
\hline & & & No association & {$[57,62,63]$} \\
\hline \multirow[t]{2}{*}{ MUC1 } & \multirow[t]{2}{*}{ VNTR } & & $\begin{array}{l}\text { Women with unexplained infertility } \\
\text { might have susceptibility to } \\
\text { implantation failure due to small MUC1 } \\
\text { allele size }\end{array}$ & [67] \\
\hline & & & No association & {$[68,69]$} \\
\hline MUC4 & VNTR & & No association & {$[70]$} \\
\hline \multirow[t]{2}{*}{ PAI-1 } & \multirow[t]{2}{*}{$4 \mathrm{G} / 5 \mathrm{G}$} & \multirow[t]{2}{*}{ rs1799889 } & $\begin{array}{l}\text { More prevalent in women with RIF [63] } \\
\text { and RPL }[42,58]\end{array}$ & {$[42,58,63]$} \\
\hline & & & No association & [62] \\
\hline
\end{tabular}


The Genetic and Biochemical Blueprint of Endometrial Receptivity: Past, Present, and Future... DOI: $h$ ttp://dx.doi.org/10.5772/intechopen.80452

\begin{tabular}{|c|c|c|c|c|}
\hline Gene & Polymorphism & rs code & Relevance & References \\
\hline \multirow[t]{3}{*}{$P R$} & $\mathrm{H} 770 \mathrm{H}-\mathrm{C} / \mathrm{T}$ & & No association & [54] \\
\hline & G/T_Val660Leu & rs1042838 & $\begin{array}{l}\text { More prevalent in women with } \\
\text { unexplained infertility }\end{array}$ & [65] \\
\hline & V660L & & No association & [54] \\
\hline \multirow[t]{2}{*}{ PT53 } & Codon 72 Pro & rs1042522 & $\begin{array}{l}\text { Homozygote genotype is associated with } \\
\text { RPL [41, 75], IRM [76] and RIF [37, 40] }\end{array}$ & $\begin{array}{l}{[37,40,41,} \\
75,76]\end{array}$ \\
\hline & Codon 72 Arg & rs1042522 & $\begin{array}{l}\text { Homozygote genotype is associated with } \\
\text { RIF }\end{array}$ & [75] \\
\hline PTGS2 & G-765C & rs20417 & $\begin{array}{l}\text { Association with implantation failure } \\
\text { susceptibility }\end{array}$ & [55] \\
\hline \multirow[t]{7}{*}{ TFF3 } & rs $225361 \mathrm{~A} / \mathrm{G}$ & rs11701143 & $\begin{array}{l}\text { Homozygous genotype is associated } \\
\text { with less live births before their first } \\
\text { spontaneous abortion }\end{array}$ & [61] \\
\hline & rs225361 A/G & rs11701143 & No association & [66] \\
\hline & rs11701143 T/C & rs 225361 & Associated with idiopathic RSA & [61] \\
\hline & rs11701143 T/C & rs225361 & No association & [66] \\
\hline & rs225439 G/A & rs225439 & No association & {$[61,66]$} \\
\hline & ros $533093 \mathrm{C} / \mathrm{T}$ & rs533093 & No association & {$[61,66]$} \\
\hline & rs77436142 G/C & rs7743614 & No association & {$[61,66]$} \\
\hline \multirow[t]{5}{*}{ VEGF } & G-1154A & rs1570360 & $\begin{array}{c}\text { Homozygote A/A genotype associated } \\
\text { with RSA [34, 35], RPL [33], and RIF } \\
{[36,37]}\end{array}$ & [33-37] \\
\hline & & & No associated & [71] \\
\hline & C-2578A & rs699947 & No associated & {$[34]$} \\
\hline & G-634C & rs2010963 & No associated & {$[34]$} \\
\hline & C936T & rs3025039 & No associated & [34] \\
\hline
\end{tabular}

Probably implicated mutations in implantation failure, studies are listed even when no association was found, $r s$ code is mentioned whenever it is reported.

Table 1.

Genetic abnormalities involved in implantation failure.

secrete proteases capable of digesting the endometrial extracellular matrix (ECM) [36]. TP53 is a potent regulator of apoptosis, cell cycle, angiogenesis, and embryonic development. A TP53 polymorphism at codon 72, encoding either proline or arginine, was reported to alter the TP53 activity and affect human fertility [40]. The Arg72 variant has been shown to induce higher apoptotic activity than Pro72. Therefore, Pro72 variant might cause inadequate trophoblast invasion, increasing the risk of RPL [41] and RIF [37, 40]. In this manner, women with Pro/Pro genotype have a higher risk of RPL than women with the Arg/Arg or Arg/Pro genotypes. Following, MDM2 and HAUSP regulate TP53. MDM2 binds to TP53 to degrade it through poly-ubiquitination, blocking its ability to function as a transcription factor. The MDM2 SNP309 is a functional SNP that increases MDM2 expression levels and attenuates TP53 pathway. HAUSP, on the other hand, acts as a specific deubiquitinase for TP53, the A allele has a significant association with infertility in young patients (<35 years) but not in the older patients, similarly to the MDM2 SNP309 G allele. Those observations suggest that MDM2 and HAUSP may be involved in the regulation of human fertility through the regulation of TP53 [40]. 


\subsubsection{Apolipoprotein $E(A P O E)$}

Due to the increase in total cholesterol levels during pregnancy, $A P O E$ plays a crucial role in lipid metabolism. $A P O E$ has three alleles in the long arm of chromosome 19 at position 13.2: $\varepsilon 2, \varepsilon 3$, and $\varepsilon 4$. Individuals harboring the allele $\varepsilon 4$ have higher cholesterol levels than the ones carrying the $\varepsilon 3 / \varepsilon 3$ allele, whereas levels in those with the $\varepsilon 2$ allele are lower [42].

\subsubsection{Estrogen receptor $\alpha$ (ESR1)}

ESR1 is a ligand-activated transcription factor essential for sexual development and reproductive function; its dysregulation leads to the development of various diseases such as cancer, cardiovascular disease, and inflammation, among others [43]. Due to alternative splicing of mRNA, it possesses three isoforms: $E R \alpha \Delta 3, E R \alpha 36$, and ER $\alpha 46$ [43]; in a study performed by Yuan and Le [44], the polymorphisms rs 2234693 and rs9340799 were related to the uncommonly thin endometrium.

\subsubsection{Leukemia inhibitor factor (LIF)}

LIF is an important implantation factor that promotes proliferation, invasion, and differentiation; its expression is regulated by the transcription factor tumor protein TP53 (TP53). Few studies have found a correlation between LIF gene polymorphism and reproductive capacity, Kang et al. demonstrated that SNP in the 3'UTR of the LIF (rs929271) gene is associated with infertility [40].

\subsubsection{Mucin 1 (MUC1), Mucin 4 (MUC4)}

MUC1 is an anti-adhesion molecule secreted by human endometrial epithelium, it has been suggested that its expression prevents the adherence of blastocyst to the endometrium. Interestingly, MUC1 must be locally removed in a paracrine fashion at the implantation site during the WOI to allow contact between the embryo and the endometrium, making it an important factor in determining ER [45-48]. MUC1 is a highly polymorphic gene that differs in the size of the region carrying the O-glycosylation sites: the variable number tandem repeat region (VNTR), which can go from 20 to 125 repeats [49]. Similarly, MUC4 is a greatly expressed mucin in endometrial epithelium [50], its gene is highly polymorphic and it contains a VNTR region that can go from 145 to 395 repeats [51]. Although its role in human infertility has not been fully explored, studies in other species have suggested that it plays a role in embryo implantation $[52,53]$.

\subsubsection{Progesterone receptor $(P R)$}

The PROGINS complex are three mutations in the $P R$ gene that may be associated with unexplained infertility and implantation failure: a $306 \mathrm{bp}$ insert in intron G of the dT2 allele in $P R$, the mutated alleleV660L, and guanine to thymine substitution in exon 4, resulting in a valine to leucine change in the hinge region of $\mathrm{PR}$, and a cytosine to thymine substitution at exon 5 [54].

\subsubsection{Prostaglandin-endoperoxide synthase 2 (PTGS2)}

PTGS2 is a key enzyme involved in the conversion of arachidonic acid to prostaglandins (PGs). The $-765 \mathrm{G}>\mathrm{C}$ SNP mutation in the promoter region of PTGS2 upstream the transcriptional start site in the putative Sp1 site can cause alterations in Sp1 binding 
The Genetic and Biochemical Blueprint of Endometrial Receptivity: Past, Present, and Future... DOI: http://dx.doi.org/10.5772/intechopen.80452

[55]. Accordingly, the hypermethylation of the NF-IL6 site within the PTGS2 promoter results in elevated gene expression in eutopic endometrium in endometriosis [56].

\subsubsection{Thrombolytic factors: coagulation factor II (F2), coagulation factor $V$ (F5), coagulation factor XIII a chain (F13A1), methylenetetrahydrofolate reductase (MTHFR), plasminogen activator inhibitor-1 (PAI-1)}

Thrombophilia, the predisposition for thrombosis, has been shown to be a risk factor for successful pregnancy due to impaired vascularization at the time of implantation. Therefore, the possible association between early pregnancy loss and polymorphisms at coagulation factors and thrombolytic genes responsible for inherited or acquired thrombophilia has been investigated. The coagulation factor II SNP G20210A in the 3'-untranslated region of F2 causes elevated prothrombin in plasma, leading to enhanced blood coagulation [57]. Furthermore, factor V Leiden mutation, G1691A, is a single nucleotide substitution in the $F 5$ gene that results in reduced clearance of factor Va due to its blocked inactivation by activated protein $\mathrm{C}$, increasing the risk of thrombosis $[42,57]$. Also, factor XIII V34L polymorphism is a guanine to thymine substitution in exon 2 of F13A1 that leads to a valine for leucine change in residue 34; this SNP leads to reduced susceptibility to fibrinolysis and influences fibrin degradation [57]. Moreover, MTHFR is the rate-limiting enzyme in the methyl cycle. C677T polymorphism causes a substitution of valine for alanine, resulting in a thermolabile variant of the enzyme with reduced catalytic activity; combined with the SNP AC1298C, it is associated with hyper-homocysteinemia, a risk factor for venous and arterial thrombosis [42, 58-60]. Additionally, PAI-1 is a key regulatory element in the fibrinolysis cascade, it is believed to control proteolysis and remodeling of maternal tissue during trophoblast invasion. The $4 \mathrm{G} / 5 \mathrm{G}$ polymorphism is located $657 \mathrm{bp}$ upstream from the start site of transcription within the PAI-1 promoter and results in an allele with decreased transcriptional activity [42].

\subsubsection{Trefoil factor 3 (TFF3)}

TFF3 is a mucin-associated peptide co-expressed in mucus cells that acts as a mitogen to promote epithelial cell migrations and mediates epithelial repair after damage. The SNP rs11701143 is located in the promoter region of TFF3 within the regulatory region of the transcription binding site, whereas rs225361 is an intron variant located within a regulatory region. The exact function of both SNPs remains to be elucidated [61].

\subsection{Immunological factors contributing to ER}

The immune system plays a major role in the process of implantation and pregnancy maintenance [62]. During decidualization, endocrine processes transform uterine fibroblasts into cells that can produce hormones, growth factors, and matrix components to support embryo implantation $[63,64]$. Furthermore, tolerance of the immune maternal system is required in pregnancy to avoid rejection of the semiallograft or allograft embryo and for its successful implantation [65]. The decidua is a privileged site for immune tolerance; a large number of molecules and immune cell types participate in this process, leukocytes, macrophages, Tlymphocytes, and dendritic cells comprise around 30 to $40 \%$ of the cells within the decidual stroma in early pregnancy. Among leukocytes, uterine natural killer (uNK) cells are activated and they significantly increase during decidualization (65-70\%) [66,67]. Increases in $\mathrm{uNK}$ cells denote three main functions in the endometrium: regulation of placental and trophoblast growth by cytokines $[68,69]$, local immunomodulation $[70,71]$, and 
control of trophoblast invasion [69]. Furthermore, trophoblast cells play a major role in immune tolerance since these cells do not express major histocompatibility complex (MHC) class I (HLA-A and HLA-B) or class II molecules; ensuring that maternal T cells with $\alpha \beta$ receptors cannot mount a classic cytotoxic attack against fetal paternal alloantigens. The trophoblast also protects itself by expressing Fas ligand (Fas L), which is important in the elimination of maternal reactive $T$ cells by apoptosis induction [72-74]. Other important component of this process is T-regulatory (Treg) cells; these cells are essential for immunosuppression, prevention of autoimmunity, and maternal tolerance to the fetus [75-78]. Treg cells have been shown to be locally enriched in decidua during early normal pregnancy [79]. Furthermore, Forkhead box P3 (Foxp3) is a master regulator of Treg cell development, function, and differentiation [80]. Expression of FOXP3 was reduced approximately two-fold in endometrial biopsies of infertile women, implicating that the impaired differentiation of uterine T-cells into the Treg phenotype is a key determinant of fertility $[81,82]$. On the other hand, helper T cells (CD4+) facilitate embryo implantation by regulating endometrial differentiation; they secrete interleukins and interferons that establish the implantation microenvironment. Successful pregnancy is dependent upon Th1/Th2 balance [83]. While Th1 cytokines are harmful for pregnancy, Th2 cytokines favor fetal growth and regulate uterine expression of fatty acid amide hydrolase (FAAH), LIF, and trophoblast release of human chorionic gonadotropin (hCG), which are known to play important roles during implantation [84-86]. Piccinni et al. demonstrated that $T$ cells from decidua of women with a miscarriage show predominantly Th1-type cytokines with decreased Th2-type [84, 87, 88]. Finally, P4 and E2 mediate the downregulation of the maternal immune system [89]. P4 stimulates decidual proliferation; therefore, pregnancy results in an upregulation of $\mathrm{P} 4$ receptors on activated lymphocytes among placental cells and decidual CD56+ cells. In the presence of sufficient $\mathrm{P} 4$, these cells express progesterone-induced blocking factor (PIBF), a mediator that exerts substantial anti-abortive activities.

\subsection{Biochemical markers involved in ER}

We review molecular markers involved in the decidualization process that could be suitable as makers to assess ER.

\subsubsection{Homeobox A10 (HOXA10)}

HOXA10 is a transcription factor member of the homeobox family, known to be involved in the genetic control of embryonic development and in the regulation of the adult female reproductive tract $[12,90]$. HOXA10 regulates downstream target genes that lead to endometrium development and receptivity acquisition [91], such as insulin-like growth factor binding protein 1 (IGFBP1) [12, 92, 93], genes of the Wnt pathway (reviewed by Sonderegger et al. [94], integrin $\beta 3$ (ITGB3) [12, 90, 92], and empty spiracles homolog $2(E M X 2)[12,95]$. HOXA10 is regulated by P4 in a dosedependent manner $[12,90,91]$. The expression of HOXA10 is low during the PP and it rapidly increases in the MSP $[12,90]$. The diminished expression of HOXA10 in endometria of women with recurrent pregnancy loss (RPL) [96], adenomyosis [97], endometriosis [92], polycystic ovary syndrome (PCOS) [98], and idiopathic infertility [99] indicates that this gene could be essential for fertility [12].

\subsubsection{Heparin-binding epidermal growth factor-like growth factor (HB-EGF)}

HB-EGF is a member of the epidermal growth factor (EGF) family, it is expressed in the human uterus at the time of implantation and its expression is under steroidal hormone control [100-103]. The transmembrane form is associated 
with cell adhesion and migration, it allows communication with the blastocyst by acting as a chemoattractant [101, 104]. HB-EGF expression is low in the PP and increases in the ESP immediately prior to the WOI, after which its levels decrease [101-103, 105]. Also, mRNA levels are low in pregnant endometrium and high in placental tissues at an early stage of development, suggesting that the HB-EGF ligand not only potentiates the health and survival of the peri-implantation embryo, but also induces the progression of its development [104]. HB-EGF stimulates epithelial expression of key endometrial proteins that are important biomarkers of the WOI, including LIF, HOXA10, and ITGB3 [100].

\subsubsection{Leukemia inhibitory factor (LIF)}

LIF is a member of a cytokine family with functional redundancy that includes interleukin 6 (IL6), oncostatin (OSM), ciliary neurotrophic factor (CNTF), and cardiotrophin 1 (CT1). They regulate proliferation, differentiation, and cell survival in different cellular systems [106]. LIF acts on cells by binding to the heterodimeric LIF receptor (LIFR), which consists of two transmembrane proteins, LIFR and glycoprotein 130 (gp130). LIFR activates several signaling pathways including the JAK/STAT, MAPK, and P13-kinase pathways, whereas gp130 participates in the activation of STAT1, STAT3, and STAT5B [107]. LIF induces the expression of cytokines and other regulatory molecules that could serve to regulate preimplantation development and embryo implantation [106-108]. LIF is one of the most important cytokines for receptivity during the WOI, the expression of LIF and LIFR reaches its highest level during the WOI in the MSP, LSP, and in early pregnancy in both surface and glandular epithelial cells under the influence of P4 [106, 107, 109, 110]. LIF can also be detected in decidual leukocytes, which are abundant at the implantation site; interestingly, LIF expression is low in women with unexplained infertility $[106,107,111]$. LIF also plays a crucial role in the regulation of fetal-maternal interactions during pregnancy, this cytokine mediates uterine receptivity through autocrine/paracrine interactions by binding to LIFR on the luminal epithelium to permit blastocyst attachment [106], but also regulates trophoblast function and vascular formation in the placenta [109].

\subsubsection{Integrin $\beta 3$ (ITGB3)}

Integrins are ubiquitous cell adhesion molecules involved in maintaining normal tissue morphology and participate in cell-cell and cell-substrate interactions $[100,110,112,113]$. In the human endometrium, integrins are involved in early embryo-endometrial interactions [90]. ITGB3 subunit is present after the ESP and its expression extend into the pregnancy $[112,114]$. It has been reported that healthy fertile women show higher ITGB3 expression than patients with unexplained infertility [46, 96, 113-115]. Moreover, its dysregulation appears to characterize two distinct pathophysiological conditions that involve distinct mechanisms of defective ER: Type I and Type II. Type I defect is an out-of-phase endometrium with negative ITGB3 subunit expression, portrays a shifted WOI, and hormonal inadequacy or responsiveness is implicated, on the other hand, Type II defect is an "in-phase" endometrium with negative ITGB3 subunit expression and connotes the complete loss of the WOI. Furthermore, ITGB3 is expressed in EnSCs and endometrial glands with the highest levels in the MSP to LSP, suggesting a role in the regulation of endometrial function and implantation $[115,116]$. Due to its temporal distribution and the effects of implantation when it is not present, ITGB3 is a useful molecular marker to assess ER. ITGB3 is regulated in the endometrium through a molecular mechanism via sex steroid signaling where HOXA10 acts as an intermediary $[90,96]$. 
Other identified markers that are important for decidualization in the human endometrium include $P R$, particularly its encoded isoform progesterone receptor A (PR-A), homeobox A11 (HOXA11), PTGS2, MUC1, and interleukin 11 receptor (IL11R) [12].

\subsection{Transcriptomic signature to determine the WOI}

Microarray technology has been widely used to determine the transcriptomic profile of the endometrium by analyzing the expression of large batches of genes at different stages of the menstrual cycle. The most representative and commercially available test in this regard is perhaps the Endometrial Receptivity Array (ERA), developed in 2009 by Diaz-Gimeno et al., this test identifies the unique transcriptomic signature of the receptive endometrium by analyzing 238 differentially expressed genes, predicting the WOI for personalized embryo transfer (pET) [108]. Various research groups have analyzed changes in gene expression during the different phases of the endometrial cycle using microarray-based technologies [117-120], however, due to differences on results, unanimity about the main genes to be analyzed to determine the WOI has not been reached. Factors that contribute to the disagreement among studies results include differences on experimental design, utilized probes, sample acquisition day, sample size, collection method, and the application of distinct statistical analyses. Nevertheless, some genes have been reported to be expressed similarly in more than one work, here, we present a compilation of the expression profiles of those candidate genes in the human endometrium (Table 2).

\section{6 miRNAs involved in ER}

Micro-RNAs (miRNAs) are small, single-stranded, non-protein-coding RNA sequences of $\sim 18-25$ nucleotides in length that play an important post-transcriptional regulatory role in gene expression $[121,122]$ by targeting mRNAs for cleavage or transcriptional repression [123]. More than two decades have passed since the initial discovery of miRNAs in Caenorhabditis elegans by Lee et al. [124]; since then, great progress has been made in the understanding of miRNAs: what they are, how are synthesized, how regulate gene expression, and how they are involved in the formation and progression of pathological disorders. Extracellular miRNAs have been ubiquitously detected in body fluids [125]. Therefore, the presence and stability of miRNAs in biological fluids have advocated their potential as noninvasive biomarkers. Nevertheless, the identification of reliable miRNA biomarkers with reproducible profiles has been a challenge, and their diagnostic promise has remained a work in progress since they have still not entered the clinical field [126]. Nonetheless, given that miRNAs are differentially expressed in the endometrium across the menstrual cycle [127-131], several studies have been conducted to explore their role in ER [131-136]. Table 3 presents a summary of these studies.

\subsection{The endometrial secretome as a potential tool to ascertain ER}

The aim to develop alternative non-invasive strategies to provide accurate receptivity assessment has drawn assiduity to the endometrial secretome, which is based in the identification of factors secreted by cells or tissues at a particular time in either physiological states or pathological conditions [137], including proteins, lipids, and metabolites. Therefore, the analysis of differentially present molecules in the uterine cavity at different time points of the menstrual cycle could potentially help to identify the WOI and to diagnose uterine pathologies. Sample collection of endometrial fluid (EF) collection in the peri-implantation period is an easy procedure performed with minimally invasive tools that could easily be implemented 
The Genetic and Biochemical Blueprint of Endometrial Receptivity: Past, Present, and Future... DOI: $h$ ttp://dx.doi.org/10.5772/intechopen.80452

\begin{tabular}{|c|c|c|c|c|}
\hline \multirow{4}{*}{$\begin{array}{l}\text { Gene } \\
\text { Annexin } 4[A N X 4]\end{array}$} & \multirow{4}{*}{$\begin{array}{l}\text { Functional category } \\
\text { Apoptosis }\end{array}$} & \multicolumn{2}{|c|}{ Expression profile } & \multirow{4}{*}{$\begin{array}{l}\text { References } \\
{[73,86,91-95]}\end{array}$} \\
\hline & & PP to MSP & $\uparrow$ & \\
\hline & & ESP to MSP & $\uparrow$ & \\
\hline & & MSP to LSP & $\downarrow$ & \\
\hline \multirow[t]{2}{*}{ Apolipoprotein D [APOD] } & \multirow{2}{*}{$\begin{array}{l}\text { Cholesterol transport and } \\
\text { trafficking }\end{array}$} & PP to ESP & $\uparrow$ & \multirow[t]{2}{*}[85,92,96]{} \\
\hline & & ESP to MSP & $\uparrow$ & \\
\hline Claudin 4 [CLDN4] & Cell adhesion & ESP to MSP & $\uparrow$ & $\begin{array}{l}{[73,85,93,94,} \\
96,97]\end{array}$ \\
\hline $\begin{array}{l}\text { Decay-accelerated factor } \\
{[\mathrm{DAF}]}\end{array}$ & $\begin{array}{l}\text { Immune modulators/ } \\
\text { cytokines }\end{array}$ & ESP to MSP & $\uparrow$ & {$[85,93,94,98]$} \\
\hline \multirow[t]{3}{*}{ Dickkopf-1 [DKK1] } & \multirow{3}{*}{$\begin{array}{l}\text { Regulation of WNT signaling } \\
\text { pathway }\end{array}$} & PP to ESP & $\uparrow$ & \multirow{3}{*}{$\begin{array}{l}{[73,85,92,94} \\
96,97,99]\end{array}$} \\
\hline & & ESP to MSP & $\uparrow$ & \\
\hline & & ESP to LSP & $\downarrow$ & \\
\hline Endothelin 3 [EDN3] & Vasoactive substances & ESP to MSP & $\downarrow$ & $\begin{array}{l}{[73,92,93} \\
100]\end{array}$ \\
\hline \multirow{3}{*}{$\begin{array}{l}\text { Growth arrest and DNA- } \\
\text { damage-inducible protein } \\
\text { [GADD45] }\end{array}$} & \multirow[t]{3}{*}{ Cell cycle } & PP to MSP & $\uparrow$ & \multirow{3}{*}{$\begin{array}{l}{[73,92-94,97,} \\
101]\end{array}$} \\
\hline & & ESP to MSP & $\uparrow$ & \\
\hline & & MSP to LSP & $\uparrow$ & \\
\hline $\begin{array}{l}\text { Glutathione peroxidase } 3 \\
\text { [GPX3] }\end{array}$ & $\begin{array}{l}\text { Response to stress and } \\
\text { oxidoreductase activity }\end{array}$ & ESP to MSP & $\uparrow$ & {$[73,86,96]$} \\
\hline \multirow[t]{2}{*}{ Homeobox A10 [HOXA10] } & \multirow[t]{2}{*}{ Transcription factor } & ESP to MSP & $\uparrow$ & \multirow{2}{*}{$\begin{array}{l}{[55,64,94,102,} \\
103]\end{array}$} \\
\hline & & MSP to LSP & $\uparrow$ & \\
\hline Inhibitor of DNA binding & Anatomical structure & ESP to MSP & $\uparrow$ & {$[73,92-94$} \\
\hline $\begin{array}{l}\text { 4, dominant negative helix- } \\
\text { loop helix protein [ID4] }\end{array}$ & development & & & 104] \\
\hline \multirow{2}{*}{$\begin{array}{l}\text { Insulin-like growth factor } \\
\text { binding protein } 1 \text { [IGFBP-1] }\end{array}$} & \multirow{2}{*}{$\begin{array}{l}\text { Anatomical structure } \\
\text { development }\end{array}$} & ESP to MSP & $\uparrow$ & \multirow[t]{2}{*}[73,94]{} \\
\hline & & MSP to LSP & $\uparrow$ & \\
\hline IL15 precursor [IL15] & Immune response & ESP to MSP & $\uparrow$ & $\begin{array}{l}{[73,85,92-94,} \\
96]\end{array}$ \\
\hline Mitogen-activated protein & Signal transduction & PP to ESP & $\uparrow$ & {$[92,101]$} \\
\hline $\begin{array}{l}\text { kinase kinase kinase } 5 \\
\text { [MAPKKK5] }\end{array}$ & & & & \\
\hline \multirow{3}{*}{$\begin{array}{l}\text { Matrix metalloproteinase } 26 \\
{[D A M M P 26]}\end{array}$} & \multirow{3}{*}{$\begin{array}{l}\text { Tissue remodeling and } \\
\text { blastocyst invasion }\end{array}$} & MP to LPP & $\uparrow$ & \multirow{3}{*}{$\begin{array}{l}{[87,94]} \\
{[73]}\end{array}$} \\
\hline & & PP to ESP & $\uparrow$ & \\
\hline & & MSP to LSP & $\downarrow$ & \\
\hline Msh homeobox homologs & Anatomical structure & ESP to MSP & $\downarrow$ & {$[73,88,91,93$} \\
\hline $1,2[M S X 1]$ & development & & & 96] \\
\hline \multirow{4}{*}{$\begin{array}{l}\text { Natural cytotoxicity- } \\
\text { triggering receptor } 3 \\
{[N C R 3]}\end{array}$} & \multirow[t]{4}{*}{ Immune response } & ESP to MSP & $\uparrow$ & \multirow[t]{4}{*}[86,87]{} \\
\hline & & MSP to LSP & $\uparrow$ & \\
\hline & & LSP to MP & $\uparrow$ & \\
\hline & & MP to PP & $\downarrow$ & \\
\hline Olfactomedin 1 [OLFM1] & Anatomical structure & PP to ESP & $\downarrow$ & {$[73,88,92,93]$} \\
\hline & development & ESP to MSP & $\downarrow$ & \\
\hline Sex-determining region & Apoptotic pathways & PP to ESP & $\downarrow$ & {$[87,88]$} \\
\hline Y-box $4[S O X 4]$ & & MSP to LSP & $\uparrow$ & \\
\hline & & MP to LPP & $\uparrow$ & \\
\hline Osteopontin [SPP1] & Cell adhesion & $\mathrm{PP}$ to SP & $\uparrow$ & {$[73,85,91-93$} \\
\hline & & ESP to MSP & $\uparrow$ & $96,97,101]$ \\
\hline Tissue inhibitor & Degradation of the & PP to ESP & $\uparrow$ & {$[73,94,95]$} \\
\hline metalloproteinase 3 & extracellular matrix & ESP to MSP & $\uparrow$ & \\
\hline$[T I M P-3]$ & & MSP to LSP & $\uparrow$ & \\
\hline
\end{tabular}

Genes expressed in human endometrium and its expression profiles at the different phases of the endometrial cycle. A compilation of the genes exhibiting the same expression profile in more than one work is presented, regardless of the differences among studies.

Table 2.

Expression profiles of genes involved in ER. 


\begin{tabular}{|c|c|c|c|}
\hline $\begin{array}{l}\text { Reference and } \\
\text { relevance }\end{array}$ & Methodology & Results & Targets \\
\hline $\begin{array}{l}{[132]} \\
\text { Shows distinct } \\
\text { miRNA profiles } \\
\text { in LPP and MSP }\end{array}$ & $\begin{array}{l}\text { Samples: Endometrial } \\
\text { biopsies LPP }[\mathrm{n}=4] \\
\text { and MSP }[\mathrm{n}=4] \\
\text { Technique: } \\
\text { Microarray } \\
\text { Technology }\end{array}$ & $\begin{array}{l}49 \text { differentially expressed } \\
\text { miRNAs: } 12 \uparrow \text { in the MSP } \\
\text { [miR-214, 503, 134, 450, } \\
382,376 \mathrm{~A}, 369-5 \mathrm{p}, 222,370, \\
542-3 \mathrm{p}, 105, \text { and } 127] \text { and } 12 \\
\downarrow \text { in LPP [miR-210, 193a-3p, } \\
345,29 \mathrm{~b}, 29 \mathrm{c}, 30 \mathrm{~b}, 204,203, \\
582-5 \mathrm{p}, 30 \mathrm{~d}, 200 \mathrm{c} \text {, and } 31]\end{array}$ & $\begin{array}{l}\text { Predicted: Cell cycle } \\
\text { pathways in the LPP. Wnt } \\
\text { signaling pathway in the } \\
\text { PP. Validated: Decreased } \\
\text { transcripts of predicted } \\
\text { targets [cyclins, CDKs, and } \\
\text { E2F3] }\end{array}$ \\
\hline $\begin{array}{l}{[134]} \\
\text { Evaluates } \\
\text { differentially } \\
\text { expressed } \\
\text { miRNAs in RIF- } \\
\text { IVF patients }\end{array}$ & $\begin{array}{l}\text { Samples: Secretory } \\
\text { endometrium; } 12 \\
\text { fertile women versus } \\
11 \text { women with RIF } \\
\text { Technique: TaqMan } \\
\text { miRNA array cards }\end{array}$ & $\begin{array}{c}13 \text { differentially expressed } \\
\text { miRNAs: } \\
10 \uparrow[\mathrm{miR}-23 \mathrm{~b}, \mathrm{I} 45,99 \mathrm{a}, 27 \mathrm{~b}, \\
652,139-5 \mathrm{p}, 195,342-3 \mathrm{p}, 150, \\
\text { and } 374 \mathrm{~b}] \text { and } 3 \downarrow[\mathrm{miR}-32, \\
628-5 \mathrm{p} \text {, and } 874]\end{array}$ & $\begin{array}{l}\text { Predicted: Wnt signaling, } \\
\text { adherents junctions, p53 } \\
\text { signaling, cell adhesion, } \\
\text { and cell cycle pathways. } \\
\text { Validated: Decreased } \\
\text { transcripts of N-cadherin, } \\
\text { H2AFX, NTN4, and } \\
\text { SFRP4. Wnt and cell cycle } \\
\text { pathways } \downarrow \text { in RIF-IVF }\end{array}$ \\
\hline $\begin{array}{l}{[154]} \\
\text { Makes } \\
\text { comparison } \\
\text { between natural } \\
\text { vs. stimulated } \\
\text { cycles. Suggests } \\
\text { that ovarian } \\
\text { stimulation may } \\
\text { shift the WOI }\end{array}$ & $\begin{array}{c}\text { Samples: Infertile } \\
\text { women. Receptive } \\
{[\mathrm{LH}+7, \mathrm{n}=5] \text { vs. }} \\
\text { prereceptive }[\mathrm{LH}+2, \\
\mathrm{n}=5] \text { in natural cycles. } \\
\text { Receptive [hCG + 7, } \\
\mathrm{n}=5] \text { vs. prereceptive } \\
\text { [hCG + 4, } \mathrm{n}=5] \text { in } \\
\text { stimulated IVF cycles } \\
\text { Technique: Next-gen } \\
\text { seq., } 626 \text { miRNAs } \\
\text { evaluated }\end{array}$ & 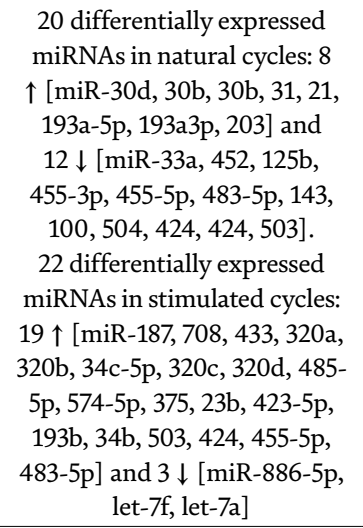 & $\begin{array}{l}\text { Predicted: Cell cycle, } \\
\text { transport, cell adhesion, } \\
\text { cell death, and metabolism }\end{array}$ \\
\hline $\begin{array}{l}{[136]} \\
\text { Provides } \\
\text { miRNA } \\
\text { signature of } \\
\text { EnSCs during } \\
\text { decidualization } \\
\text { in vitro }\end{array}$ & $\begin{array}{l}\text { Samples: Endometrial } \\
\text { samples on oocyte } \\
\text { retrieval day from } \\
\text { healthy ovum donors } \\
{[\mathrm{n}=50] . \text { EnSCs }} \\
{[\mathrm{n}=20] \text { isolated and }} \\
\text { cultured } \\
\text { Technique: miRNA } \\
\text { PCR array, } 704 \\
\text { miRNAs + specific } \\
\text { miRNA-200b primers } \\
\text { evaluated }\end{array}$ & $\begin{array}{c}43 \text { differentially expressed } \\
\text { miRNAs: } 26 \uparrow[\text { miR-95, 888, } \\
\text { 936, } 1185,518 f, 548 \mathrm{k}, 593, \\
486-5 \mathrm{p}, 29 \mathrm{c}, 449 \mathrm{~b}, 300,371- \\
\text { 5p, 1224-3p, 891a, 365, 541, } \\
\text { 409-5p, 33b, 154, 376a, 133a, } \\
\text { 218-2, 22, 614, 369-3p, 185] } \\
\text { and } 17 \downarrow[\mathrm{miR}-146 \mathrm{a}, 155, \\
\text { 181b, } 181 \mathrm{a}, 135 \mathrm{~b}, 181 \mathrm{~d}, 200 \mathrm{c}, \\
\text { 141, } 182,429,483-3 \mathrm{p}, 200 \mathrm{a}, \\
96,183,9,30 \mathrm{a}, 126] \\
\text { miR-95 } \uparrow \text { by P4 and E2 + P4; } \\
\text { miR-96 and miR-135b both } \downarrow \\
\text { by E2 or P4 }\end{array}$ & $\begin{array}{l}\text { Predicted: Growth } \\
\text { factors, interleukins, ECM } \\
\text { remodeling enzymes. } \\
\text { - Top pathways by } \downarrow \\
\text { miRNAs: axon guidance, } \\
\text { adherents junction, actin } \\
\text { cytoskeleton regulation, } \\
\text { ErbB [EGFR] signaling, } \\
\text { and renal cell carcinoma. } \\
\text { - Top pathways by } \uparrow \\
\text { miRNAs: actin cytoskel- } \\
\text { eton regulation, adherent } \\
\text { junction, axon guidance, } \\
\text { Wnt signaling, and MAPK }\end{array}$ \\
\hline $\begin{array}{l}{[133]} \\
\text { Provides } \\
\text { miRNA } \\
\text { signature of } \\
\text { fertile human } \\
\text { endometria: } \\
\text { receptive vs. } \\
\text { prereceptive }\end{array}$ & $\begin{array}{l}\text { Samples: Receptive } \\
\text { MSP }[\mathrm{LH}+7, \mathrm{n}=4] \\
\text { vs. prereceptive } \\
\text { ESP }[\mathrm{LH}+2, \mathrm{n}=5] \\
\text { endometrial biopsies } \\
\text { from } 9 \text { healthy fertile } \\
\text { women } \\
\text { Technique: } \\
\text { Microarray, } 723 \\
\text { human and } 76 \\
\text { human viral miRNAs } \\
\text { evaluated }\end{array}$ & $\begin{array}{c}4 \text { significantly expressed } \\
\text { different miRNAs in receptive } \\
\text { samples: } 2 \uparrow \text { [hsa-miR-30b and } \\
\text { 30d] and } 2 \downarrow \text { [hsa-miR-494 } \\
\text { and 923] } \\
\text { Suggests } 12 \text { genes that could } \\
\text { serve as a new panel for ER: } \\
\text { CAST, CFTR, DPYSL2, FI IR, } \\
\text { FGFR2, LIF, MTFI, NPAS2, } \\
\text { P4HA2, PPARGCIA, TACC2, } \\
\text { RAB40B }\end{array}$ & $\begin{array}{l}\text { Predicted: Transcription, } \\
\text { cell proliferation, and } \\
\text { apoptosis. Involvement } \\
\text { in pathways such as axon } \\
\text { guidance, Wnt/ } \beta \text {-catenin, } \\
\text { ERK/MAPK, TGF- } \beta \text {, p53 } \\
\text { and leukocyte extravasation. } \\
\text { They identified SEPT7, } \\
\text { CRMP1, SLC44A1, HES1, } \\
\text { FXR2, and TNF144B as } \\
\text { genes that interact with } \\
\text { genes } M I R 30 B \text { and MIR30D }\end{array}$ \\
\hline
\end{tabular}


The Genetic and Biochemical Blueprint of Endometrial Receptivity: Past, Present, and Future... DOI: http://dx.doi.org/10.5772/intechopen.80452

\begin{tabular}{|c|c|c|c|}
\hline $\begin{array}{l}\text { Reference and } \\
\text { relevance }\end{array}$ & Methodology & Results & Targets \\
\hline $\begin{array}{l}{[130]} \\
\text { Differential } \\
\text { miRNAs across } \\
\text { cycle. Release } \\
\text { of miRNAs into } \\
\text { the EF and its } \\
\text { uptake by the } \\
\text { embryo }\end{array}$ & $\begin{array}{l}\text { Samples: EF }[\mathrm{n}=20] \\
\text { at different phases of } \\
\text { the menstrual cycle } \\
\text { of healthy women. } \\
\text { Timing of sample } \\
\text { collection: EPP, LPP, } \\
\text { ESP, WOI, and LSP } \\
\text { Technique: } \\
\text { Microarray, } 866 \\
\text { miRNAs evaluated }\end{array}$ & $\begin{array}{l}\text { Compared with the WOI, } \\
9 \text { differentially expressed } \\
\text { miRNAs were identified in the } \\
\text { EPP, } 8 \text { in the LPP, } 6 \text { in the ESP } \\
\text { and } 4 \text { in the LSP. } \\
\text { MiR-30d was the most } \\
\text { differentially secreted } \\
\text { maternal miRNA in the EF } \\
\text { during the WOI }\end{array}$ & $\begin{array}{l}\text { Predicted: Cell cycle and } \\
\text { endocrine processes }\end{array}$ \\
\hline $\begin{array}{l}{[135]} \\
\text { Shows a } \\
\text { significant } \\
\text { different } \\
\text { expression of } \\
\text { miRNAs in the } \\
\text { WOI of RIF } \\
\text { patients that } \\
\text { may contribute } \\
\text { to impaired ER }\end{array}$ & $\begin{array}{l}\text { Samples: Endometrial } \\
\text { biopsies from the } \\
\text { WOI [5-7 days after } \\
\text { ovulation]: } 7 \text { from } \\
\text { RIF group and } 5 \text { from } \\
\text { control group [infertile } \\
\text { patients that delivered } \\
\text { after one transfer } \\
\text { attempt] } \\
\text { Technique: } \\
\text { Microarray } \\
\text { Technology }\end{array}$ & $\begin{array}{l}\text { With a 2-fold threshold: } 105 \\
\text { miRNAs were differentially } \\
\text { expressed: } 93 \uparrow \text { and } 12 \downarrow \text {. } \\
\text { After raw signal value } \\
\text { correction, } 15 \text { were found to } \\
\text { be significantly different. } 10 \\
\uparrow \text { [hsa-miR-374a-5p, 145-5p, } \\
\text { 30b-5p, 196b-5p, 199a-5p, } \\
\text { 199b-5p, 449a, 424-5p, } \\
\text { 125b-5p, 21-5p] and } 5 \downarrow \\
\text { [hsa-miR-1207-5p, 4306, 572, } \\
\text { 5739, 6088] }\end{array}$ & $\begin{array}{l}\text { Predicted: TAM analysis: } \\
\text { miR-30 family, human } \\
\text { embryonic stem cell } \\
\text { regulation, epithelial- } \\
\text { mesenchymal transition, } \\
\text { and miRNA tumor } \\
\text { suppressors. Network } \\
\text { regulatory analysis: } 176 \\
\text { miRNA-mRNA interactions. } \\
\text { The top core mRNA } \\
\text { were ABP1, AQP3, ASS1, } \\
\text { and TIMP3, the top core } \\
\text { miRNAs were has-miR- } \\
\text { 4668-5p, 429, and 5088 }\end{array}$ \\
\hline
\end{tabular}

Studies conducted to analyze miRNA expression profiles during the menstrual cycle as potential biomarkers of the WOI. A summary of the differentially expressed miRNAs and predicted targets found in recent studies is presented. Its relevance regarding the role of miRNAs is also addressed.

Table 3.

Studies of miRNA-profiling during the WOI.

in ART procedures. Proteomics of EF has already rendered valuable information regarding ER; Casado-Vela et al. identified 803 proteins in EF aspirates using three different proteomic strategies [138]. Additionally, Boomsma et al. [139] analyzed endometrial secretions prior to embryo transfer from 210 women undergoing IVF to determine differences in cytokine profiling at the time of implantation, finding a negative and a positive association of monocyte chemo-attractant protein-1 (MCP-1) and IFN- $\gamma$-inducible $10 \mathrm{kDa}$ protein (IP-10) levels and implantation, respectively. Lipidomics, on the other hand, seems to have rendered slight information on receptivity [140], nevertheless, a study performed by Berlanga et al. [141] and followed by Vilella et al. [142, 143] carried out lipidomic analyses of EF from patients at different stages of their menstrual cycle, they determined a significant increase in Prostaglandin E2 (PGE2) and Prostaglandin F2 $\alpha$ (PGF2 $\alpha$ ) between days 19 and 21, coincident with the WOI. In a recent study performed by Durairaj, Aberkane et al. [144], the contribution of EnSCs to failed implantation was examined by analyzing the secretome profile of EnSCs cultures in-vitro. From there, they encountered that secretome profiles of pregnant women are less divergent in implantation-positivecultures particularly in Day 0 (undifferentiated cells), suggesting that endometrial defects linked to reproductive failure could be more prominent in the PP, a phase that is commonly thought to be not relevant for ER studies. This research group also demonstrated that the secretome of undifferentiated EnSCs compromises blastocyst development. Finally, they determined that a deficiency of endometrial mesenchymal stem-like cells (MSCs) could lead to aberrant EnSC function and implantation failure. Overall, this study remarks the importance of progenitor cell populations in 
the endometrium that supports the acquisition of receptivity and raises the prospect of screening the endometrium before the initiation of an ART procedure.

\subsection{The microbiome as a novel aspect of ER}

Historically, the uterus was assumed to be free of bacteria as the fetal environment was considered to be physiologically sterile [145], this notion implies that the neonate's microbiome is acquired only during and after birth. Although recent research still supports this conception [146], others have characterized upper genital tract microbiota [147-150], suggesting that the endometrial and vaginal microbiota not be identical [151]. What is more, the study by Moreno et al. $[147,152]$, which defined the microbiota in the EF as Lactobacillus-dominated (LD) or non-Lactobacillus-dominated (NLD), suggested that the presence of an NLD microbiota in a receptive endometrium was associated with a significant decrease in implantation, pregnancy, ongoing pregnancy, and live birth rates. Nevertheless, they acknowledge that in the absence of pathological signs, an NLD microbiota could be considered normal since Lactobacillus-deficient communities have been identified in the genital tract of otherwise healthy asymptomatic women [153]. This conception sets the stage for further research of the human microbiome, expands the possibilities to assess individualized receptivity based on the endometrial microbiome, and opens the door to explore targeted therapies for an altered endometrial microbial habitat.

\section{Remarks}

This review encloses different aspects of ER, spotlighting the opening of the WOI. Altogether, this compilation could aid in the development of new clinical practices that define an individual's receptive window for $\mathrm{pET}$ to improve ART results ultimately.

Nowadays, ER is the rate-limiting step in successful ART procedures that end up in pregnancy and child delivery. The endometrial tissue is a ponderous element in fertility; it constitutes the soil in which a viable embryo will implant to achieve progeny. The attainment of ER involves an extensive assortment of genetic and biochemical mechanisms that must integrate in a parallel manner. Understanding of this process as an entity is still insufficient; nevertheless, the surge of new technologies is contributing in the deciphering of receptivity mechanisms and in search of novel biomarkers that could serve to detect the WOI. Notably, although most studies focus on individual genetic mutations, a more comprehensive view of the parental genetics is needed to determine whether an endometrium is adequate for embryo transfer before the initiation of an ART procedure. Due to ambiguous or non-conclusive results in search of genetic predispositions of endometrialassociated infertility, it would be controversial to provide genetic counseling currently. Perhaps, in the future, massive sequencing could help to provide insights into the importance of single and multiple genetic mutations to establish a receptive or non-receptive profile. If assertive, this profile could be applied as an endometrial pre-implantation parental test to improve the rates of healthy pregnancies and live births. With this in mind, in our opinion, the best short-term approaches towards detecting or improving ER are the transcriptome, microbiome, and miRNA signatures, all achievable using the power of NGS. This review encloses different aspects of ER, spotlighting the opening of the WOI. Altogether, this compilation could aid in the development of new clinical practices that define an individual's receptive window for $\mathrm{pET}$ to improve ART results ultimately. 
The Genetic and Biochemical Blueprint of Endometrial Receptivity: Past, Present, and Future... DOI: http://dx.doi.org/10.5772/intechopen.80452

\section{Abbreviations and nomenclatures}

\begin{tabular}{|c|c|}
\hline $3 \mathrm{D}$ & three-dimensional \\
\hline ApoE & apolipoprotein E \\
\hline ART & assisted reproductive tech \\
\hline CNTF & ciliary neurotrophic factor \\
\hline CT1 & cardiotrophin 1 \\
\hline E2 & estrogen \\
\hline ECM & extracellular matrix \\
\hline $\mathrm{EF}$ & endometrial fluid \\
\hline EGF & epithermal growth factor \\
\hline EMX2 & empty spiracles homolog 2 \\
\hline eNOS & endometrial nitric-oxide synthase \\
\hline EnSCs & endometrial stromal cells \\
\hline EPP & early-proliferative phase \\
\hline ER & endometrial receptivity \\
\hline ERA & endometrial receptivity array \\
\hline ESP & early-secretory phase \\
\hline ESR1 & estrogen receptor 1 \\
\hline F13A1 & coagulation factor XIII A chain \\
\hline F2 & coagulation factor II \\
\hline F5 & coagulation factor $\mathrm{V}$ \\
\hline F8 & coagulation factor 8 \\
\hline FAAH & fatty acid amide hydrolase \\
\hline Fas L & Fas ligand \\
\hline FGB & $\beta$ fibrinogen \\
\hline Foxp3 & Forkhead box P3 \\
\hline gp130 & glycoprotein 130 \\
\hline GPIIIa & glycoprotein IIIa \\
\hline HAUSP & herpesvirus-associated ubiquitin-specific protease \\
\hline HB-EGF & heparin-binding epithermal growth factor-like growth factor \\
\hline hCG & human chorionic gonadotropin \\
\hline HOXA10 & homeobox A10 \\
\hline HOXA11 & homeobox A11 \\
\hline HPA1 & human platelet alloantigens 1 \\
\hline HSCORE & histological score \\
\hline IGFBP1 & insulin-like growth factor binding protein 1 \\
\hline IL11R & interleukin 11 receptor \\
\hline IL6 & interleukin 6 \\
\hline IP-10 & IFN- $\gamma$-inducible $10 \mathrm{kDa}$ protein \\
\hline ITGB3 & integrin $\beta 3$ \\
\hline IVF & in-vitro fertilization \\
\hline LD & lactobacillus-dominated \\
\hline $\mathrm{LH}$ & luteinizing hormone \\
\hline LIF & leukemia inhibitory factor \\
\hline LIFR & leukemia inhibitory factor receptor \\
\hline LPP & late-proliferative phase \\
\hline LSP & late-secretory phase \\
\hline MCP-1 & monocyte chemo-attractant protein-1 \\
\hline MDM2 & murine double minute 2 \\
\hline MHC & major histocompatibility complex \\
\hline MiRNA & microRNA \\
\hline $\mathrm{MP}$ & menstrual phase \\
\hline
\end{tabular}


MSCs mesenchymal stem-like cells

MSP mid-secretory phase

MTHFR methylenetetrahydrofolate reductase

MUC1 Mucin 1

MUC4 Mucin 4

NGS next generation sequencing

NLD non-lactobacillus-dominated

OSM oncostatin

P4 progesterone

TP53 tumor protein 53

PAI-1 plasminogen activator inhibitor-1

PCOS polycystic ovarian syndrome

PCR polymerase chain reaction

pET personalized embryo transfer

PGE2 prostaglandin E2

PGF2 $\alpha \quad$ prostaglandin F2 $\alpha$

PGs prostaglandins

PIBF progesterone-induced blocking factor

$\mathrm{PP} \quad$ proliferative phase

PR progesterone receptor

PR-A progesterone receptor A

RIF repeated implantation failure

RPL recurrent pregnancy loss

RSA recurrent spontaneous abortion

SNP single-nucleotide polymorphism

SP secretory phase

TAM tool annotations human miRNAs

TFF3 trefoil factor 3

Treg T-regulatory cells

uNK uterine natural killer

VEGF vascular endothelial growth factor

VNTR variable number tandem repeats

WOI window of implantation 
The Genetic and Biochemical Blueprint of Endometrial Receptivity: Past, Present, and Future... DOI: http://dx.doi.org/10.5772/intechopen.80452

\section{Author details}

Almena López-Luna ${ }^{1,2}$, Dinorah Hernández-Melchor ${ }^{1,2}$, Leticia Ramírez-Martínez ${ }^{2}$ and Esther López-Bayghen ${ }^{2 *}$

1 Laboratorio de Investigación y Diagnóstico Molecular, Instituto de Infertilidad y Genética SC, INGENES, Mexico

2 Departamento de Toxicología, Cinvestav-IPN, Ciudad de México, Mexico

*Address all correspondence to: ebayghen@cinvestav.mx

\section{IntechOpen}

(C) 2018 The Author(s). Licensee IntechOpen. This chapter is distributed under the terms of the Creative Commons Attribution License (http://creativecommons.org/licenses/ by/3.0), which permits unrestricted use, distribution, and reproduction in any medium, provided the original work is properly cited. (cc) BY 


\section{References}

[1] Lessey BA. The role of the endometrium during embryo implantation. Human Reproduction. 2000;15(Suppl 6):39-50

[2] Diedrich K et al. The role of the endometrium and embryo in human implantation. Human Reproduction Update. 2007;13(4):365-377

[3] Strowitzki T et al. The human endometrium as a fertility-determining factor. Human Reproduction Update. 2006;12(5):617-630

[4] Teh WT, McBain J, Rogers P. What is the contribution of embryo-endometrial asynchrony to implantation failure? Journal of Assisted Reproduction and Genetics. 2016;33(11):1419-1430

[5] Achache H, Revel A. Endometrial receptivity markers, the journey to successful embryo implantation. Human Reproduction Update. 2006;12(6):731-746

[6] Reed BG, Carr BR. The normal menstrual cycle and the control of ovulation. In: De Groot LJ et al., editors. South Dartmouth (MA): Endotext; 2000

[7] Cha J, Sun X, Dey SK. Mechanisms of implantation: Strategies for successful pregnancy. Nature Medicine. 2012;18(12):1754-1767

[8] Mahajan N. Endometrial receptivity array: Clinical application. Journal of Human Reproductive Sciences. 2015;8(3):121-129

[9] Heger A, Sator M, Pietrowski D. Endometrial receptivity and its predictive value for IVF/ICSI-outcome. Geburtshilfe und Frauenheilkunde. 2012;72(8):710-715

[10] Beier HM, Beier-Hellwig K. Molecular and cellular aspects of endometrial receptivity.
Human Reproduction Update. 1998;4(5):448-458

[11] Lockwood CJ et al. The role of decidualization in regulating endometrial hemostasis during the menstrual cycle, gestation, and in pathological states. Seminars in Thrombosis and Hemostasis. 2007;33(1):111-117

[12] Lu Z, Hardt J, Kim JJ. Global analysis of genes regulated by HOXA10 in decidualization reveals a role in cell proliferation. Molecular Human Reproduction. 2008;14(6):357-366

[13] Jabbour HN et al. Endocrine regulation of menstruation. Endocrine Reviews. 2006;27(1):17-46

[14] Fox C et al. Local and systemic factors and implantation: What is the evidence? Fertility and Sterility. 2016;105(4):873-884

[15] Murray MJ et al. A critical analysis of the accuracy, reproducibility, and clinical utility of histologic endometrial dating in fertile women. Fertility and Sterility. 2004;81(5):1333-1343

[16] Coutifaris C et al. Histological dating of timed endometrial biopsy tissue is not related to fertility status. Fertility and Sterility. 2004;82(5):1264-1272

[17] Nikas G. Endometrial receptivity: Changes in cell-surface morphology. Seminars in Reproductive Medicine. 2000;18(3):229-235

[18] Quinn CE, Casper RF. Pinopodes: A questionable role in endometrial receptivity. Human Reproduction Update. 2009;15(2):229-236

[19] Zhang T et al. The role of threedimensional power Doppler ultrasound parameters measured on hCG day in the prediction of pregnancy during in vitro 
The Genetic and Biochemical Blueprint of Endometrial Receptivity: Past, Present, and Future... DOI: http://dx.doi.org/10.5772/intechopen.80452

fertilization treatment. European Journal of Obstetrics, Gynecology, and Reproductive Biology. 2016;203:66-71

[20] Abdalla HI et al. Endometrial thickness: A predictor of implantation in ovum recipients? Human

Reproduction. 1994;9(2):363-365

[21] Yuval Y et al. The relationships between endometrial thickness, and blood flow and pregnancy rates in in-vitro fertilization. Human Reproduction. 1999;14(4):1067-1071

[22] Schild RL et al. Endometrial receptivity in an in vitro fertilization program as assessed by spiral artery blood flow, endometrial thickness, endometrial volume, and uterine artery blood flow. Fertility and Sterility. 2001;75(2):361-366

[23] Noyes N et al. Factors useful in predicting the success of oocyte donation: A 3-year retrospective analysis. Fertility and Sterility. 2001;76(1):92-97

[24] Friedler S et al. The role of ultrasonography in the evaluation of endometrial receptivity following assisted reproductive treatments: A critical review. Human Reproduction Update. 1996;2(4):323-335

[25] Khalifa E et al. Sonographic appearance of the endometrium: The predictive value for the outcome of in-vitro fertilization in stimulated cycles. Human Reproduction. 1992;7(5):677-680

[26] Sundström P. Establishment of a successful pregnancy following in-vitro fertilization with an endometrial thickness of no more than $4 \mathrm{~mm}$. Human Reproduction (Oxford, England). 1998;13(6):1550-1552

[27] Remohi J et al. Endometrial thickness and serum oestradiol concentrations as predictors of outcome in oocyte donation. Human
Reproduction (Oxford, England). 1997;12(10):2271-2276

[28] Mercé LT. Ultrasound markers of implantation. The Ultrasound Review of Obstetrics and Gynecology. 2002;2(2):110-123

[29] Raga F et al. Assessment of endometrial volume by threedimensional ultrasound prior to embryo transfer: Clues to endometrial receptivity. Human Reproduction. 1999;14(11):2851-2854

[30] Zhao J, Zhang Q, Li Y. The effect of endometrial thickness and pattern measured by ultrasonography on pregnancy outcomes during IVF-ET cycles. Reproductive Biology and Endocrinology. 2012;10:100

[31] Zhao J et al. Endometrial pattern, thickness and growth in predicting pregnancy outcome following 3319 IVF cycle. Reproductive Biomedicine Online. 2014;29(3):291-298

[32] Fatemi HM, Popovic-Todorovic B. Implantation in assisted reproduction: A look at endometrial receptivity. Reproductive Biomedicine Online. 2013;27(5):530-538

[33] Coulam CB, Jeyendran RS. Vascular endothelial growth factor gene polymorphisms and recurrent pregnancy loss. American Journal of Reproductive Immunology. 2008;59(4):301-305

[34] Papazoglou D et al. Vascular endothelial growth factor gene polymorphisms and idiopathic recurrent pregnancy loss. Fertility and Sterility. 2005;83(4):959-963

[35] Lee $\mathrm{HH}$ et al. Association study of vascular endothelial growth factor polymorphisms with the risk of recurrent spontaneous abortion. Fertility and Sterility. 2010;93(4):1244-1247 
[36] Goodman C, Jeyendran RS, Coulam CB. Vascular endothelial growth factor gene polymorphism and implantation failure. Reproductive Biomedicine Online. 2008;16(5):720-723

[37] Goodman C, Jeyendran RS, Coulam CB. P53 tumor suppressor factor, plasminogen activator inhibitor, and vascular endothelial growth factor gene polymorphisms and recurrent implantation failure. Fertility and Sterility. 2009;92(2):494-498

[38] Xu X et al. Association of VEGF genetic polymorphisms with recurrent spontaneous abortion risk: A systematic review and meta-analysis. PLoS One. 2015;10(4):e0123696

[39] Su MT, Lin SH, Chen YC. Genetic association studies of angiogenesis- and vasoconstriction-related genes in women with recurrent pregnancy loss: A systematic review and meta-analysis. Human Reproduction Update. 2011;17(6):803-812

[40] Kang HJ et al. Single-nucleotide polymorphisms in the p53 pathway regulate fertility in humans. Proceedings of the National Academy of Sciences of the United States of America. 2009;106(24):9761-9766

[41] Coulam CB, Kay C, Jeyendran RS. Role of p53 codon 72 polymorphism in recurrent pregnancy loss.

Reproductive Biomedicine Online. 2006;12(3):378-382

[42] Yenicesu GI et al. A prospective case-control study analyzes 12 thrombophilic gene mutations in Turkish couples with recurrent pregnancy loss. American Journal of Reproductive Immunology. 2010;63(2):126-136

[43] Jia M, Dahlman-Wright K, Gustafsson JA. Estrogen receptor alpha and beta in health and disease. Best Practice \& Research. Clinical Endocrinology \& Metabolism. 2015;29(4):557-568
[44] Yuan R, Le AW. A study on the estrogen receptor alpha gene polymorphism and its expression in thin endometrium of unknown etiology. Gynecologic and Obstetric Investigation. 2012;74(1):13-20

[45] Hey NA et al. The polymorphic epithelial mucin MUC1 in human endometrium is regulated with maximal expression in the implantation phase. The Journal of Clinical Endocrinology and Metabolism. 1994;78(2):337-342

[46] Xu B et al. Pinopodes, leukemia inhibitory factor, integrin-beta3, and mucin- 1 expression in the peri-implantation endometrium of women with unexplained recurrent pregnancy loss. Fertility and Sterility. 2012;98(2):389-395

[47] Meseguer $\mathrm{M}$ et al. Human endometrial mucin MUC1 is up-regulated by progesterone and down-regulated in vitro by the human blastocyst. Biology of Reproduction. 2001;64(2):590-601

[48] Brayman M, Thathiah A, Carson DD. MUC1: A multifunctional cell surface component of reproductive tissue epithelia. Reproductive Biology and Endocrinology. 2004;2:4

[49] Carson DD, DeSouza MM, Regisford EG. Mucin and proteoglycan functions in embryo implantation. BioEssays. 1998;20(7):577-583

[50] Audie JP et al. Mucin gene expression in the human endocervix. Human Reproduction. 1995;10(1):98-102

[51] Nollet $S$ et al. Human mucin gene MUC4: Organization of its $5^{\prime}$-region and polymorphism of its central tandem repeat array. The Biochemical Journal. 1998;332(Pt 3):739-748

[52] Ferrell AD et al. Sialomucin complex (Muc4) expression in porcine endometrium during the oestrous cycle 
The Genetic and Biochemical Blueprint of Endometrial Receptivity: Past, Present, and Future... DOI: http://dx.doi.org/10.5772/intechopen.80452

and early pregnancy. Reproduction in Domestic Animals. 2003;38(1):63-65

[53] Carraway KL, Idris N. Regulation of sialomucin complex/Muc4 in the female rat reproductive tract. Biochemical Society Transactions. 2001;29(Pt 2):162-166

[54] Coulam CB, Jeyendran R, Roussev $\mathrm{R}$. Association of progesterone receptor polymorphisms with recurrent implantation failure after in vitro fertilization and embryo transfer. Journal of Assisted Reproduction and Genetics. 2008;25(4):119-122

[55] Salazar LA et al. Association of $-765 \mathrm{G}>\mathrm{C}$ polymorphism of the COX-2 gene with recurrent embryo implantation failure in Southern Chilean women. Clinica Chimica Acta. 2010;411(21-22):1822-1824

[56] Wang D et al. DNA

hypomethylation of the COX-2 gene promoter is associated with up-regulation of its mRNA expression in eutopic endometrium of endometriosis. European Journal of Medical Research. 2012;17:12

[57] Pihusch R et al. Thrombophilic gene mutations and recurrent spontaneous abortion: Prothrombin mutation increases the risk in the first trimester. American Journal of Reproductive Immunology. 2001;46(2):124-131

[58] Goodman CS et al. Which thrombophilic gene mutations are risk factors for recurrent pregnancy loss? American Journal of Reproductive Immunology. 2006;56(4):230-236

[59] Vacquier VD. Oogenesis: Developmental biology. Science. 1985;229(4718):1078-1079

[60] Qublan HS et al. Acquired and inherited thrombophilia: Implication in recurrent IVF and embryo transfer failure. Human Reproduction. 2006;21(10):2694-2698
[61] Haroun S et al. Association between trefoil factor 3 gene variants and idiopathic recurrent spontaneous abortion. Reproductive Biomedicine Online. 2014;29(6):737-744

[62] Singh M, Chaudhry P, Asselin E. Bridging endometrial receptivity and implantation: Network of hormones, cytokines, and growth factors. The Journal of Endocrinology. 2011;210(1):5-14

[63] Croy BA et al. Decidual natural killer cells: Key regulators of placental development (a review). Journal of Reproductive Immunology. 2002;57(1-2):151-168

[64] Abrahamsohn PA, Zorn TM. Implantation and decidualization in rodents. The Journal of Experimental Zoology. 1993;266(6):603-628

[65] Gleicher N, Kushnir VA, Barad $\mathrm{DH}$. Redirecting reproductive immunology research toward pregnancy as a period of temporary immune tolerance. Journal of Assisted Reproduction and Genetics. 2017;34(4):425-430

[66] Lash GE, Robson SC, Bulmer JN. Review: Functional role of uterine natural killer (uNK) cells in human early pregnancy decidua. Placenta. 2010;31(Suppl):S87-S92

[67] Bulmer JN, Williams PJ, Lash GE. Immune cells in the placental bed. The International Journal of Developmental Biology. 2010;54(2-3):281-294

[68] King A, Loke YW. Effect of IFNgamma and IFN-alpha on killing of human trophoblast by decidual LAK cells. Journal of Reproductive Immunology. 1993;23(1):51-62

[69] Dosiou C, Giudice LC. Natural killer cells in pregnancy and recurrent pregnancy loss: Endocrine and immunologic perspectives. Endocrine Reviews. 2005;26(1):44-62 
[70] Koopman LA et al. Human decidual natural killer cells are a unique NK cell subset with immunomodulatory potential. The Journal of Experimental Medicine. 2003;198(8):1201-1212

[71] Rachmilewitz J et al. Negative regulation of $\mathrm{T}$ cell activation by placental protein 14 is mediated by the tyrosine phosphatase receptor CD45. The Journal of Biological Chemistry. 2003;278(16):14059-14065

[72] Poole JA, Claman HN. Immunology of pregnancy. Clinical Reviews in Allergy \& Immunology. 2004;26(3):161-170

[73] Runić R et al. Apoptosis and Fas expression in human fetal Membranes1. The Journal of Clinical Endocrinology \& Metabolism. 1998;83(2):660-666

[74] Aschkenazi S et al. Differential regulation and function of the Fas/Fas ligand system in human trophoblast Cells1. Biology of Reproduction. 2002;66(6):1853-1861

[75] Saito S, Sasaki Y, Sakai M. CD4(+) $\mathrm{CD} 25$ high regulatory $\mathrm{T}$ cells in human pregnancy. Journal of Reproductive Immunology. 2005;65(2):111-120

[76] La Rocca C et al. The immunology of pregnancy: Regulatory $\mathrm{T}$ cells control maternal immune tolerance toward the fetus. Immunology Letters. 2014;162 (1 Pt A):41-48

[77] Guerin LR, Prins JR, Robertson SA. Regulatory T-cells and immune tolerance in pregnancy: A new target for infertility treatment? Human Reproduction Update. 2009;15(5):517-535

[78] Heitmann RJ et al. Maternal T regulatory cell depletion impairs embryo implantation which can be corrected with adoptive $\mathrm{T}$ regulatory cell transfer. Reproductive Sciences. 2017;24(7):1014-1024
[79] Dimova T et al. Maternal Foxp3 expressing CD4+ CD25+ and CD4+ CD25regulatory $\mathrm{T}$-cell populations are enriched in human early normal pregnancy decidua: A phenotypic study of paired decidual and peripheral blood samples. American Journal of Reproductive Immunology. 2011;66(Suppl 1):44-56

[80] Haiqi H, Yong Z, Yi L. Transcriptional regulation of Foxp3 in regulatory T cells. Immunobiology. 2011;216(6):678-685

[81] Jasper MJ, Tremellen KP, Robertson SA. Primary unexplained infertility is associated with reduced expression of the T-regulatory cell transcription factor Foxp3 in endometrial tissue. Molecular Human Reproduction. 2006;12(5):301-308

[82] Betz AG. Tolerating pregnancy. Nature. 2012;490:47

[83] Weetman AP. The immunology of pregnancy. Thyroid. 1999;9(7):643-646

[84] Clark DA, Croitoru K. TH1/TH2,3 imbalance due to cytokine-producing NK, gammadelta T and NK-gammadelta $T$ cells in murine pregnancy decidua in success or failure of pregnancy. American Journal of Reproductive Immunology. 2001;45(5):257-265

[85] Saito S. Cytokine network at the feto-maternal interface. Journal of Reproductive Immunology. 2000;47(2):87-103

[86] Szekeres-Bartho J. Immunological relationship between the mother and the fetus. International Reviews of Immunology. 2002;21(6):471-495

[87] Piccinni MP, Romagnani

S. Regulation of fetal allograft survival by a hormone-controlled Th1- and Th2type cytokines. Immunologic Research. 1996;15(2):141-150

[88] Piccinni MP et al. Role of hormonecontrolled Th1- and Th2-type cytokines 
The Genetic and Biochemical Blueprint of Endometrial Receptivity: Past, Present, and Future... DOI: http://dx.doi.org/10.5772/intechopen.80452

in successful pregnancy. Journal of Neuroimmunology. 2000;109(1):30-33

[89] Szekeres-Bartho J, Wegmann TG. A progesterone-dependent immunomodulatory protein alters the Th1Th2 balance. Journal of Reproductive Immunology. 1996;31(1):81-95

[90] Daftary GS et al. Direct regulation of beta3-integrin subunit gene expression by HOXA10 in endometrial cells. Molecular Endocrinology. 2002;16(3):571-579

[91] Taylor HS et al. HOXA10 is expressed in response to sex steroids at the time of implantation in the human endometrium. The Journal of Clinical Investigation. 1998;101(7):1379-1384

[92] Kim JJ et al. Altered expression of HOXA10 in endometriosis:

Potential role in decidualization. Molecular Human Reproduction. 2007;13(5):323-332

[93] Ruiz-Alonso M, Blesa D, Simon C. The genomics of the human endometrium. Biochimica et Biophysica Acta. 2012;1822(12):1931-1942

[94] Sonderegger S, Pollheimer J, Knofler $\mathrm{M}$. Wnt signalling in implantation, decidualisation and placental differentiation--review. Placenta. 2010;31(10):839-847

[95] Troy PJ et al. Transcriptional repression of peri-implantation EMX2 expression in mammalian reproduction by HOXA10. Molecular and Cellular Biology. 2003;23(1):1-13

[96] Germeyer A et al. Endometrial beta3 integrin profile reflects endometrial receptivity defects in women with unexplained recurrent pregnancy loss. Reproductive Biology and Endocrinology. 2014;12:53

[97] Fischer CP, Kayisili U, Taylor HS. HOXA10 expression is decreased in endometrium of women with adenomyosis. Fertility and Sterility. 2011;95(3):1133-1136

[98] Cermik D, Selam B, Taylor

HS. Regulation of HOXA-10 expression by testosterone in vitro and in the endometrium of patients with polycystic ovary syndrome. The Journal of Clinical Endocrinology and Metabolism. 2003;88(1):238-243

[99] Szczepanska M et al. Expression of HOXA-10 and HOXA-11 in the endometria of women with idiopathic infertility. Folia Histochemica et Cytobiologica. 2011;49(1):111-118

[100] Lessey BA et al. Regulated expression of heparin-binding EGF-like growth factor (HB-EGF) in the human endometrium: A potential paracrine role during implantation. Molecular Reproduction and Development. 2002;62(4):446-455

[101] Stavreus-Evers A et al.

Co-existence of heparin-binding epidermal growth factor-like growth factor and pinopodes in human endometrium at the time of implantation. Molecular Human Reproduction. 2002;8(8):765-769

[102] Yoo HJ, Barlow DH, Mardon HJ. Temporal and spatial regulation of expression of heparin-binding epidermal growth factor-like growth factor in the human endometrium: A possible role in blastocyst implantation. Developmental Genetics. 1997;21(1):102-108

[103] Birdsall MA et al. Expression of heparin-binding epidermal growth factor messenger RNA in the human endometrium. Molecular Human Reproduction. 1996;2(1):31-34

[104] Chobotova K et al. Heparinbinding epidermal growth factor and its receptor ErbB4 mediate implantation of the human blastocyst. Mechanisms of Development. 2002;119(2):137-144 
[105] Leach RE et al. Multiple roles for heparin-binding epidermal growth factor-like growth factor are suggested by its cell-specific expression during the human endometrial cycle and early placentation. The Journal of Clinical Endocrinology and Metabolism. 1999;84(9):3355-3363

[106] Cullinan EB et al. Leukemia inhibitory factor (LIF) and LIF receptor expression in human endometrium suggests a potential autocrine/ paracrine function in regulating embryo implantation. Proceedings of the National Academy of Sciences of the United States of America. 1996;93(7):3115-3120

[107] Aghajanova L et al. Coexpression of pinopodes and leukemia inhibitory factor, as well as its receptor, in human endometrium. Fertility and Sterility. 2003;79(Suppl 1):808-814

[108] Diaz-Gimeno P et al. A genomic diagnostic tool for human endometrial receptivity based on the transcriptomic signature. Fertility and Sterility. 2011;95(1):50-60 60e1-15

[109] Guzeloglu-Kayisli O, Kayisli UA, Taylor HS. The role of growth factors and cytokines during implantation: Endocrine and paracrine interactions. Seminars in Reproductive Medicine. 2009;27(1):62-79

[110] Lessey BA et al. Distribution of integrin cell adhesion molecules in endometrial cancer. The American Journal of Pathology. 1995;146(3):717-726

[111] Steck T et al. Leukaemia inhibitory factor (LIF) gene mutations in women with unexplained infertility and recurrent failure of implantation after IVF and embryo transfer. European Journal of Obstetrics, Gynecology, and Reproductive Biology. 2004;112(1):69-73
[112] Lessey BA et al. Integrin adhesion molecules in the human endometrium. Correlation with the normal and abnormal menstrual cycle. The Journal of Clinical Investigation. 1992;90(1):188-195

[113] Lessey BA et al. Further characterization of endometrial integrins during the menstrual cycle and in pregnancy. Fertility and Sterility. 1994;62(3):497-506

[114] Lessey BA et al. Integrins as markers of uterine receptivity in women with primary unexplained infertility. Fertility and Sterility. 1995;63(3):535-542

[115] Dorostghoal M et al. Endometrial expression of beta 3 integrin, calcitonin and plexin-B1 in the window of implantation in women with unexplained infertility. International Journal of Reproductive BioMedicine (Yazd, Iran). 2017;15(1):33-40

[116] von Wolff $M$ et al. Endometrial osteopontin, a ligand of beta3-integrin, is maximally expressed around the time of the "implantation window". Fertility and Sterility. 2001;76(4):775-781

[117] Carson DD et al. Changes in gene expression during the early to midluteal (receptive phase) transition in human endometrium detected by high-density microarray screening. Molecular Human Reproduction. 2002;8(9):871-879

[118] Ponnampalam AP et al. Molecular classification of human endometrial cycle stages by transcriptional profiling. Molecular Human Reproduction. 2004;10(12):879-893

[119] Punyadeera C et al. Oestrogenmodulated gene expression in the human endometrium. Cellular and Molecular Life Sciences. 2005;62(2):239-250 
The Genetic and Biochemical Blueprint of Endometrial Receptivity: Past, Present, and Future... DOI: http://dx.doi.org/10.5772/intechopen.80452

[120] Talbi S et al. Molecular phenotyping of human endometrium distinguishes menstrual cycle phases and underlying biological processes in normo-ovulatory women. Endocrinology. 2006;147(3):1097-1121

[121] Bartel DP. MicroRNAs: Genomics, biogenesis, mechanism, and function. Cell. 2004;116(2):281-297

[122] Shukla GC, Singh J, Barik S. MicroRNAs: Processing, maturation, target recognition and regulatory functions. Molecular and Cellular Pharmacology. 2011;3(3):83-92

[123] Lim LP et al. Microarray analysis shows that some microRNAs downregulate large numbers of target mRNAs. Nature. 2005;433(7027):769-773

[124] Lee RC, Feinbaum RL, Ambros $\mathrm{V}$. The C. elegans heterochronic gene lin-4 encodes small RNAs with antisense complementarity to lin-14. Cell. 1993;75(5):843-854

[125] Weber JA et al. The microRNA spectrum in 12 body fluids. Clinical Chemistry. 2010;56(11):1733-1741

[126] Pogribny IP. MicroRNAs as biomarkers for clinical studies. Experimental Biology and Medicine (Maywood, NJ). 2018;243(3):283-290

[127] Pan Q, Chegini N. MicroRNA signature and regulatory functions in the endometrium during normal and disease states. Seminars in Reproductive Medicine. 2008;26(6):479-493

[128] Hull ML, Nisenblat V. Tissue and circulating microRNA influence reproductive function in endometrial disease. Reproductive Biomedicine Online. 2013;27(5):515-529

[129] Katzorke N et al. Diagnosis of endometrial-factor infertility:
Current approaches and new avenues for research. Geburtshilfe und Frauenheilkunde. 2016;76(6):699-703

[130] Vilella F et al. Hsa-miR-30d, secreted by the human endometrium, is taken up by the pre-implantation embryo and might modify its transcriptome. Development. 2015;142(18):3210-3221

[131] Cuman C et al. Human blastocyst secreted microRNA regulate endometrial epithelial cell adhesion. eBioMedicine. 2015;2(10):1528-1535

[132] Kuokkanen S et al. Genomic profiling of microRNAs and messenger RNAs reveals hormonal regulation in microRNA expression in human endometrium. Biology of Reproduction. 2010;82(4):791-801

[133] Altmae S et al. MicroRNAs miR-30b, miR-30d, and miR494 regulate human endometrial receptivity. Reproductive Sciences. 2013;20(3):308-317

[134] Revel A et al. MicroRNAs are associated with human embryo implantation defects. Human Reproduction. 2011;26(10):2830-2840

[135] Shi C et al. Endometrial MicroRNA signature during the window of implantation changed in patients with repeated implantation failure. Chinese Medical Journal. 2017;130(5):566-573

[136] Estella C et al. miRNA signature and dicer requirement during human endometrial stromal decidualization in vitro. PLoS One. 2012;7(7):e41080

[137] Zullo J et al. The cell secretome, a mediator of cell-to-cell communication. Prostaglandins \& Other Lipid Mediators. 2015;120:17-20

[138] Casado-Vela J et al. Comprehensive proteomic analysis 
of human endometrial fluid aspirate. Journal of Proteome Research. 2009;8(10):4622-4632

[139] Boomsma CM et al. Endometrial secretion analysis identifies a cytokine profile predictive of pregnancy in IVF. Human Reproduction. 2009;24(6):1427-1435

[140] Demiral I et al. Genomic, proteomic and lipidomic evaluation of endometrial receptivity. Turkish Journal of Obstetrics and Gynecology. 2015;12(4):237-243

[141] Berlanga O et al. How endometrial secretomics can help in predicting implantation. Placenta. 2011;32(Suppl 3):S271-S275

[142] Vilella F, Ramirez LB, Simon C. Lipidomics as an emerging tool to predict endometrial receptivity. Fertility and Sterility. 2013;99(4):1100-1106

[143] Vilella F et al. PGE2 and PGF2alpha concentrations in human endometrial fluid as biomarkers for embryonic implantation. The Journal of Clinical Endocrinology and Metabolism. 2013;98(10):4123-4132

[144] Peter Durairaj RR et al.

Deregulation of the endometrial stromal cell secretome precedes embryo implantation failure. Molecular Human Reproduction. 2017;23(8):582

[145] Ansbacher R, Boyson WA, Morris JA. Sterility of the uterine cavity. American Journal of Obstetrics and Gynecology. 1967;99(3):394-396

[146] Perez-Munoz ME et al. A critical assessment of the "sterile womb" and "in utero colonization" hypotheses: Implications for research on the pioneer infant microbiome. Microbiome. 2017;5(1):48

[147] Moreno I et al. Evidence that the endometrial microbiota has an effect on implantation success or failure. American Journal of Obstetrics and Gynecology. 2016;215(6):684-703

[148] Aagaard K et al. The placenta harbors a unique microbiome. Science Translational Medicine. 2014;6(237):237ra65

[149] Verstraelen H et al.

Characterisation of the human uterine microbiome in non-pregnant women through deep sequencing of the V1-2 region of the $16 \mathrm{~S}$ rRNA gene. Peer Journal. 2016;4:e1602

[150] Franasiak JM et al. Endometrial microbiome at the time of embryo transfer: Next-generation sequencing of the $16 \mathrm{~S}$ ribosomal subunit. Journal of Assisted Reproduction and Genetics. 2016;33(1):129-136

[151] Mitchell CM et al. Colonization of the upper genital tract by vaginal bacterial species in nonpregnant women. American Journal of Obstetrics and Gynecology. 2015;212(5):611. e1-611.e9

[152] Moreno I, Franasiak

JM. Endometrial microbiota-new player in town. Fertility and Sterility. 2017;108(1):32-39

[153] Ravel J et al. Vaginal microbiome of reproductive-age women. Proceedings of the National Academy of Sciences of the United States of America. 2011;108(Suppl 1):4680-4687

[154] Sha AG, Liu JL, Jiang XM, Ren JZ, Ma CH, Lei W, Su RW, Yang ZM. Genome-wide identification of microribonucleic acids associated with human endometrial receptivity in natural and stimulated cycles by deep sequencing. Fertil Steril. 2011;96(1):150-155 e155 


\title{
Aneuploidy Rates Inversely Correlate with Implantation during In Vitro Fertilization Procedures: In Favor of PGT
}

\author{
Elizabeth Schaeffer, Leonardo Porchia, Almena López-Luna, \\ Dinorah Hernández-Melchor and Esther López-Bayghen
}

\begin{abstract}
Aneuploidy, the hold of an abnormal number of chromosomes that differs from the normal karyotype, is a recognized leading cause of miscarriage and congenital disabilities. In human gametes and embryos, aneuploidy rates are prevalent, and these rates increase with advanced maternal age; additionally, it has been suggested that hormonal stimulation for achieving in vitro fertilization (IVF) protocols further increases aneuploidy rates. Although about $65 \%$ of chromosomally abnormal embryos culminate in spontaneous miscarriages, there is still evidence of live births harboring crucial aneuploidies. Furthermore, although some frequent aneuploidies are consistent, others differ between countries, making it harder to focus on a specific set of anomalies but vital to focus regionally on those more prevalent. Preimplantation genetic testing (PGT) is a highly endorsed technique in assisted reproductive treatments to evaluate possible embryo aneuploidies, genetic defects, and congenital disorders. On this subject, this study shows that IVF aneuploidy rates in embryo cohorts of high morphological quality are inversely associated with implantation rates. In its entirety, this study reinforces the utility of PGT for embryo evaluation.
\end{abstract}

Keywords: aneuploidy, preimplantation genetic testing, embryo implantation, in vitro fertilization, karyotype

\section{Introduction}

Aneuploidy is defined as a chromosome number that is not an exact multiple of the usually haploid number [1]. The terms haploid and diploid that describe single (n) and double (2n) chromosome sets in cells originate from the Greek terms haplóos meaning single and diplóos meaning double. The term ploidy was subsequently derived to describe the total chromosome content of cells. Consequently, the term euploid refers to a chromosome with an exact multiple of the haploid number [2]. Human body cells (somatic cells) are diploid, carrying two complete sets of chromosomes: one set of 23 chromosomes from their father and one set of 23 chromosomes from their mother; the two sets combined provide a full complement 
of 46 chromosomes. Human gametes (or sex cells), sperm and oocytes, are haploid and contain only one set of 23 chromosomes.

Aneuploidies can occur either by chromosome gains (trisomies) and losses (monosomies) due to chromosome segregation errors, the so-called "whole chromosomal" aneuploidy or due to rearrangements of chromosomal parts, often accompanied by deletions, amplifications, or translocations of large regions of the genome that is referred to as a "structural" or "segmental" aneuploidy [3]. Whole chromosomal aneuploidies might arise due to random and sporadic chromosome missegregation events that occur with low frequency during any cell division. The missegregation levels range from $1 / 1000$ to $1 / 10,000$ in human cells [4].

Meiosis generates haploid gametes through a specialized cell division process that consists of one round of DNA replication followed by two cell divisions. The first division, or meiosis I (MI), involves the segregation of homologous chromosomes from each other, whereas meiosis II (MII) involves the segregation of the sister chromatids. Missegregation can also occur in germline cells, and the errors that arise in meiosis result in aneuploid embryos [5]. This chapter aims to provide evidence that supports the use of PGT for embryo evaluation and euploid embryo selection due to a positive correlation with fertilization rates.

\section{Incidence of aneuploidy}

Errors in meiotic chromosome segregation frequently occur during oogenesis ( $\sim 20 \%)$, especially during the first meiotic division; this incidence of meiotic errors in oocytes is more elevated in women with advanced maternal age and may be due to the prolonged time that oocytes spend arrested at meiosis I stage, before ovulation [6]. However, some patterns of nondisjunction appear to be chromosomespecific; almost all cases of trisomy 16 are linked to errors at maternal MI, while MII errors are surprisingly common in trisomy 18. Oppositely, in sperm the incidence of aneuploidy is only $2 \%$. Another considerable percentage of errors ( $20 \%)$ arise during the first mitosis after fertilization. Among clinically recognized spontaneous abortions (fetal deaths occurring between 6 and 8 weeks and 20 weeks gestation), the incidence increases to $\sim 50 \%$ [7]; the most common specific abnormalities are sex-chromosome monosomy $(45, \mathrm{X})$, accounting for nearly $10 \%$ of all spontaneous abortions, and trisomies 16,21 , and 22 , which together constitute $50 \%$ of all trisomies identified in spontaneous abortions. The incidence among stillbirths (fetal

\begin{tabular}{lll}
\hline Chr & Case report & References \\
\hline 1 & Pure duplication 1q41-qter: further delineation of trisomy 1q syndromes & {$[9]$} \\
& Partial duplication 1q: reports of five cases and review of the literature & {$[10,11]$} \\
\hline 2 & Duplication 2q2.1-q3.1 & {$[12,13] ;$} \\
& Partial trisomy 2q: two cases & {$[14]$} \\
\hline 3 & Duplication 3p syndrome: reports of three cases and review of the literature & {$[15-17]$} \\
\hline 4 & Patient with trisomy 4p & {$[18]$} \\
& Partial duplication and duplication region 4q28.3-qter in monozygotic twins with & {$[19,20]$} \\
& discordant phenotypes & {$[21-23]$} \\
\hline 5 & Trisomy 5p: reports of four cases report and review of the literature & {$[24]$} \\
\hline 6 & De novo “pure" partial trisomy (6) (p22.3 $\rightarrow$ pter): case report/review & {$[25]$} \\
\hline & Familial trisomy 6p in mother and daughter & {$[26]$} \\
\hline 7 & Interstitial de novo tandem duplication of 7 (q31.1-q35) & {$[27]$} \\
\hline
\end{tabular}


Aneuploidy Rates Inversely Correlate with Implantation during In Vitro...

DOI: http://dx.doi.org/10.5772/intechopen.81884

\begin{tabular}{|c|c|c|}
\hline Chr & Case report & References \\
\hline 8 & Trisomy 8: report of four cases & {$[28]$} \\
\hline \multirow[t]{2}{*}{9} & Pure 9p trisomy derived from a terminal balanced unreciprocal translocation & [29] \\
\hline & Trisomy 9: review and report of two new cases & {$[30]$} \\
\hline \multirow[t]{2}{*}{10} & Distal $10 \mathrm{q}$ trisomy with copy number gain in chromosome region $10 \mathrm{q} 23.1-10 \mathrm{q} 25.1$ & [31] \\
\hline & Proximal 10q duplication in a child with severe central hypotonia & [32] \\
\hline 11 & Partial 11q trisomy syndrome: two cases & {$[33,34]$} \\
\hline 12 & Clinical report of a patient with de novo trisomy 12q23.1q24.33 & [35] \\
\hline 13 & Trisomy 13, Patau's syndrome: reports of three cases & [36-38] \\
\hline 14 & Partial proximal trisomy 14 & [39] \\
\hline 15 & Duplication of distal 15q: reports of 14 cases & {$[40,41]$} \\
\hline \multirow[t]{2}{*}{16} & Partial trisomy/long arm of chromosome 16: case report/review of literature & [42] \\
\hline & Complete trisomy 16: a case report & {$[43]$} \\
\hline 17 & A $790 \mathrm{~kb}$ chromosome $17 \mathrm{p} 13.3$ microduplication: case report/literature review & {$[44,45]$} \\
\hline 18 & Trisomy 18, Edward's syndrome: reports of five cases and discussion & [46-48] \\
\hline 19 & Three cases of trisomy 19 & {$[49,50]$} \\
\hline 20 & $20 \mathrm{q} 11.2$ duplication syndrome and pure trisomy $20 \mathrm{p}$ & {$[51,52]$} \\
\hline 21 & Cardiovascular and general health status of adults with trisomy 21 & {$[53]$} \\
\hline 22 & Trisomy 22 syndrome: a report of four cases in newborns and literature review & [54-56] \\
\hline $\mathrm{X}$ & Fragile $\mathrm{X}$ syndrome: a case report/review of clinical and molecular diagnoses & {$[57,58]$} \\
\hline $\mathrm{Y}$ & Morphology and pathogenesis of $47, \mathrm{XYY} / 47, \mathrm{XY}$ patients super male syndrome & [59] \\
\hline
\end{tabular}

Table 1.

Case reports of live births with complete or partial chromosomal abnormalities (mosaic or multiple aberrations are not considered).

deaths occurring between $\sim 20$ weeks gestation and term) is $\sim 4 \%$ with the types of abnormality being similar to those identified in newborns, and $\sim 0.3 \%$ of live-born are aneuploid with the most common abnormalities being trisomies 21, 18, and 13 and sex-chromosome trisomies 47,XXX, 47,XXY, and 47,XYY [5, 8].

\subsection{Aneuploidies and live births}

Although about $65 \%$ of chromosomally abnormal embryos culminate in spontaneous miscarriages, there is still evidence of live births harboring crucial aneuploidies. Table 1 describes cases that are well documented.

\section{Impact of aneuploidy on the efficiency of ART}

Assisted reproduction is a solution in many of the growing cases of infertile couples worldwide. A high rate of embryos produced in vitro presents chromosomal aneuploidy $(\sim 50 \%)$, and such aneuploid embryos have reduced the potential for achieving a viable pregnancy. Such abnormalities are recognized as the leading cause of implantation failure and spontaneous miscarriage [60]. Among conceptions that survive to term, aneuploidy is the leading genetic cause of developmental 
disabilities and mental retardation [5]. Table 2 describes data from different infertility centers predominantly showing that aneuploidy rates are similar.

The relatively high aneuploidy rate observed in human embryos after an IVF/ ICSI cycle has been attributed to the technique itself since this prevalence seems to be lower in natural conceptions [61]. Many hypotheses have been proposed that may explain these findings: (1) controlled ovarian stimulation treatments, (2) factors related to the ICSI technique and (3) lab conditions as embryo culture.

\subsection{Ovarian stimulation and the incidence of embryo aneuploidy}

To increase the number of oocytes that can be retrieved for IVF, gonadotrophins are commonly used for superovulation in humans. Exogenous administration of gonadotrophins results in higher concentrations of steroids that may affect oocyte and embryo quality. Ovarian stimulation effects have been well characterized mainly in the murine model and have shown that aggressive stimulation leads to a poorer embryo development potential that could increase the chromosomal abnormality rate [79]. In humans, studies are scarce and less conclusive. A recent study in a population of young normovulatory women showed that a high ovarian response after controlled ovarian stimulation with moderate gonadotropin doses did not increase the embryo aneuploidy rate. Indeed, the higher the ovarian response, the more the euploid embryos obtained [80]; the remaining question is whether this can also be extrapolated to infertile patients with good ovarian reserve.

\subsection{Intracytoplasmic sperm injection (ICSI) technique and the incidence of embryo aneuploidy}

ICSI has become critical for the treatment of severe male infertility. The principal feature of ICSI is the direct injection of spermatozoa into an oocyte, which facilitates the production of fertilized embryos regardless of semen characteristics, such as sperm concentration and motility. However, the chromosomal integrity of ICSI zygotes is degraded compared to zygotes obtained from an in vitro fertilization $[81,82]$. During the ICSI procedure, a sperm pretreatment is performed to mimic the conditions of natural fertilization and support the progression of fertilization effects. Studies on mouse models revealed that the chromosomal integrity of zygotes derived from ICSI without any pretreatment of spermatozoa was impaired in comparison with zygotes derived from conventional IVF [83]; even the culture sperm conditions may affect the chromosomal stability of the embryo [84]. Chromosomal damage may occur due to the injection of non-capacitated, acrosomeintact spermatozoa, so to reduce the risk of chromosomal aberrations during the ICSI procedure, it is crucial that sperm capacitation and the acrosome reaction be appropriately artificially induced in the proper medium before use [85].

\subsection{Embryo culture and the incidence of embryo aneuploidy}

Fertilization and embryo development in vitro have the potential to introduce (often inadvertently) stress which cannot only impair embryo development in the laboratory but also have downstream effects after transfer.

In vivo, the developing preimplantation embryo is exposed to gradients of nutrients, hormones, cytokines, and growth factors as it progresses through the fallopian tube to the uterus. Within the lumen of the female tract, the embryo resides in a few 100 nanoliters of a complex viscous fluid characterized by high levels of mucins, albumin, and glycosaminoglycans and by reduced levels of oxygen 
Aneuploidy Rates Inversely Correlate with Implantation during In Vitro...

DOI: http://dx.doi.org/10.5772/intechopen.81884

\begin{tabular}{|c|c|c|c|c|c|c|c|}
\hline $\begin{array}{l}\mathrm{N} \\
\text { samples } \\
\text { (country) }\end{array}$ & $\begin{array}{c}\text { Day } \\
\text { of } \\
\text { biopsy }\end{array}$ & $\begin{array}{l}\text { Aneuploidy } \\
\text { rate }\end{array}$ & $\begin{array}{c}\text { Trisomy } \\
\%\end{array}$ & $\begin{array}{c}\text { Monosomy } \\
\%\end{array}$ & $\begin{array}{l}\text { Most affected } \\
\text { chromosomes }\end{array}$ & $\begin{array}{l}\text { Less affected } \\
\text { chromosomes }\end{array}$ & Ref. \\
\hline 87 (India) & 3 & 54 & $14.9^{*}$ & $42.5^{*}$ & 22,18 & No data & {$[62]$} \\
\hline $\begin{array}{l}150 \\
\text { (Japan) }\end{array}$ & 5 & 40.6 & $18^{*}$ & $21.3^{*}$ & $15,22,21,16,18$ & 4,12 & {$[63]$} \\
\hline 52 (UK) & 5 & 40.4 & $51.3^{\#}$ & $48.7^{\#}$ & $\begin{array}{c}22,16,15,18 \\
21, \mathrm{X}\end{array}$ & $\begin{array}{c}1,2,5,10,17 \\
19\end{array}$ & {$[64]$} \\
\hline 12 (UK) & 3 & 75 & $22^{*}$ & $11^{*}$ & $20,21,22$ & 6 & {$[65]$} \\
\hline \multirow{2}{*}{$\begin{array}{l}5879 \\
\text { (USA) }\end{array}$} & 3 & 70.6 & \multirow[t]{2}{*}{ No data } & \multirow[t]{2}{*}{ No data } & \multirow[t]{2}{*}{ No data } & \multirow[t]{2}{*}{ No data } & \multirow[t]{2}{*}[66]{} \\
\hline & 5 & 47.8 & & & & & \\
\hline 759 (UK) & 3 & 64.6 & $40^{\#}$ & $60^{\#}$ & $16,22,21,4,5$ & 4,6 & {$[67]$} \\
\hline 274 (US) & 3 & 72.3 & $39.8^{*}$ & $44.5^{*}$ & $22,16,7$ & $6,9,19$ & {$[68]$} \\
\hline 192 (Italy) & 5 & 55.2 & $37.9^{*}$ & $42.7^{*}$ & No data & No data & [69] \\
\hline \multirow{2}{*}{$\begin{array}{l}240 \\
\text { (Mexico, } \\
\text { Center A) }\end{array}$} & 5 & 36.3 & $5.34^{*}$ & $\sim 5^{*}$ & \multirow[t]{2}{*}{ 16, 22, XXX, 9} & \multirow{2}{*}{$\begin{array}{c}3,7,8,10,12 \\
18,20\end{array}$} & \multirow[t]{4}{*}[70]{} \\
\hline & 6 & 61.1 & $5.55^{*}$ & $\sim 10^{*}$ & & & \\
\hline \multirow{2}{*}{$\begin{array}{l}210 \\
\text { (Mexico, } \\
\text { Center B) }\end{array}$} & 5 & 48.9 & $15.96^{*}$ & $\sim 4^{*}$ & \multirow[t]{2}{*}{$15,16,21,4$} & \multirow{2}{*}{$\begin{array}{c}1,2,3,5,8,9 \\
10,11,12,14 \\
17,20,22, X, Y\end{array}$} & \\
\hline & 6 & 43.1 & $14.65^{*}$ & $\sim 5^{*}$ & & & \\
\hline $\begin{array}{l}404 \\
\text { (Mexico) }\end{array}$ & $\begin{array}{l}\text { No } \\
\text { data }\end{array}$ & 60.89 & No data & No data & $4,15,22,16$ & No data & {$[71]$} \\
\hline $\begin{array}{l}15,169 \\
\text { (USA) }\end{array}$ & $\begin{array}{l}\text { No } \\
\text { data }\end{array}$ & No data & No data & No data & $\begin{array}{c}13,15,16,18 \\
19,21,22\end{array}$ & $1,12,3$ & {$[72]$} \\
\hline \multirow{3}{*}{$\begin{array}{l}2204 \\
\text { (UK) }\end{array}$} & 0 & 74 & $56^{\#}$ & $44^{\#}$ & $16,21,22,15,19$ & \multirow[t]{3}{*}{ No data } & \multirow[t]{3}{*}{ [73] } \\
\hline & 3 & 83 & $49^{\#}$ & $51^{\#}$ & $22,16,19,21,13$ & & \\
\hline & 5 & 58 & $47^{\#}$ & $53^{\#}$ & $22,16,15,21,19$ & & \\
\hline \multirow{3}{*}{$\begin{array}{l}21 \text { sets } \\
\text { (Italy) }\end{array}$} & $0 / 1$ & 97.4 & \multirow{3}{*}{\multicolumn{2}{|c|}{$\begin{array}{c}\text { Chromosomal loss three } \\
\text { times more frequent } \\
\text { than gain }\end{array}$}} & \multirow[t]{3}{*}{$22,15,16,17$} & \multirow[t]{3}{*}{ No data } & \multirow[t]{3}{*}[74]{} \\
\hline & 3 & $47.6^{+}$ & & & & & \\
\hline & 5 or 6 & $80^{++}$ & & & & & \\
\hline \multirow[t]{2}{*}{195 (USA) } & $0 / 1$ & 65.5 & $39.86^{\#}$ & $60.14^{\#}$ & $\begin{array}{c}22,13,15,16 \\
19,21\end{array}$ & \multirow[t]{2}{*}{$6,5, Y, 3$} & \multirow[t]{2}{*}{ [75] } \\
\hline & $5 / 6$ & 45.2 & $52^{\#}$ & $48^{\#}$ & $22, X, 16,18,21$ & & \\
\hline $\begin{array}{l}1025 \\
\text { (Mexico) }\end{array}$ & $3 / 5$ & 43.9 & $59.3^{\#}$ & $40.7^{\#}$ & $\begin{array}{c}16,21,22,19 \\
15,20\end{array}$ & $8,4,3,2,7,1$ & $\begin{array}{c}\text { Current } \\
\text { study }\end{array}$ \\
\hline
\end{tabular}

\footnotetext{
"Percentage of the total number of samples.

\#Percentage of the total number of aneuploid samples.

${ }^{+}$Rate from the previous stage of development, PBs to blastomere.

${ }^{++}$Rate from the previous stage of development blastomere to TE, $P B s=$ polar bodies, $T E=$ trophectoderm.

For the current study, infertile patients who underwent ART at the Ingenes Institute were included. The patients were clinically evaluated according to a standardized protocol that includes family and personal clinical history. The protocol was approved by the Ethics Committee of the Ingenes Institute, and a signed informed consent was obtained from all patients. IVF, embryo biopsy, and $m$ CGH were performed according to the standard protocols of the Institute Ingenes as previously described [76, 77]. Only optimal morphological embryos were considered for this study. Selection and embryo transfer were done on Day 3 or Day 5 of development according to the embryo morphological assessment, using the criteria established by the Istanbul consensus Workshop on Embryo Assessment [78].
}

Table 2.

Aneuploidy rates of different IVF clinics around the world; when mentioned, the most commonly affected chromosomes are listed. 
(typically 2-8\%). The embryo is in constant motion, moved by gentle ciliated and muscular action of the female tract [86]. This scenario is in stark contrast to the laboratory environment, where typical gametes and embryos are exposed to relatively large volumes of culture medium, remain static during culture while resting on a polystyrene substrate, and create unstirred layers where the end products of metabolism concentrate and nutrients become limited [87].

Embryos are sensitive to both chemical and physical signals within their microenvironment. Factors within the laboratory as oxygen level, ammonium released from amino acids into the culture, poor laboratory air quality, temperature and $\mathrm{pH}$, oil overlay, embryo culture volume/density, the static nature of culture, light, or even mechanical factors as pipetting, can negatively impact gametes and embryos and generate stress. When more than one stress factor is present in the laboratory, more negative synergies can result, and these factors play a significant role in influencing the development and events post transfer [88]. For example, recent studies have reported that a decrease in temperature has the potential to affect the stability of the oocyte's meiotic spindle, reducing fertilization rates, delaying embryo development, and decreasing clinical pregnancy rates [89]. However, more studies are needed to demonstrate the impact of embryo culture on aneuploidy rates.

\section{Aneuploidy detection: techniques for PGT}

PGT is the genetic diagnosis analysis performed to identify euploid embryos before uterine transfer [90]. PGT determines the numeric chromosomal constitution of a cellular biopsy sample obtained from a cultured embryo to determine its competence [91, 92].

PGT was first described in 1990 by Handyside et al. [93] when the sex of the sixto eight-cell stage embryos from two couples with a known risk of transmitting Xlinked diseases was assessed by DNA amplification of a Y chromosome-specific repeat sequence. The earliest PGT studies in the 2000s were based on the fluorescence in situ hybridization (FISH) technique where 3-12 chromosomes can be analyzed on the cleavage stage or polar body biopsies [90]. Those studies had disappointing results in clinical practice since it had no beneficial effect on live birth rate after IVF [94]. The major drawback of FISH-based PGT is the limited number of chromosomes that can be analyzed considering that aneuploidy can affect any of the 22 autosomes and both sex chromosomes [95]; consequently, there have been dramatic improvements in PGT technology to make it valuable for clinical practice.

Nowadays, several methodologies for 24-chromosome analysis are available for clinical use that aim to increase implantation rates and decrease miscarriage rates associated with IVF [90]: microarray comparative genomic hybridization (mCGH), single-nucleotide polymorphism (SNP) microarray, real-time polymerase chain reaction (qPCR), and next-generation sequencing (NGS) [96, 97]. This review will focus on the relevant aspects of the PGT techniques used in our laboratory.

\subsection{Microarray comparative genomic hybridization (mCGH)}

$\mathrm{mCGH}$ is a ratio labeling protocol to compare the DNA product of a clinical sample to a healthy control. For PGT, biopsied embryonic cells must be lysed to extract the sample's DNA, which will be further amplified by a protocol that provides whole genome coverage $[90,95,98]$. The resulting DNA products are co-hybridized with a standard DNA control sample (46,XY and 46,XX) with a series of site-specific fluorophores on a microarray chip with approximately 4000 markers spaced throughout the genome [90]. Then, a confocal laser platform 
detects the relative color intensity, and a bioinformatics compares the intensity of each fluorophore in the sample versus the control to identify any bias and determine the ploidy status of the sample [90, 95, 98].

The mCGH analysis reports the ratio of sample DNA to a reference DNA, as a chromosomic profile where the molecular karyotype is represented. Usually, the sample DNA is labeled with a green fluorescent dye, while the reference DNA sample is tagged red [99]. Thus, diploid embryos will have a relatively equal ratio of green-to-red fluorescence in every pair of chromosomes, represented as a continuous horizontal plot line. Monosomy will be represented as a clear downward deviation in the plotted line, indicating a relative lack of green-to-red signal intensity; in contrary, a trisomy will be displayed as an upward deviation in the plotted line due to a relative increase in the green-to-red signal intensity.

The specificity rate of mCGH-based PGT is about 99\% [90]. The test results can be available within 12-15 h, considering that the entire analysis can be performed during this short time frame [90,91]. Additionally, brand-specific features are offered by each manufacturer: Agilent's GenetiSure Pre-Screen Microarray offers a detection rate of $100 \%$ for aberrations $>10 \mathrm{Mb}$ and $89 \%$ for $>5.3 \mathrm{Mb}$ [100]; KaryoLite BoBs Kit from Perkin Elmer uses an alternative BACs-on-Beads technology and results are interpreted by the BoBsoft ${ }^{\mathrm{TM}}$ analysis software [99]; and RHS's EmbryoCellect Kit is the only mCGH-based PGT validated for mosaicism detection [101]. Recently, Illumina's 24sure PGS Microarray had been discontinued, and the NGS-based VeriSeq PGS is now offered as an alternative solution [102].

mCGH entails some disadvantages: first, the embryo sample requires a previous whole genome amplification (WGA) process to support single-cell diagnostics by $\mathrm{mCGH}$ [95], raising the possibility of introducing errors during the amplification [91]; second, mCGH is a semiquantitative technique that only reports the ratio of sample DNA to a reference DNA; it is to say that only imbalances in DNA content can be identified. Therefore, $\mathrm{mCGH}$ is unable to detect uniparental disomic or triploid embryos as it cannot discriminate between 46,XX from 69,XXX, and 46, XY from 69,XXY $[90,91,95]$. Last, the mCGH used for PGS cannot identify structural chromosome aberrations or diagnose mosaicism in a trophectoderm sample [90].

\subsection{Next-generation sequencing (NGS)}

NGS refers to the emerging technology of non-Sanger-based DNA sequencing that allows the sequence in parallel millions of DNA strands with high-throughput yield. In the field of ART, this powerful tool is being applied for PGT to replace cytogenetic microarrays [98, 102].

Different platforms are commercially available for NGS with different technological approaches. Illumina's MiSeq NGS platform applies a sequencing-bysynthesis method, where DNA is attached and amplified in situ to be subsequently used as a template for synthetic sequencing with fluorescent-labeled reversibleterminator nucleotides [103]. Ion Torrent NGS technology, commercialized by ThermoFisher Scientific, is based on collecting data by sensing the hydrogen ions that are released as by-products when nucleotides are incorporated by a templatedirected DNA polymerase synthesis on an ion chip [104].

Despite the dissimilarities between platforms, the common basis of chromosome copy number analysis by NGS is the fragmentation of the amplified DNA sample into small segments of 100-200 base pairs that are further sequenced in parallel until the number of reads covering a determined position in the genome is attained, in general, a $30 \times$ coverage (sequencing each base pair 30 times) ensures sufficient accuracy. The sequence data obtained are then compared with a reference genome 
and counted by bioinformatics software. The copy number of a specific chromosome should be proportional to the number of counted sequences; therefore, an increase or reduction in the number of reads will, respectively, represent a trisomy or monosomy [97, 99].

NGS allows to simultaneously perform both qualitative and quantitative analyses of multiple embryos with high-resolution data for chromosomal analysis $[96,97]$. The higher sensitivity and precision offered by NGS $[96,105,106]$ makes possible to exclude embryos with mosaicism $[105,106]$ and partial aneuploidies or triploidies [106], improving pregnancy outcomes due to its enhanced capability for detecting those challenging abnormalities.

PGT by NGS can predict not only chromosome copy number for the diagnosis of whole chromosome aneuploidy with $99.98 \%$ assignment consistency [97] but also single-gene disorders [107], abnormalities of the mitochondrial genome [108], and segmental chromosome imbalances [97, 99]. Balanced chromosomal rearrangements cannot be detected by NGS [97].

The increasing demand and accelerated development are continuously reducing the cost of NGS technology [109]. Also, potential cost-benefit ratios can be achieved when the full sequencing capacity of the apparatus is exploited [96, 97, 99]. Furthermore, molecular tools, like barcoding, are being implemented to allow multiplex high-throughput sequencing [110]; this promising strategy will reduce the diagnosis' cost per patient by performing simultaneous analysis of multiple embryos from different patients [97].

\section{Aneuploidy and women age}

In our study, by analyzing the mCGH data, the total number of aneuploidies was found to be 734, and from these, 641 (87.3\%) were derived from patients and $93(12.7 \%)$ from donors. Overall, this study displayed similar rates of monosomies, trisomies, double aneuploidies, and multiple aneuploidies. The total number of monosomies (191) was similar to the number of trisomies (194), accounting for 26 and $26.4 \%$ of the total aneuploidies, correspondingly.

Furthermore, the total number of double (165) and multiple (184) aneuploidies was also very similar, accounting for 22.5 and $25.1 \%$ of the total aneuploidies, correspondingly. Nevertheless, it is worth noticing that when considering only the donor group, monosomies seem to be more prevalent: $38.7 \%$ of the total donors' aneuploidies were monosomies vs. $24.7 \%$ of trisomies, $16.1 \%$ of double aneuploidies, and $20.4 \%$ of multiple aneuploidies; what is more, the percentage of monosomies in the donor group is higher than that of the monosomies of the patient group (38.7 vs. $24.3 \%$ ). The most common monosomies affected chromosomes 15 , 16 , and 22, whereas the most common trisomy affected chromosomes 16, 19, and 21 (Table 3).

It has been shown that the lowest risk for embryonic aneuploidy is between ages 26 and 30, with aneuploidy rates steadily increasing with maternal age after 26 years of age [111] and leaping significantly from the age of 39 [112]. For this reason, women of advanced maternal age are encouraged to favor oocyte donation to yield high-quality viable embryos.

Interestingly, some studies have identified that women of younger ages possess an increased prevalence of aneuploidy, with $>40 \%$ of aneuploidy in women of 23 years and under [111] and 58\% of aneuploidy in women of $<31$ years of age. In the current study, both the donor ( $\leq 29$ years) and the patient group of $\leq 29$ years 
Aneuploidy Rates Inversely Correlate with Implantation during In Vitro...

DOI: http://dx.doi.org/10.5772/intechopen.81884

\begin{tabular}{|c|c|c|c|}
\hline & All & Patients & Donors \\
\hline Total & 734 & 641 & 93 \\
\hline Monosomy & $191(26.0 \%)$ & $155(24.3 \%)$ & $36(38.7 \%)$ \\
\hline -Chr 15 & 13 & 13 & 0 \\
\hline -Chr 16 & 21 & 18 & 3 \\
\hline -Chr 22 & 22 & 22 & 0 \\
\hline- Chr X & 10 & 8 & 2 \\
\hline -Chr Y & 40 & 26 & 14 \\
\hline Trisomy & $194(26.4 \%)$ & $171(26.7 \%)$ & $23(24.7 \%)$ \\
\hline +Chr 16 & 26 & 24 & 2 \\
\hline +Chr 18 & 9 & 7 & 2 \\
\hline +Chr 19 & 23 & 21 & 2 \\
\hline+ Chr 20 & 17 & 13 & 4 \\
\hline+ Chr 21 & 20 & 20 & 0 \\
\hline+ Chr 22 & 19 & 19 & 0 \\
\hline+ Chr X & 10 & 8 & 2 \\
\hline+ Chr Y & 1 & 1 & 0 \\
\hline Dual & $165(22.5 \%)$ & $150(23.4 \%)$ & 15 (16.1\%) \\
\hline Multiple & $184(25.1 \%)^{\mathrm{a}}$ & $165(25.7 \%)^{\mathrm{b}}$ & $19(20.4 \%)^{c}$ \\
\hline \multicolumn{4}{|c|}{$\begin{array}{l}\text { The current study included } 441 \text { patients, resulting in } 474 \text { cycles. A total of } 1629 \text { embryos were analyzed; from those, } 5 \\
\text { were excluded due to failed WGA, leaving } 1575 \text { embryos for analysis, } 1258 \text { from patients, and } 317 \text { from donors. } \\
\text { Biopsies were performed at the blastomere (Day } 3 \text {, patients }=238 \text { and donors }=50 \text { ) and blastocyst stages (Day } 5 \text {, } \\
\text { patients }=1020 \text { and donors }=267 \text { ). Finally, } 734 \text { embryos }(46.6 \%) \text { were found to be aneuploid (patients }=641 \text { and } \\
\text { donors }=93 \text { ). The total number of monosomies and trisomies is provided along with their respective percentages; } \\
\text { furthermore, the number of the most common aneuploidies of the } m \text { CGH data is listed. } \\
{ }^{a} \text { Nine embryos had completely abnormal mCGH profiles. } \\
{ }^{b} \text { Even embryos had completely abnormal mCGH profiles. } \\
{ }^{c} \text { Two embryos had completely abnormal mCGH profiles. }\end{array}$} \\
\hline
\end{tabular}

Table 3.

Most frequent types of aneuploidies in the mCGH data of the current study.

displayed high aneuploid rates, 28.5 and 27.4\%, respectively (Table 4). Given the high rates of aneuploidy in younger women, attention should be paid in detecting aneuploidy in embryos from women of young maternal age, especially since this group of patients is not routinely encouraged to perform a PGT. Still, whether there is a difference between the distribution of aneuploidies between donors and patients remains uncertain.

When stratifying our analysis in age groups (a, $\leq 29$; b, 30-34; c, 35-37; d, 38-40; e, 41-43; and $f, \geq 44$ years of age), a visible continuous increase in aneuploidy rate can be observed as maternal age increases (Table 4); furthermore, this increase in aneuploidy goes hand in hand with a continuous decrease in implantation, as it can be observed in the decrease of positive beta-human chorionic gonadotropin $(\beta$-hCG) values as age increases $(\beta$-hCG values $\geq 10 \mathrm{mUI} / \mathrm{ml}$ from Day 14 after transference were considered positive). 


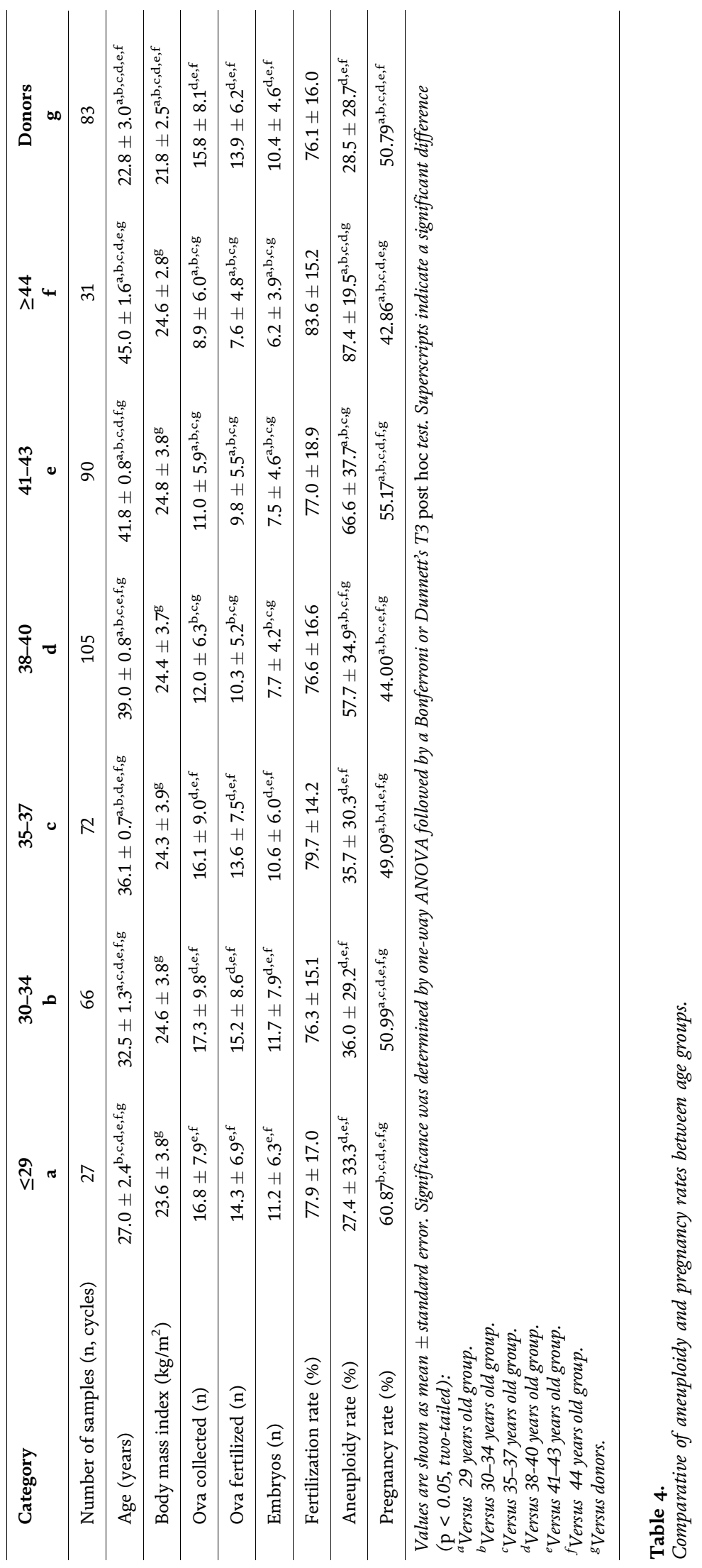




\section{Remarks}

One of the most critical reasons for unsuccessful IVF procedures is implantation failure due to aneuploid embryos. Aneuploidies are the primary cause of perinatal death and genetic abnormalities; consequently, the detection of chromosomal disorders constitutes the most frequent indication for PGT. Here, we report on the aneuploidy rates found in IVF procedures in Mexico. Even though there are studies that assert that PGT does not improve pregnancy rates, we show that aneuploidy rates inversely correlate with implantation and that levels of aneuploidy among high morphological quality embryos are still an important issue to be faced in everyday ART practice, and this evidence works in favor of continuing to use PGT analysis.

\section{Acknowledgements}

This work was supported by the Consejo Nacional de Ciencia y Tecnología (Conacyt-Programa de Estímulos a la Innovación 2018-253224).

\section{Abbreviations}

\begin{tabular}{|c|c|}
\hline ANOVA & analysis of variance \\
\hline ART & assisted reproductive techniques \\
\hline Chr & chromosome \\
\hline FISH & fluorescence in situ hybridization \\
\hline ICSI & intracytoplasmic sperm injection \\
\hline IVF & in vitro fertilization \\
\hline $\mathrm{mCGH}$ & microarray comparative genomic hybridization \\
\hline MI & meiosis I \\
\hline MII & meiosis II \\
\hline NGS & next-generation sequencing \\
\hline OR & odds ratio \\
\hline PGS & preimplantation genetic screening \\
\hline PGT & preimplantation genetic testing \\
\hline qPCR & real-time polymerase chain reaction \\
\hline SNP & single-nucleotide polymorphism \\
\hline WGA & whole genome amplification \\
\hline$\beta$-hCG & beta-human chorionic gonadotropin \\
\hline
\end{tabular}




\section{Author details}

Elizabeth Schaeffer ${ }^{1}$, Leonardo Porchia ${ }^{1,3}$, Almena López-Luna ${ }^{1,2}$, Dinorah Hernández-Melchor ${ }^{1,2}$ and Esther López-Bayghen ${ }^{1,2 *}$

1 Laboratorio de Investigación y Diagnóstico Molecular, Instituto de Infertilidad y Genética SC, INGENES, CDMX, México

2 Departamento de Toxicología, Cinvestav-IPN, CDMX, México

3 Tecnologías DAAT SA de CV, Xalapa, Veracruz, México

*Address all correspondence to: ebayghen@cinvestav.mx

\section{IntechOpen}

(C) 2018 The Author(s). Licensee IntechOpen. This chapter is distributed under the terms of the Creative Commons Attribution License (http://creativecommons.org/licenses/ by/3.0), which permits unrestricted use, distribution, and reproduction in any medium, provided the original work is properly cited. (cc) BY 
Aneuploidy Rates Inversely Correlate with Implantation during In Vitro...

DOI: http://dx.doi.org/10.5772/intechopen.81884

\section{References}

[1] Torres EM, Williams BR, Amon A. Aneuploidy: Cells losing their balance. Genetics. 2008;179(2):737-746

[2] Orr B, Godek KM, Compton D. Aneuploidy. Current Biology. 2015; 25(13):R538-R542

[3] Storchova Z. The causes and consequences of aneuploidy in eukaryotic cells. In: Aneuploidy in Health and Disease. Croatia: InTech; 2012. pp. 3-22

[4] Hassold T, Hall H, Hunt P. The origin of human aneuploidy: Where we have been, where we are going. Human Molecular Genetics. 2007;16:R203R208. Spec no. 2

[5] Hassold T, Hunt P. To err (meiotically) is human: The genesis of human aneuploidy. Nature Reviews. Genetics. 2001;2(4):280-291

[6] Battaglia DE et al. Influence of maternal age on meiotic spindle assembly in oocytes from naturally cycling women. Human Reproduction. 1996;11(10):2217-2222

[7] Kim JW et al. Chromosomal abnormalities in spontaneous abortion after assisted reproductive treatment. BMC Medical Genetics. 2010;11:153

[8] Hassold T et al. Human aneuploidy: Incidence, origin, and etiology. Environmental and Molecular Mutagenesis. 1996;28(3):167-175

[9] Kulikowski LD et al. Pure duplication 1q41-qter: Further delineation of trisomy 1q syndromes. American Journal of Medical Genetics. Part A. 2008;146A(20):2663-2667

[10] Campos TCaF, Puntero B. Trisomía parcial 1q por translocación materna.
Anales Españoles de Pediatría. 2000;52: 178-184

[11] Rasmussen SA et al. Partial duplication 1q: Report of four patients and review of the literature. American Journal of Medical Genetics. 1990;36(2): 137-143

[12] Acosta Sabatés MM, Hernández García I, García Martínez DA, Lavaut Sánchez K. Duplication 2 q 2.1- q 3.1: A case report. Revista Cubana de Pediatría. 2008;80:1

[13] Sebold CD et al. Partial trisomy 2q: Report of a patient with dup (2) (q33.1q35). American Journal of Medical Genetics. Part A. 2005;134A(1):80-83

[14] Schumacher RE, Rocchini AP, Wilson GN. Partial trisomy 2q. Clinical Genetics. 1983;23(3):191-194

[15] Dworschak GC et al.

Comprehensive review of the duplication $3 q$ syndrome and report of a patient with Currarino syndrome and de novo duplication 3q26.32-q27.2. Clinical Genetics. 2017;91(5):661-671

[16] Natera-de Benito D et al. A patient with a duplication of chromosome $3 p$ ( 2 24.1p26.2): A comparison with other partial 3p trisomies. American Journal of Medical Genetics. Part A. 2014;164A(2): 548-550

[17] Charrow J, Cohen MM, Meeker D. Duplication 3p syndrome: Report of a new case and review of the literature. American Journal of Medical Genetics. 1981;8(4):431-436

[18] Varley J, Wehner T, Sisodiya S. Diaphragm myoclonus followed by generalised atonia in a patient with trisomy 4p: Unusual semiology in an unusual condition. Epileptic Disorders. 2015;17(4):473-477 
[19] Collia A et al. Partial duplication of chromosome 4 in a patient with bilateral ocular coloboma. Archivos Argentinos de Pediatría. 2012;110(4):e59-e62

[20] Celle L et al. Duplication of chromosome region 4q28.3-qter in monozygotic twins with discordant phenotypes. American Journal of Medical Genetics. 2000;94(2):125-140

[21] Velagaleti GV, Morgan DL, Tonk VS. Trisomy 5p. A case report and review. Annales de Génétique. 2000;43 (3-4):143-145

[22] Fujita $M$ et al. A new case of "complete" trisomy $5 \mathrm{p}$ with isochromosome $5 \mathrm{p}$ associated with a de novo translocation $\mathrm{t}(5 ; 8)$ (q11;p23). Clinical Genetics. 1994;45(6):305-307

[23] Orye E, Benoit Y, van Mele B. Complete trisomy $5 \mathrm{p}$ owing to de novo translocation $\mathrm{t}(5 ; 22)$ (q11;p11) with isochromosome $5 p$ associated with a familial pericentric inversion of chromosome 2, inv 2(p21q11). Journal of Medical Genetics. 1983;20(5):394-396

[24] Sivasankaran A et al. De-novo 'pure' partial trisomy $(6)(\mathrm{p} 22.3 \rightarrow$ pter $):$ A case report and review of the literature. Clinical Dysmorphology. 2017;26(1): 26-32

[25] Savarese M et al. Familial trisomy $6 p$ in mother and daughter. American Journal of Medical Genetics. Part A. 2013;161A(7):1675-1681

[26] Zelante L et al. Interstitial "de novo" tandem duplication of 7(q31.1-q35): First reported case. Annales de Génétique. 2003;46(1):49-52

[27] Alfonsi M et al. A new case of pure partial 7q duplication. Cytogenetic and Genome Research. 2012;136(1):1-5

[28] Mellado C, Moreno R, López F, Sanz P, Castillo S, Villaseca C, et al. Trisomia
8: Reporte de cuatro casos. Revista

Chilena de Pediatría. 1997;53(2):93-98

[29] Brambila-Tapia AJ et al. Pure 9p trisomy derived from a terminal balanced unreciprocal translocation. Genetic Counseling. 2014;25(3):289-297

[30] Arnold GL et al. Trisomy 9: Review and report of two new cases. American Journal of Medical Genetics. 1995;56(3): 252-257

[31] Wong SL et al. Distal 10q trisomy with copy number gain in chromosome region 10q23.1-10q25.1: The Wnt signaling pathway is the most pertinent to the gene content in the region of copy number gain: A case report. BMC

Research Notes. 2015;8:250

[32] Manolakos E et al. Proximal 10q duplication in a child with severe central hypotonia characterized by arraycomparative genomic hybridization: A case report and review of the literature. Experimental and Therapeutic Medicine. 2014;7(4):953-957

[33] Utine GE et al. Partial trisomy 11q syndrome (11q23.1 $\rightarrow 11$ qter) due to de novo t (11q; 13q) detected by multicolor fluorescence in situ hybridisation. Genetic Counseling. 2005;16(3):291-295

[34] Pihko H, Therman E, Uchida IA. Partial 11q trisomy syndrome. Human Genetics. 1981;58(2):129-134

[35] Geckinli BB et al. Clinical report of a patient with de novo trisomy 12q23.1q24.33. Genetic Counseling. 2015;26(4):393-400

[36] Oka N et al. Norwood procedure performed on a patient with trisomy 13 . International Heart Journal. 2016;57(1): 121-122

[37] Tunca Y, Kadandale JS, Pivnick EK. Long-term survival in Patau syndrome. 
Aneuploidy Rates Inversely Correlate with Implantation during In Vitro...

DOI: http://dx.doi.org/10.5772/intechopen.81884

Clinical Dysmorphology. 2001;10(2): $149-150$

[38] Lu HT, Han XH. One case report of Patau syndrome. Zhonghua Er Ke Za Zhi. 2011;49(7):555-556

[39] Dutta UR, Pidugu VK, Dalal A. Partial proximal trisomy 14: Identification and molecular characterization in a girl with global developmental delay. Genetic Counseling. 2013;24(2):207-216

[40] Lacro RV et al. Duplication of distal 15q: Report of five new cases from two different translocation kindreds. American Journal of Medical Genetics. 1987;26(3):719-728

[41] Schnatterly P et al. Distal 15q trisomy: Phenotypic comparison of nine cases in an extended family. American Journal of Human Genetics. 1984;36(2): $444-451$

[42] Laus AC et al. Karyotype/phenotype correlation in partial trisomies of the long arm of chromosome 16: Case report and review of literature. American Journal of Medical Genetics. Part A. 2012;158A(4):821-827

[43] Aviña Fierro JA, Blum ER, Aviña DAH. Trisomía 16 completa. Reporte de un caso clínico. Revista Mexicana de Pediatría. 2005;72(5):237-239

[44] Ho AC et al. A newborn with a 790 kb chromosome 17p13.3

microduplication presenting with aortic stenosis, microcephaly and dysmorphic facial features-Is cardiac assessment necessary for all patients with 17p13.3 microduplication? European Journal of Medical Genetics. 2012;55(12):758-762

[45] Belligni EF et al. $790 \mathrm{~kb}$ microduplication in chromosome band 17p13.1 associated with intellectual disability, afebrile seizures, dysmorphic features, diabetes, and hypothyroidism.
European Journal of Medical Genetics. 2012;55(3):222-224

[46] Saldarriaga W, Rengifo-Miranda H, Ramirez-Cheyne J. Trisomy 18 syndrome: A case report. Revista Chilena de Pediatría. 2016;87(2):129-136

[47] Zellweger H, Beck K, Hawtrey CE. Trisomy 18. Report of a case and discussion of the syndrome. Archives of Internal Medicine. 1964;113:598-605

[48] Bharucha BA et al. Trisomy 18: Edward's syndrome (a case report of 3 cases). Journal of Postgraduate Medicine. 1983;29(2):129-132

[49] Jung SI et al. Two cases of trisomy 19 as a sole chromosomal abnormality in myeloid disorders. The Korean Journal of Laboratory Medicine. 2008;28(3): 174-178

[50] Humphries JE, Wheby MS. Trisomy 19 in a patient with myelodysplastic syndrome and thrombocytosis. Cancer Genetics and Cytogenetics. 1990;44(2): 187-191

[51] Avila $\mathrm{M}$ et al. Delineation of a new chromosome 20q11.2 duplication syndrome including the ASXL1 gene. American Journal of Medical Genetics. Part A. 2013;161A(7):1594-1598

[52] Sidwell RU et al. Pure trisomy 20p resulting from isochromosome formation and whole arm translocation. Journal of Medical Genetics. 2000; 37(6):454-458

[53] Hayes SA et al. Cardiovascular and general health status of adults with trisomy 21. International Journal of Cardiology. 2017;241:173-176

[54] He X, Yao D, Zhao ZY. Trisomy 22 syndreom: A report of 2 cases.

Zhongguo Dang Dai Er Ke Za Zhi. 2015; 17(5):524-525 
[55] Heinrich T et al. Live-born trisomy 22: Patient report and review. Molecular Syndromology. 2013;3(6):262-269

[56] Petersen MB, Hansen M, Djernes BW. Full trisomy 22 in a newborn infant. Annales de Génétique. 1987; 30(2):101-104

[57] Ciaccio $\mathrm{C}$ et al. Fragile $\mathrm{X}$ syndrome: A review of clinical and molecular diagnoses. Italian Journal of Pediatrics. 2017;43(1):39

[58] Vazquez Gonzalez B. Turner syndrome; case report. Ginecología y Obstetricia de México. 1958;13(2): 103-110

[59] Song Y et al. Morphology and pathogenesis of 47, XYY/47, XY, +mar identified in patients with super male syndrome. Zhonghua Yi Xue Yi Chuan Xue Za Zhi. 2015;32(3):378-380

[60] Lathi RB, Westphal LM, Milki AA. Aneuploidy in the miscarriages of infertile women and the potential benefit of preimplanation genetic diagnosis. Fertility and Sterility. 2008; 89(2):353-357

[61] Simon C et al. Increased chromosome abnormalities in human preimplantation embryos after in-vitro fertilization in patients with recurrent miscarriage. Reproduction, Fertility, and Development. 1998;10(1):87-92

[62] Majumdar G et al. Preimplantation genetic screening for all 24 chromosomes by microarray comparative genomic hybridization significantly increases implantation rates and clinical pregnancy rates in patients undergoing in vitro fertilization with poor prognosis. Journal of Human Reproductive Sciences. 2016;9(2): 94-100

[63] Chung MK et al. Comprehensive chromosome analysis of blastocysts before implantation using array CGH. Molecular Cytogenetics. 2013;6(1):22

[64] Fragouli E et al. Cytogenetic analysis of human blastocysts with the use of FISH, CGH and aCGH: Scientific data and technical evaluation. Human Reproduction. 2011;26(2):480-490

[65] Wells D, Delhanty JD. Comprehensive chromosomal analysis of human preimplantation embryos using whole genome amplification and single cell comparative genomic hybridization. Molecular Human Reproduction. 2000;6(11):1055-1062

[66] Harton GL et al. Diminished effect of maternal age on implantation after preimplantation genetic diagnosis with array comparative genomic hybridization. Fertility and Sterility. 2013;100(6):1695-1703

[67] Gutierrez-Mateo C et al. Validation of microarray comparative genomic hybridization for comprehensive chromosome analysis of embryos. Fertility and Sterility. 2011;95(3): 953-958

[68] Rabinowitz $\mathrm{M}$ et al. Origins and rates of aneuploidy in human blastomeres. Fertility and Sterility. 2012; 97(2):395-401

[69] Fiorentino F et al. Application of next-generation sequencing technology for comprehensive aneuploidy screening of blastocysts in clinical preimplantation genetic screening cycles. Human Reproduction. 2014; 29(12):2802-2813

[70] Sánchez-Usabiaga RA, González Becerra J, Vera-Aguado MG, Ramírez EG, Durand-Montaño C. Incidence and parental origin of aneuploidies in blastocysts: Comparison between two centers of assisted reproduction in Mexico. Ginecología y Obstetricia de México. 2017;85(5):289-297 
[71] López-Rioja MJ, Aguinaga-Ríos M, Sánchez-González CM, Recio-López Y, Zavala-González PN, García-Sánchez R, et al. Preimplantation genetic testing for aneuploidies PGT-A: Results of the transition between different technologies. Ginecología y Obstetricia de México. 2018;86(2):96-107

[72] Franasiak JM et al. Aneuploidy across individual chromosomes at the embryonic level in trophectoderm biopsies: Changes with patient age and chromosome structure. Journal of Assisted Reproduction and Genetics. 2014;31(11):1501-1509

[73] Fragouli E et al. The origin and impact of embryonic aneuploidy. Human Genetics. 2013;132(9): 1001-1013

[74] Capalbo A et al. Sequential comprehensive chromosome analysis on polar bodies, blastomeres and trophoblast: Insights into female meiotic errors and chromosomal segregation in the preimplantation window of embryo development. Human Reproduction. 2013;28(2):509-518

[75] Fragouli E et al. Comprehensive chromosome screening of polar bodies and blastocysts from couples experiencing repeated implantation failure. Fertility and Sterility. 2010; 94(3):875-887

[76] Schaeffer E et al. Whole genome amplification of day 3 or day 5 human embryos biopsies provides a suitable DNA template for PCR-based techniques for genotyping, a complement of preimplantation genetic testing. BioMed Research International. 2017;2017:1209158

[77] Camargo-Diaz F et al. Colony stimulating factor-1 and leukemia inhibitor factor expression from current-cycle cannula isolated endometrial cells are associated with increased endometrial receptivity and pregnancy. BMC Womens Health. 2017; 17(1):63

[78] Medicine, A.S.I.R. and E.S.I.G. Embryology. Istanbul consensus workshop on embryo assessment: Proceedings of an expert meeting. Reproductive Biomedicine Online. 2011; 22(6):632-646

[79] Elbling L, Colot M. Abnormal development and transport and increased sister-chromatid exchange in preimplantation embryos following superovulation in mice. Mutation Research. 1985;147(4):189-195

[80] Labarta E et al. A higher ovarian response after stimulation for IVF is related to a higher number of euploid embryos. BioMed Research International. 2017;2017:5637923

[81] In't Veld PA et al. Intracytoplasmic sperm injection (ICSI) and chromosomally abnormal spermatozoa. Human Reproduction. 1997;12(4): 752-754

[82] Macas E, Imthurn B, Keller PJ. Increased incidence of numerical chromosome abnormalities in spermatozoa injected into human oocytes by ICSI. Human Reproduction. 2001;16(1):115-120

[83] Tateno H. Possible causal factors of structural chromosome aberrations in intracytoplasmic sperm injection of the mouse. Reproductive Medicine and Biology. 2009;8(3):89-95

[84] Tateno H, Kamiguchi Y. Evaluation of chromosomal risk following intracytoplasmic sperm injection in the mouse. Biology of Reproduction. 2007; 77(2):336-342

[85] Watanabe H. Risk of chromosomal aberration in spermatozoa during intracytoplasmic sperm injection. 
The Journal of Reproduction and Development. 2018 Oct 12;64(5):371376. DOI: 10.1262/jrd.2018-040. Epub 2018 Jul 7

[86] Gardner DK et al. Environment of the preimplantation human embryo in vivo: Metabolite analysis of oviduct and uterine fluids and metabolism of cumulus cells. Fertility and Sterility. 1996;65(2):349-353

[87] Gardner DK, Lane M. Culture of viable mammalian embryos. In: Cibelli J, Wilmut I, Jaenisch R, Gurdon J, Lanza $\mathrm{R}$, West M, Campbell K, editors. Principles of Cloning. 2nd ed. Elsevier; 2014. pp. 63-84. DOI: https://doi.org/ 10.1016/C2010-0-66663-6

[88] Wale PL, Gardner DK. The effects of chemical and physical factors on mammalian embryo culture and their importance for the practice of assisted human reproduction. Human

Reproduction Update. 2016;22(1):2-22

[89] Wang WH et al. Limited recovery of meiotic spindles in living human oocytes after cooling-rewarming observed using polarized light microscopy. Human Reproduction. 2001;16(11):2374-2378

[90] Brezina PR, Anchan R, Kearns WG. Preimplantation genetic testing for aneuploidy: What technology should you use and what are the differences? Journal of Assisted Reproduction and Genetics. 2016;33(7):823-832

[91] Brezina PR, Kutteh WH. Clinical applications of preimplantation genetic testing. BMJ. 2015;350:g7611

[92] Brezina PR, Brezina DS, Kearns WG. Preimplantation genetic testing. BMJ. 2012;345:e5908

[93] Handyside AH et al. Pregnancies from biopsied human preimplantation embryos sexed by Y-specific DNA amplification. Nature. 1990;344(6268): 768-770

[94] Mastenbroek S et al.

Preimplantation genetic screening: A systematic review and meta-analysis of RCTs. Human Reproduction Update. 2011;17(4):454-466

[95] Kaser DJ, Ginsburg ES. Embryo biopsy for aneuploidy detection in the general infertility population. Seminars in Reproductive Medicine. 2014;32(2): 100-106

[96] Imudia AN, Plosker S. The past, present, and future of preimplantation genetic testing. Clinics in Laboratory Medicine. 2016;36(2):385-399

[97] Fiorentino F et al. Development and validation of a next-generation sequencing-based protocol for 24chromosome aneuploidy screening of embryos. Fertility and Sterility. 2014; 101(5):1375-1382

[98] Kurahashi $\mathrm{H}$ et al. Preimplantation genetic diagnosis/screening by comprehensive molecular testing. Reproductive Medicine and Biology. 2016;15(1):13-19

[99] Sermon K. Novel technologies emerging for preimplantation genetic diagnosis and preimplantation genetic testing for aneuploidy. Expert Review of Molecular Diagnostics. 2017;17(1):71-82

[100] Agilent. GenetiSure Pre-Screen Kit Details \& Specifications. Available from: https://www.genomics.agilent.com/a rticle.jsp?pageId=8100002

[101] RHS. EmbryoCellect. Available from: http://www.rhsc.com.au/ourproducts/embryocellect/

[102] Illumina. 24sure PGS Microarray. Available from: https://support.illumina. com/array/array_kits/24surepgs-microarray-kit.html 
[103] Bentley DR et al. Accurate whole human genome sequencing using reversible terminator chemistry. Nature. 2008;456(7218):53-59

[104] Rothberg JM et al. An integrated semiconductor device enabling nonoptical genome sequencing. Nature. 2011;475(7356):348-352

[105] Fragouli E. Next generation sequencing for preimplantation genetic testing for aneuploidy: Friend or foe? Fertility and Sterility. 2018;109(4): 606-607

[106] Friedenthal J et al. Next generation sequencing for preimplantation genetic screening improves pregnancy outcomes compared with array comparative genomic hybridization in single thawed euploid embryo transfer cycles. Fertility and Sterility. 2018;

109(4):627-632

[107] Treff NR et al. Evaluation of targeted next-generation sequencingbased preimplantation genetic diagnosis of monogenic disease. Fertility and Sterility. 2013;99(5):1377-1384 e6

[108] Fragouli E et al. Altered levels of mitochondrial DNA are associated with female age, aneuploidy, and provide an independent measure of embryonic implantation potential. PLoS Genetics. 2015;11(6):e1005241

[109] Yin X et al. Massively parallel sequencing for chromosomal abnormality testing in trophectoderm cells of human blastocysts. Biology of Reproduction. 2013;88(3):69

[110] Knapp M, Stiller M, Meyer M. Generating barcoded libraries for multiplex high-throughput sequencing. Methods in Molecular Biology. 2012;

840:155-170

[111] Franasiak JM et al. The nature of aneuploidy with increasing age of the female partner: A review of 15,169 consecutive trophectoderm biopsies evaluated with comprehensive chromosomal screening. Fertility and Sterility. 2014;101(3):656-663 e1

[112] Lukaszuk K et al. Next generation sequencing for preimplantation genetic testing of blastocysts aneuploidies in women of different ages. Annals of Agricultural and Environmental Medicine. 2016;23(1):163-166 



\title{
Screening (Bi Test, Triple Test, Panorama Test) and Amniocentesis for Early Diagnosis of Congenital Malformations
}

\author{
Gladys Cristina Al Jashi and Isam Al Jashi
}

\begin{abstract}
The genetic consult is very important in the diagnosis of early fetal malformations and its complications at birth and after it. Our research is based on a 3-year research on 6097 pregnant women who underwent screening Bi-Test or Triple Test. We discovered 408 pregnant women who were found positive and needed amniocentesis for a diagnostic of certitude. Out of them, 14 had a positive result from which 10 were found with Down syndrome and 4 with Edwards syndrome. In Romania, amniocentesis has become the most used method of prenatal diagnosis for pregnant women at 35 or above with a family history of hereditary congenital anomalies. However, the latest screening test from maternal blood, the Panorama test, can discover many malformations (for chromosomes 21, 18, and 13 and the abnormality of the sex chromosome). The accuracy for false positive is $2 \%$ and false negative $98 \%$. In that light, the purpose of our study is to decrease the use of amniocentesis and to introduce the latest tests (Panoramic) for the early diagnosis of fetal malformation, the use of maternal blood, and the avoidance of using invasive medical procedures.
\end{abstract}

Keywords: screening Bi-Test, Triple Test, Panorama Test, amniocentesis for early detection of fetal malformations

\section{Introduction}

Talking with the patient about his or her family medical history, such as if the couple had a person with Down syndrome in their family or any other malformation, is important. That can be considered as a 'genetic consultation' in order to find out about any possible genetic problems before screening or any other tests. The specialist tries, in the first place, to make the patient understand the nature of his disease he is confronting, what's the most possible evolution of it, and last but not least what are the possibilities of treating it. A major objective of the genetic consult is to make the patient understand what are the factors that lead to the development of the disease, what are the mechanisms that transmit the disease, and how high is the risk of appearance to other family members. The doctor establishes, after running different tests, the correct diagnosis of the disease, its evolution, its prognosis, as well as the possibilities of treatment for a higher quality of life. 
The genetic consult is very important in the diagnosis of early fetal malformations and their complications at birth and after it. The consult is necessary for pregnant women with high risk in developing a malformation (e.g., if the woman has in the family history a newborn with malformations, if she gave birth before to a baby with malformations, if she lives in a toxic environment).

In Romania, it is mandatory that every pregnant woman should do the BI-TEST or TRIPLE TEST, depending on the pregnancy weeks.

The cytogenetic prenatal diagnosis refers to early detection of intrauterine fetal abnormalities and genetic malformations, very often determined by genetics, which complicate and threaten the life of $3-5 \%$ of newborn. These abnormalities explain the $20 \%$ deaths in the newborn period and the much higher percentage of deaths in childhood and puberty [1]. From the fetal abnormalities, 95\% are unexpected and appear at pregnancies that are not considered at risk for these situations. They can be light or severe.

The severe abnormalities are not compatible with life or can cause a long-term handicap [2].

There are multiple purposes for the detection of intrauterine prenatal illness such as:

- Establishing the high-risk diagnosis and possibly the termination of the pregnancy (abortion), the pregnancy representing a high risk of death both for the mother and fetus

- Identifying a situation that can influence the date, the place, or the childbirth method

- Identifying fetuses that will benefit of early pediatric intervention

- Identifying situations that can affect future pregnancies

Opinions are different when it comes to knowing the diagnosis; many families decide to keep the pregnancy even if there are severe malformations, thinking that they can fight this problem by taking care of the baby and not terminating the pregnancy. But most of the families decide to terminate the pregnancies and seek treatments for future pregnancies.

In conclusion, the most important thing in the prenatal diagnosis is obtaining very early in the pregnancy of correct informations about the fetus and making a correct and easy decision in conformity with family principles [3].

The indications for prenatal diagnosis are:

- Pregnancy-women at age of 35 or above

- Husband aged 45 or above

- Past pregnancy with a fetus with chromosomal abnormality

- One of the parents has a chromosomal abnormality including being a carrier of a balanced translocation or other structural rearrangements

- Down syndrome

- Pregnancies with risk of Mendelian or polygenic diseases (e.g., Tay-Sachs disease) 
- Abnormal fetus diagnosed by the ultrasound procedure within the first weeks of pregnancy

- Maternal anxiety

- Determination of fetal risk in pregnancies with high risk for hereditary $\mathrm{x}$-linked diseases, for that there is not yet a specific prenatal diagnosis (it is obtained better by determining the Y-chromosomal material with the new ADN techniques)

- History of two or more abortions without the possibility of effectuation of the cytogenic analysis to both parents or a noninvasive prenatal diagnosis [4]

The screening programs focus on the most common chromosomal abnormalitythe Down syndrome (trisomy 21) - and they not only detect very often other fetal abnormalities.

\section{The BI-TEST}

The screening of the first trimester is a prenatal text that offers informations about early pregnancy and the risk of the baby to develop some specific chromosomal abnormalities- the Down syndrome (trisomy 21) and the Edwards syndrome (trisomy 18).

The Down syndrome determines a lifetime affectation of the mental and social development and also some physical modifications. As for Edwards syndrome, it is a much more severe condition, and often it is fatal until the early age of 1 year [5].

The screening tests from the first trimester of pregnancy do not evaluate the risk of defects of the neural tube, such as spina bifida.

We do the BI-TEST (the screening of the first trimester in pregnancy) because it can be done much earlier than other tests of screening; the results can be available in the first weeks of pregnancy, which offers the parents much more time in taking the best decision regarding additional tests, medical treatment, and the course of pregnancy [6].

Normally, the screening of the first trimester (the BI-TEST) is made between weeks 11 and 14 of pregnancy. The results of the test are formulated as positive or negative and also like a probability, e.g., 1:5000 risk to have a baby with Down syndrome. In general, the test is considered positive if the risk is 1:300 or above. The BI-TEST implies two steps: a blood test that measures the level of two hormones that are specific in pregnancy (pregnancy-associated plasma protein A (PAPP-A) and human chorionic gonadotropin (hCG)) and an ultrasound examination which measures the size of the transparent space behind the neck of the fetus (the nuchal translucency) [7]. Correlating the values obtained from the blood tests with the ultrasound examination and some specific parameters of the mother (age, height, weight, blood pressure, smoking, diabetes, assisted reproductive techniques), the specialist can calculate the risk of the mother of having a baby with chromosomal abnormalities [6].

Frequently, a positive result will enforce the performance of secondary diagnosis tests:

- The chorial biopsy-it is done normally in the first trimester of pregnancy, and it is an invasive test which implies cropping a piece of the placenta, with a low 
risk of abortion. It is used to detect chromosomal abnormalities, like the Down syndrome.

- Amniocentesis - it can be used to identify chromosomal abnormalities but also defects of the neural tube, like spina bifida. During the amniocentesis, which frequently is done in the second trimester of pregnancy, a small amount of amniotic liquid is estranged. It also had a low risk of abortion [6].

\section{The TRIPLE TEST}

A continuance of the BI-TEST from the first trimester and the screening TRIPLE TEST (made in the second trimester of pregnancy) is more and more often requested by us. With the help of it, we can evaluate the risks of the baby developing a neural tube disorder (spina bifida) or chromosomal abnormalities such as the Down syndrome (trisomy 21) or the Edwards syndrome (trisomy 18) [6].

Between the 15 and 20 weeks of pregnancy (with optimal results in the weeks 16-18), pregnant women can be tested with a simple blood test known as the TRIPLE TEST (or triple marker test or second trimester screening). It is made in combination with an ultrasound examination [3].

For the triple marker testing, a blood test is required that will measure the levels of:

- hCG (human chorionic gonadotropin) secreted by the placenta.

- Unconjugated estriol, a product of the placenta and the fetus.

- Alpha-fetoprotein (AFP gene) produced by the fetus's liver.

- Sometimes it also tested the inhibin A (produced by the placenta), because it considerably grows the chances of detection of the Down syndrome, which is also known as the quadruple test.

The level of each substance present in the blood helps the doctor identify if the fetus is exposed to the risk of developing congenital disorders and chromosomal abnormalities. Exactly as in the case of the BI-TEST, multiples of the median (MoM) is measured depending on the clinical data of the mother (age, height, weight, race, smoker, age of the fetus) [4]. The results of the tests are available in 2 weeks from the blood tests. Usually, if the results of the TRIPLE TEST show a high level of alphafetoprotein, it indicates a neural tube defect. The doctor will recommend an ultrasound examination of the fetal cranium and spinal cord. The mother is also purposed to do an amniocentesis, which involves extracting a small amount of amniotic liquid from the uterus for further investigation.

On the other hand, low levels of alpha-fetoprotein (AFP) and unconjugated estriol indicate a high risk of Down syndrome. In this situation, it is recommended that an amniocentesis should be done.

\section{Amniocentesis}

Amniocentesis is a medical procedure used in prenatal diagnosis of chromosomal abnormalities, in which a small amount of amniotic fluid which contains fetal tissues is sampled from the amniotic sac and which is afterward tested.

It is a two-person procedure which requires a lot of experience and care from the side of the doctor. One of the doctors assures the ultrasound examination, and the 
other doctor places the puncture needle. This way, he can manipulate the needle with all the attention and care to attain the desired target. There has to be an incredible collaboration between both doctors, because they have to anticipate each other's moves.

Before the procedure, it is mandatory that the sanguine groups $\mathrm{ABO}$ and $\mathrm{RH}$ be determined and also to perform an ultrasound examination, which will determine the number of fetuses, the position and viability, the localization of the placenta, the amount of amniotic fluid, and the largest amniotic sac that will be punctured and will assure that the fetus is anatomically normal. Also the gestational age of the fetus by the fetal biparietal diameter, the length of the thigh bone, and the abdominal circumference is determined.

Choosing the place of puncture is made after the initial evaluation. When doing the amniocentesis, it is important to choose the place of the puncture needle in the amniotic cavity wisely, namely by carefully avoiding the placenta, the umbilical cord insertion place and the fetus. Colored Doppler ultrasound can facilitate the choosing of the place for the transplacental puncture, to avoid fetal hemorrhage.

Diagnosis of chromosomal abnormalities and diagnosis of the neural tube defects are the most common indications for amniocentesis in the beginning of the second trimester of pregnancy. As for the evaluation of the fetal pulmonary maturation, it is the most common indication for amniocentesis in the third trimester [8].

At the end of the first trimester and the beginning of the second trimester, the indications for amniocentesis are:

- Cytogenetic diagnosis

- Diagnosis of neural tube defects

- Diagnosis of metabolic disorders

At the end of the second trimester and the beginning of the third trimester, the indications for amniocentesis are:

- Evaluation of the severity of Rh immunization

- Evaluation of fetal pulmonary maturation

- Diagnosis of intra-amniotic infections

- Confirmation of the ruptured membranes

Last, but not the least, the therapeutic purpose of the amniocentesis has indications in the polyhydramnios drainage and the medical treatment of fetal diseases.

Ultrasound examination (localization of the placenta, fetus, and amniotic liquid bag) and the insertion of the needle can take up to $20 \mathrm{~min}$. Extraction of the amniotic liquid can take up to 5 min.

Some women don't feel pain (painless procedure), while other pregnant women feel cramps as the needle punctures the uterus or a pressure sensation during the procedure of extracting amniotic liquid.

Local anesthetic is not normally used. Associated factors to the high level of pain during the amniocentesis are considered to be maternal anxiety, presence of menstrual cramps in the past, an anterior amniocentesis, and the insertion of the needle in the inferior part of the uterus, where the pain is less felt by the patient [9], although there aren't any data to support this practice [10]. 


\section{Panoramic Test}

The Panorama Test is a prenatal noninvasive test, which analyzes the fetal DNA from the maternal blood and establishes the risk of common fetal aneuploidies in pregnant women, most interestingly the 21,18 , and 13 chromosomes but also the analyzes the sexual chromosomes $\mathrm{X}$ and $\mathrm{Y}$.

Aneuploidies are chromosomal abnormalities characterized by the alteration of the number of chromosomes, for example, more or less chromosomes instead of the exact number of chromosomes; the trisomy, when there is an extra chromosome; or monosomy, when there is missing a chromosome.

Trisomy 21 is caused by the presence of an extra chromosome to the 21st pair, and it's known as the Down syndrome. It is the most frequent cause of mental retardation. The patients with Down syndrome present cardiac disease or other diseases which require surgical interventions or specific medical treatment. Other symptoms are, for example, ophthalmological problems [11].

Trisomy 18 is caused by the presence of an extra chromosome to the 18th pair, and it's known as the Edwards syndrome. It is a serious cause of mental retardation. The majority of the children with trisomy 18 present severe cerebral malformations, severe heart malformations, or severe malformations of other organs. Often, the growth retardation is found, which can lead to the termination of pregnancy (abortion). Most of the children who are born with the growth retardation die within their first year of life. Patients who survive present severe intellectual disability and have problems of growth and development [12].

Trisomy 13 is caused by the presence of an extra chromosome to the 13th pair, and it's known as the Patau syndrome. It is a cause of severe mental retardation. The majority of the patients present serious cerebral and other organs abnormalities. In many situations the pregnancy doesn't get to its due date, and the newborn dies very fast. Half of the born babies die in their first month of life, and $90 \%$ from those who survive in the first year of life present heart malformations, renal malformations, and renal malformations.

Aneuploidies of the sexual chromosomes are caused by the presence or the absence of one of the sexual chromosomes. The test can detect the risk for XXX, $\mathrm{XYY}, \mathrm{XXYY}$, and XXY (the Klinefelter Syndrome) and for the X monosomy (the Turner syndrome). A significant variability exists in regarding the severity of these genetic conditions, but the majority of the affected individuals are characterized by slight modifications physically and mentally.

During pregnancy some fragments of the fetal DNA run through the maternal blood. The fetal DNA is detectable since the 5th week of pregnancy. The concentration increases successively in the next weeks of pregnancy and disappears right after childbirth. The circulating fetal DNA quantity is found from the 9th to 10th weeks of pregnancy, and it's sufficient to guarantee the relevance and the sensibility of the Panorama Test.

The test is done by collecting a blood sample from the pregnant woman from at least the 10th week of unique and twin pregnancies. In the laboratory a complex analysis is made, where the fetal DNA from the maternal blood is isolated. This procedure identifies the eventual chromosomal abnormalities, like aneuploidy, and cutting-edge sequencing technology is used, along with advanced bioinformatics analysis.

The results obtained in the Panorama Test are:

- "High risk" implies that there is a probability that the fetus can present an aneuploidy of the 21st, 18th, and 13th pairs of chromosomes or an aneuploidy of 
$\mathrm{X}$ and $\mathrm{Y}$ sexual chromosomes. This result indicates that there is a high chance that the fetus can present one of the abovementioned abnormalities, but it is not sure the fetus will have that condition. The endorsed advice is an invasive prenatal diagnosis test, like chorionic villus biopsy or amniocentesis.

- "Low risk" implies that the test detected a risk $<1 / 10,000(0.01 \%)$ for the fetus to be affected by a chromosomal aneuploidy.

- In some cases, when the quantity of fetal DNA is not enough, the test can show.

- Incomplete results or no results. In this situation, a new blood sample will be collected for the repetition of the test. In case the sexual analysis is demanded, this result can also be provided.

\section{The accuracy of the Panorama Test}

\begin{tabular}{lcc}
\hline & \% diagnosis (sensibility) & \% false positive ( specificity) \\
\hline Trisomy 21 (the Down syndrome) & $99(>99 \%)$ & $<0.1 \%(>99 \%)$ \\
\hline Trisomy 18 (the Edwards syndrome) & $99(>99 \%)$ & $<0.1 \%(>99 \%)$ \\
\hline Trisomy 13 (the Patau syndrome) & $08 / 10 / 16$ & $<0.1 \%(>99 \%)$ \\
\hline Determination of the fetal sex & $99(>99 \%)$ & $<0.1 \%(>99 \%)$ \\
\hline
\end{tabular}

The test can detect the risk of a sexual chromosomal aneuploidy with a rate of detection which varies depending on the type of detected aneuploidy: 13th, 18th, and 21st.

The test was validated for women with unique and twin pregnancies, with at least 10 weeks of pregnancy. This test evaluates just the chromosomal aneuploidies of the 13th, 18th, 21st, X, and Y. In the case of pregnancy with more fetuses, informations about the sexual chromosomes will not be provided. This procedure does not replace the invasive prenatal diagnosis (choriocentesis or amniocentesis).

Also, the analysis cannot highlight the equilibrated chromosomal rearrangements, partial abnormalities of the analyzed chromosomes, structural chromosome abnormalities, fetal or placental chromosomal mosaicism in a small percentage (the presence of two cellular lines with a different set of chromosomes, with a cellular line weakly represented), point mutations, methylation defects, and polyploidy. In particular, the analysis does not reveal the presence of hereditary genetic disorders with the Mendelian transmission. The test can give a false-positive result in the case of chromosomal mosaicism, but this thing can limit itself to the placenta. The sex of the fetus is mentioned as masculine or feminine, based on the presence or absence of the $\mathrm{Y}$ chromosome, not on the presence or absence of the SRY gene.

Pregnancies with abnormal ultrasound results should be studied with other types of prenatal investigations, such as fetal karyotype from the chorionic villi or amniotic liquid. Although this test is very precise, the results are not a diagnosis, and they should be evaluated in the clinical context of the patient and the family medical history. The test is limited to offer just informations about the risks of aneuploidies for the analyzed chromosomes.

A "low-risk" result can significantly reduce the possibility for the fetus to present an aneuploidy of the examined chromosomes, but it cannot guarantee that these chromosomes are normal or that the fetus is healthy. 
This test can be done for 13th, 18th, and 21st aneuploidies also in case of twin pregnancies and of pregnancies obtained by fertilization in vitro.

This study seeks the degree of accuracy of the prenatal screening which indicates a high risk. The results are established after the confirmation or information of the diagnosis by the invasive diagnosis method for genetical abnormalities, the amniocentesis procedure. The interventions have been made by the obstetrician, helped by different doctors, based on the "2 operatives" technique. The puncture and the extraction of the amniotic liquid will be done by the obstetrician, and the doctor helping him would monitor by ultrasound the whole intervention.

Our study is based on a 3-year research (2012-2015). We evaluated 6097 pregnant women, from which 408 had an indication for effectuation of amniocentesis with the purpose of establishing a correct diagnosis. The dynamics of the number of pregnancies in the analyzed period presents significant decreases from $15 \%-14.65 \%$ in 2014 to $11.15 \%$ in 2015.

From the total amount of 408, 114 were made in the year 2012, 102 in the year 2013, 97 in the year 2014, and 95 in the year 2015.

\begin{tabular}{ccc}
\hline Year & Number of pregnancies & Number of amniocentesis \\
\hline 2012 & 1641 & 114 \\
\hline 2013 & 1596 & 102 \\
\hline 2014 & 1402 & 97 \\
\hline 2015 & 1458 & 95 \\
\hline TOTAL & $\mathbf{6 0 9 7}$ & $\mathbf{4 0 8}$ \\
\hline
\end{tabular}

Comparing the dynamics of the number of amniocentesis procedures done in 2015 with the amniocentesis procedures done in 2012, they have a pronounced decreasing rhythm, so that in 2013 the level decreased by 10.53\%, in 2014 the level decreased by $14.91 \%$, and in 2015 the level decreased by $16.67 \%$ due do the apparition of the Panorama Test sampled from the maternal blood.

\begin{tabular}{ccccc}
\hline Year & $\begin{array}{c}\text { Number of } \\
\text { pregnancies }\end{array}$ & $\begin{array}{c}\text { Number of amniocentesis } \\
\text { procedures }\end{array}$ & \multicolumn{2}{c}{ Dynamics than 2012 } \\
\cline { 4 - 5 } & & 114 & $\begin{array}{c}\text { Number of } \\
\text { pregnancies }\end{array}$ & $\begin{array}{c}\text { Number of amniocentesis } \\
\text { procedures }\end{array}$ \\
\hline 2012 & 1641 & 102 & - & - \\
\hline 2013 & 1596 & 97 & 97.26 & 89.47 \\
\hline 2014 & 1402 & 95 & 85.44 & 85.09 \\
\hline 2015 & 1458 & $\mathbf{4 0 8}$ & - & - \\
\hline Total & $\mathbf{6 0 9 7}$ & & & \\
\hline
\end{tabular}

By the fact that, in medical practice, age above 35 years old in pregnant women represents a risk factor; the patients have been divided in two groups such as patients aged until 35 years old and patients above 35 years old.

\begin{tabular}{lccccc}
\hline Group of age & $\mathbf{2 0 1 2}$ & $\mathbf{2 0 1 3}$ & $\mathbf{2 0 1 4}$ & $\mathbf{2 0 1 5}$ & TOTAL \\
\hline Under 35 years old & 74 & 66 & 57 & 54 & 251 \\
\hline Above 35 years old & 40 & 36 & 40 & 41 & 157 \\
\hline Total number of patients & $\mathbf{1 1 4}$ & $\mathbf{1 0 2}$ & $\mathbf{9 7}$ & $\mathbf{9 5}$ & $\mathbf{4 0 8}$ \\
\hline
\end{tabular}


In the year of our study, 408 amniocentesis procedures have been made. Two hundred and fifty-one procedures were done on patients with age under 35 years old, which represents a percentage of $61.5 \%$. One hundred and fifty-seven procedures were made on patients with age above 35 years old, with a percentage of $38.5 \%$.

The distribution of the patients based on the pregnancy period and the number of amniocentesis procedures done in percentage:

\begin{tabular}{lcccccc}
\hline Weeks of pregnancy & $\mathbf{2 0 1 2}$ & $\mathbf{2 0 1 3}$ & $\mathbf{2 0 1 4}$ & $\mathbf{2 0 1 5}$ & Total & \% \\
\hline Week 15 & 15 & 15 & 14 & 14 & 58 & 14.22 \\
\hline Week 16 & 36 & 34 & 32 & 39 & 141 & 34.56 \\
\hline Week 17 & 31 & 28 & 26 & 24 & 109 & 26.72 \\
\hline Week 18 & 14 & 13 & IO & 8 & 45 & 11.03 \\
\hline Week 19 & 9 & 5 & 10 & 6 & 30 & 7.35 \\
\hline Week 20 & 7 & 5 & 3 & 2 & 17 & 4.17 \\
\hline Week 21 & 2 & 2 & 2 & 2 & 8 & 1.96 \\
\hline Total & $\mathbf{1 1 4}$ & $\mathbf{1 0 2}$ & $\mathbf{9 7}$ & $\mathbf{9 5}$ & $\mathbf{4 0 8}$ & $\mathbf{1 0 0 \%}$ \\
\hline
\end{tabular}

Even though the number of amniocentesis procedures has slightly decreased, the number of BI-TESTS has significantly increased since year 2012. In year 2013, the increasing number has been a percentage of $+115.4 \%$, in 2013 it has been $+315.45 \%$, and in the year 2015, it has been $269.2 \%$. In the last 2 years, the percentage for positive tests for Down syndrome in amniocentesis has been $50 \%$. In all our period of research, $35.05 \%$ of the patients have effectuated the double-positive test for the Down syndrome.

\begin{tabular}{|c|c|c|c|c|c|}
\hline \multirow[t]{2}{*}{ Year } & \multirow[t]{2}{*}{$\begin{array}{c}\text { Number of } \\
\text { amniocentesis } \\
\text { procedures }\end{array}$} & \multirow[t]{2}{*}{$\begin{array}{l}\text { Triple Test positive } \\
\text { for Down syndrome }\end{array}$} & \multirow[t]{2}{*}{$\begin{array}{l}\text { Triple Test positive } \\
\text { for Edwards } \\
\text { syndrome }\end{array}$} & \multicolumn{2}{|c|}{$\begin{array}{l}\text { Percentage of positive } \\
\text { Triple Test (minus } \\
\text { the number of } \\
\text { amniocentesis } \\
\text { procedures) for: }\end{array}$} \\
\hline & & & & $\begin{array}{c}\text { Down } \\
\text { syndrome }\end{array}$ & $\begin{array}{l}\text { Edwards } \\
\text { syndrome }\end{array}$ \\
\hline 2012 & 114 & 93 & 5 & 81 & 4.39 \\
\hline 2013 & 102 & 64 & 3 & 62.75 & 2.94 \\
\hline 2014 & 97 & 36 & 1 & 37.11 & 1.03 \\
\hline 2015 & 95 & 33 & 1 & 34.74 & 1.05 \\
\hline Total & 408 & 226 & 10 & 55.39 & 2.45 \\
\hline
\end{tabular}

In the period of our research, the percentage for Down syndrome and Edwards syndrome of the TRIPLE TEST decreased in relation to the number of amniocentesis procedures. In this period the result positive for these tests is considered:

- In 2012 the test for Down syndrome represented 81.58\%, and 4.39\% for Edwards syndrome.

- In 2013 the test for Down syndrome represented 62.75\% and 2.94\% for Edwards syndrome. 
- In 2014 the test for Down syndrome represented 37.11\% and $1.03 \%$ for the Edwards syndrome.

Although in 2012 the highest number of amniocentesis procedures (114) was recorded, a single case was recorded in which amniocentesis had as an indication the maternal age, which represents a percentage of $0.88 \%$. In 2013, a slight increase with a percentage of $6.86 \%$ is noted (in $2014,4.12 \%$, and in $2015,3.16 \%$ ). In all, there were 15 procedures made after the indication of the maternal age above 35 years old, with a percentage of $3.68 \%$.

\begin{tabular}{cccc}
\hline Year & Number of amniocentesis procedures & Age of the mother $>$ 35 & Percentage \% \\
\hline 2012 & 114 & 1 & 0.88 \\
\hline 2013 & 102 & 7 & 6.86 \\
\hline 2014 & 97 & 4 & 4.12 \\
\hline 2015 & 95 & 3 & 3.16 \\
\hline Total & $\mathbf{4 0 8}$ & $\mathbf{1 5}$ & 3.68 \\
\hline
\end{tabular}

The distribution of the amniocentesis procedures based on priors:

- Down syndrome in the family

- Prior pregnancy with Down syndrome

- Prior pregnancy with Turner syndrome

\begin{tabular}{ccccc}
\hline Year & $\begin{array}{c}\text { Number of } \\
\text { amniocentesis } \\
\text { procedures }\end{array}$ & $\begin{array}{c}\text { Down syndrome } \\
\text { in the family }\end{array}$ & $\begin{array}{c}\text { Prior pregnancy with } \\
\text { Down syndrome }\end{array}$ & $\begin{array}{c}\text { Prior pregnancy with } \\
\text { Turner syndrome }\end{array}$ \\
\hline 2012 & 114 & 1 & 1 & 0 \\
\hline 2013 & 102 & 0 & 0 & 0 \\
\hline 2014 & 97 & 1 & 0 & $\mathbf{0}$ \\
\hline 2015 & $\mathbf{9 5}$ & $\mathbf{0}$ & $\mathbf{0}$ & 1 \\
\hline
\end{tabular}

It is observed that in 2012, from the amount of 114 amniocentesis procedures, 2 of them had as indication the pathological chromosomal history. One of the patients presents in her family history a member of the family who has Down syndrome. Another patient had a prior pregnancy with Down syndrome. These indications represent $1.75 \%$ of the indications for year 2012. In 2014 two more pregnant women have been diagnosed. One of them was coming from a family with Down syndrome, and the other one had a prior pregnancy with Turner syndrome. These indications represent a percentage of $2.61 \%$ for the year 2014 .

From a total of 408 pregnancies, the indications for pathological chromosomal history represent a percentage of $0.97 \%$.

\begin{tabular}{lcc}
\hline Number of amniocentesis procedures & 408 & $100 \%$ \\
\hline BI-TEST & 131 & $32.10 \%$ \\
\hline TRIPLE TEST & 258 & $63.23 \%$ \\
\hline Indication for maternal age 35 years or above & 15 & $3.67 \%$ \\
\hline
\end{tabular}


From the amount of 408 pregnancies which underwent the amniocentesis procedure, 149 of them were on their first pregnancy, with a percentage of $36.52 \%$. One hundred and ninety-eight of the pregnant women were on their second pregnancy (48.53\%), and 61 were on their third or more pregnancy $(14.95 \%)$.

Distribution of the patients depending on environmental residence

\begin{tabular}{lcccccc}
\hline Environment & $\mathbf{2 0 1 2}$ & $\mathbf{2 0 1 3}$ & $\mathbf{2 0 1 4}$ & $\mathbf{2 0 1 5}$ & Total & \% \\
\hline Rural & 16 & 34 & 25 & 20 & 95 & 23.28 \\
\hline Urban & 98 & 68 & 72 & 75 & 313 & 76.72 \\
\hline Total & $\mathbf{1 1 4}$ & $\mathbf{1 0 2}$ & $\mathbf{9 7}$ & $\mathbf{9 5}$ & $\mathbf{4 0 8}$ & $\mathbf{1 0 0}$ \\
\hline
\end{tabular}

It is concluded that only $23.28 \%$ of the pregnant women came from a rural environment; the rest of $76.72 \%$ came from an urban environment.

Distribution of patients depending on chronic diseases

\begin{tabular}{lcc}
\hline Chronic diseases & Number of patients & $\%$ \\
\hline Diabetes mellitus & 11 & 2.70 \\
\hline Hepatitis A and hepatitis B & 5 & 1.23 \\
\hline High blood pressure & 9 & 2.21 \\
\hline Obesity & 10 & 2.45 \\
\hline Kidney diseases & 3 & 0.74 \\
\hline
\end{tabular}

Distribution of patients depending on vicious behavior

\begin{tabular}{lcccccc}
\hline & $\mathbf{2 0 1 2}$ & $\mathbf{2 0 1 3}$ & $\mathbf{2 0 1 4}$ & $\mathbf{2 0 1 5}$ & Total & $\%$ \\
\hline Smoker & 38 & 49 & 36 & 37 & $\mathbf{1 6 0}$ & 39.22 \\
\hline Non-smoker & 76 & 53 & 61 & 58 & $\mathbf{2 4 8}$ & $\mathbf{6 0 . 7 8}$ \\
\hline Total & $\mathbf{1 1 4}$ & $\mathbf{1 0 2}$ & $\mathbf{9 7}$ & $\mathbf{9 5}$ & $\mathbf{4 0 8}$ & $\mathbf{1 0 0}$ \\
\hline
\end{tabular}

It can be observed that, despite the fact that smoking affects the pregnancy and the fetus, a quite high percentage of pregnant women smoke (39.22\%).

Distribution of the patients depending on the result of the amniocentesis

\begin{tabular}{lcc}
\hline Result & Number of patients & \% \\
\hline Normal results & 394 & 96.57 \\
\hline Down syndrome & 10 & 2.45 \\
\hline Edwards syndrome & 4 & 0.98 \\
\hline Total & $\mathbf{4 0 8}$ & $\mathbf{1 0 0}$ \\
\hline
\end{tabular}

The percentage of Down syndrome reported to the total number of pregnancies (6097 patients) represents $1.6 \%$ above the European statistics. The percentage of Edwards syndrome reported to the total number of pregnancies represents $0.656 \%$ above the European statistics. 
Maternal ages for women diagnosed with pregnancies with Down syndrome were $28,31,32,38$, and 40 years old.

\begin{tabular}{lc}
\hline Age of the mother diagnosed with pregnancies with Down syndrome & Number of cases \\
\hline 28 & 2 \\
\hline 31 & 1 \\
\hline 32 & 2 \\
\hline 38 & 3 \\
\hline 40 & 2 \\
\hline
\end{tabular}

All the patients with babies diagnosed with Down syndrome or Edwards syndrome decided to terminate the pregnancy.

The 14 cases positive for Down syndrome and Edwards syndrome ( 4 cases positive for Edwards syndrome and 10 cases positive for Down syndrome) were actually found because of the indications of the TRIPLE TEST, 4 more cases positive for Down syndrome were found because of the indications for BI-TEST, and just 1 case of Down syndrome was found because of the indications for maternal age.

Amniocentesis has become the most used prenatal diagnosis method for women aged 35 and above or even for younger women with a family history specific for hereditary congenital abnormalities.

In our studied group, 157 pregnant women asked for a prenatal diagnosis for Down syndrome. They were aged 35 or above 35 and demanded the association of some pathological biochemical markers (double test, TRIPLE TEST).

The frequency of the structural chromosomal abnormalities (translocations, deletions, inversions) did not show a similar numeric relationship regarding the maternal age.

According to the literature, the screening tests have a margin of error in the diagnosis of fetal malformations, so the diagnosis of certainty will result after the amniocentesis.

The majority of the specialists consider that amniocentesis is an invasive procedure, so it is recommended that the number of these procedures should be decreased. In this regard, our study did very well: the result of the utilization of the other methods (BI-TEST, TRIPLE TEST) was positive. The BI-TEST can detect trisomy 21 (the Down syndrome) and trisomy 18 (the Edwards syndrome).

There are tests like Panorama Test which are cutting-edge technology, and they reduce the use of amniocentesis. But the cost of this test is high and not covered by the National Health, which is the reason why it is not accessible for all patients.

Our study has been made on a large segment of the population which had access to all the screening tests (BI-TEST, TRIPLE TEST), but not all of the patients had this possibility.

The TRIPLE TEST in pregnancy can help in tracking down the neural tube defects and chromosomal abnormalities such as trisomy 18 and trisomy 21. So, if a high level of alpha-fetoprotein (AFP gene) is found in the blood, it is likely that the fetus presents a neural tube defect (more exactly the brain and the spinal cord), defects such as spina bifida or anencephaly. If the results of the TRIPLE TEST show a low level of alpha-fetoprotein (AFP gene) and estriol, it can indicate trisomy 21 (the Down syndrome), trisomy 18 (Edwards syndrome), or other chromosomal abnormalities.

Before we proceeded with the amniocentesis procedure, we acquired from every patient and her partner a written consent after informing them about what the procedure implies. 
In obstetrical practice the risk of carrying out an amniocentesis is evaluated permanently, compared to the individual risk of numerical chromosomal abnormalities or structural chromosomal abnormalities. We recommend the amniocentesis as an invasive diagnosis prenatal method when the risk of a detectable abnormality is higher than the risk of the procedure itself.

It is important that the patient should be informed about the pam felt during the amniocentesis.

Numerical chromosomal abnormalities (aneuploidies) - in the case of amniocentesis procedures done to pregnant women with age 35 or above from our consignment-have a frequency of $3.18 \%$ ( 5 cases out of 157 ).

The majority of the patients questioned said that the procedure was a painful method. Pain is a multidimensional sensation and complex, which varies in quality, intensity, duration, localization, and inconvenience from an individual to another. The intensity and inconvenience of the pain is not directly connected to the nature and the extension of the tissue lesion. Cultural, genetic, familial, growth, psychological, and social variables have a strong impact in the perception of the pain and in its expression from the patient.

The objective quantification of the pain is difficult. Before any invasive procedure effectuated throughout pregnancy, the biggest concern of the patient is the risk and the intensity of the pain during procedures.

\section{Ultrasound conclusions in cases of chromosomal abnormalities}

\begin{tabular}{|c|c|}
\hline Trisomy & Ultrasound conclusions \\
\hline $\begin{array}{l}\text { Trisomy } 21 \text { (Down } \\
\text { syndrome) }\end{array}$ & $\begin{array}{l}\text { - Duodenal atresia, tracheoesophageal fistula, and hydramnios are present } \\
\text { usually if there are gastrointestinal damages } \\
\text { - Heart abnormalities-defects of the atrial septum } \\
\text { - Hypoplasia of the middle phalanx of the 5th finger of the hand } \\
\text { - Conclusions from the second trimester: increased cervical skinfold } \\
(>6 \mathrm{~mm}) \text {, ratio of the actual femur (length), and the expected } \\
\text { femur }=0.91\end{array}$ \\
\hline $\begin{array}{l}\text { Trisomy } 18 \text { (Edwards } \\
\text { syndrome) }\end{array}$ & $\begin{array}{l}\text { - Growth retardation in uterus } \\
\text { - Hydramnios } \\
\text { - Hand wrapped with superimposed fingers (the index covers the third } \\
\text { finger, and the fifth finger covers the fourth finger) } \\
\text { - Ankle equinus with prominent calcaneus and clubfoot. } \\
\text { - Heart abnormalities: ventricular septal defect } \\
\text { - Omphalocele, diaphragmatic hernia } \\
\text { - Cyst of the choroid plexus }\end{array}$ \\
\hline $\begin{array}{l}\text { Trisomy } 13 \text { (Patau } \\
\text { syndrome) }\end{array}$ & $\begin{array}{l}\text { - Holoprosencephaly (defects of the facial break line) } \\
\text { - Cleft palate } \\
\text { - Heart abnormalities such as ventricular septal defect } \\
\text { - Polydactylism } \\
\text { - Omphalocele } \\
\text { - Polycystic kidneys }\end{array}$ \\
\hline
\end{tabular}

\section{Conclusions}

In conclusion, all the pregnant women who underwent the amniocentesis procedure and had a negative result had an on-term pregnancy and delivered healthy newborn babies.

As for the pregnant women who underwent the amniocentesis procedure and had a positive result, all of them decided to terminate their pregnancy due to existent fetal malformations. 
The purpose of our study was to decrease the use of amniocentesis procedures and to introduce a cutting-edge technology, which is the Panorama Test for early diagnosis of fetal malformations. We tried to implement a noninvasive method (Panorama Test made from the mother's blood sample) over an invasive method which is the amniocentesis.

Our purpose has been achieved by the decrease of amniocentesis and by increasing the use of cutting-edge technology without affecting the final results in the percentage of the fetal malformations statistics worldwide.

\section{Author details}

Gladys Cristina $\mathrm{Al} \mathrm{Jashi}{ }^{1 *}$ and Isam $\mathrm{Al} \mathrm{Jashi}{ }^{2}$

1 Primary Physician in Obstetrics and Gynecology at Sfantul Pantelimon Emergency Hospital, Bucharest, Romania

2 Faculty of Medicine, Titu Maiorescu University, Primary Physician in Obstetrics and Gynecology at Regina Maria Private Hospital, Bucharest, Romania

*Address all correspondence to: dr.jashi@yahoo.com

\section{IntechOpen}

(C) 2019 The Author(s). Licensee IntechOpen. This chapter is distributed under the terms of the Creative Commons Attribution License (http://creativecommons.org/licenses/ by/3.0), which permits unrestricted use, distribution, and reproduction in any medium, provided the original work is properly cited. (c) BY 


\section{References}

[1] D’Alton ME, DeCherney AH. Prenatal diagnosis. New England Journal of Medicine. 1993;328:114-120

[2] O’Reilly DB, Bottomley C, Rymer J. Essentials of Obstetrics and Gynaecology. Elsevier Health Sciences; 2005. pp. 219-235

[3] Wieacker P, Steinhard J. The prenatal diagnosis of genetic diseases. Deutches Ärzteblatt International. 2010;107(48): 875-862. DOI: 10.3238/arztebl.2010. 0857

[4] Rary JM, Park IJ, Heller RH, Jones HW Jr, Baramki TA. Prenatal cytogenetic analysis of women with high risk for genetic disorders. Journal of Heredity. 1974;65(4):209-212

[5] Wang J, Cui YX. Advances in rapid prenatal detection of fetal chromosome abnormalities. Zhonghua Nan Ke Xue. 2010;16(4):359-363 Review. Chinese

[6] Available from: https://www.regina maria.ro/articole-medicale/testele-scree ning-de-trimestru-1-bitestul-sau-testulcombinat- 0

[7] Nanu D et al. Esențialul în Obstetrică. Medicală Amaltea; 2015

[8] Feinstein SJ, Vintzileos AM, Lodeiro JG, Campbell WA, Weinbaum PJ, Nochimson DJ. Amniocentesis with premature rupture of membrane. Obstetrics and Gynecology. 1986

[9] Leukskul N, Tannirandorn Y. The location of needle insertion effect on maternal pain in amniocentesis. Journal of the Medical Association of Thailand. 2006

[10] Verny RT. Pre-And Peri-Natal Psychology: An Introduction. New York: Human Sciences Press;

[11] Available from: https://en.wikipedia. org/wiki/Down_syndrome
[12] Leigh Simpson J. Genetic Counseling and Prenatal Diagnosis. pp. 215-238, chapter 9 in Gabe SG

[13] Niebil JR, Simpson JL. Obstetrics: Normal and Problem Pregnancies. 3rd ed. Churchill Livingstone; 1996 

Section 3

Cancer Genetics 



\title{
Genetic Contributors to Hereditary Cancer Predispositions: Do We Have Enough Information?
}

\author{
Tom Nolis and Rodney J. Scott
}

\begin{abstract}
Genomics medicine and molecular genetics are experiencing a surge of interest as well as a push for a more prominent role in mainstream medicine. This, coupled with the advancement of next-generation sequencing, along with a national, if not global, steering of funding to support the advancement and development of genetics is suggesting that we are entering a new age of medicine. As this push begins to gain some momentum, the impact of genomics medicine on clinical utility and the influence of supporting data on genes that make their way from research to diagnostic medicine are worth reviewing.
\end{abstract}

Keywords: genetics, genomics, utility, cancer, $B R C A 1, B R C A 2, P A L B 2$, population, family, epidemiology, multigene, panels

\section{Introduction}

One of the most fundamental clinical validity and clinical utility questions currently at the forefront of molecular genetic testing is as important today as it was nearly 30 years ago, "is the genetic variation detectable in the genes of interest actually associated with a clear and quantifiable risk for disease?” or in other words, "are the variants that we are finding in these genes relevant for the disease of interest?"

The question above is a very important one, and to be able to answer, it we must take a step back and explore clinical utility and epidemiology in genetics more thoroughly. The answer to this question requires an inevitable focus on cancer genetics as breast and ovarian cancer are excellent examples of both past and present accomplishments in genomics medicine. These disease entities are topical and have enough data to appropriately highlight the genetic journey previously taken into genomics medicine, and they are also able to shed light on how new genetic players are entering the diagnostic scene (e.g., PALB2).

Finally, the following text will briefly compare and contrast the significant influence of family-based and population studies on genetic data. This chapter will close on a more general note by reviewing the current cancer assessment guidelines and how these reflect the current clinical utility of genomics medicine. 


\subsection{Key points}

- Clinical utility in genetics is largely a continual revamp of the ACCE framework.

- Genetic epidemiology has followed a natural flow paralleling the advancement of technology and detection.

- Family-based studies and population data are still at the forefront of both research genetics and diagnostic genomics.

- BRCA1 and BRCA2 are excellent models for useful genetics input.

- This has led to a complete change in the identification and treatment of a very tangible cancer entity.

- Less penetrant genes in breast and ovarian cancer, such as PALB2, along with multigene panels have their place in genomics medicine, but, generally, quality supportive data are lacking.

\section{Clinical utility in genetic testing}

Clinical utility is a broad concept and one that is deeply fundamental in the world of medicine. At its most basic level, it is the essence of what propels medical advancement. It answers the question of "what should I do next?" when this question is asked by physicians, but it can also be a much larger almost all encompassing concept; as if to ask, "what is worth doing next?" in any field of medicine. Clinical utility, by many sources, can be simply defined as "the balance of benefits to risks" or more broadly refer to any use of test results to inform clinical decision-making [1]. A genetic test can be defined as a "test that involves the analysis of chromosomes, deoxyribonucleic acid (DNA), ribonucleic acid (RNA), genes, or gene products (e.g., enzymes and other proteins) to detect heritable or somatic variations related to disease or health. Whether a laboratory method is considered a genetic test also depends on the intended use, claim or purpose of a test" [2].

In some fields, such as in colorectal surgery, it is easy to determine clinical utility: if the patient's morbidity or mortality is improved by removing a tumor, then you remove it; otherwise you do not. In the realm of genetic testing, the concept of clinical utility can be difficult to precisely define-or even quantify. Indeed, this was reinforced when experts in evidence-based medicine and genetics for the Centers for Disease Control and Prevention (CDC) in 2005 failed to come to a consensus on the term "clinical utility" despite initially claiming to be confident in its meaning beforehand [1]. As a consequence, the term had to be elaborated on by the Analytic validity, Clinical validity, Clinical utility, and Ethical, legal and social implications (ACCE) project that was carried out by the Foundation for Blood Research with support from the CDC [1]. In screening or in diagnostic testing, clinical utility broadly refers to the ability of a test to prevent or ameliorate adverse health outcomes such as mortality, morbidity, or disability through the adoption of efficacious treatments conditioned on test results (Figure 1) [1]. The perceived value of genotypic information, at this point in time, includes a more thorough understanding of a patient's diagnosis, prognosis, risk, and disease or treatment susceptibility; the caveat is that this knowledge may not influence clinical management at all. Clinical utility in the ACCE framework was expanded to include 


\section{Clinical Utility in Genetics}

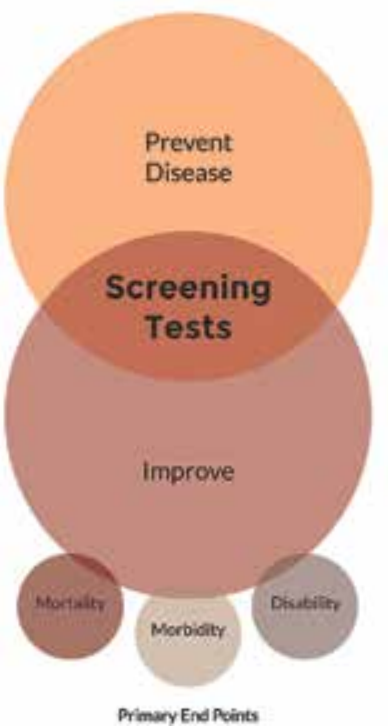

\section{Diagnostic Tests}

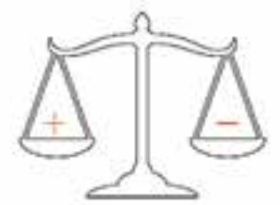

Balances Benefits to Risks in

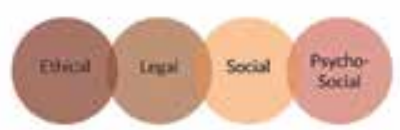

PrimaryEnd Points

Figure 1.

Clinical utility in genetics. The clinical utility in screening tests is to provide preventative care and to improve primary end points such as overall morbidity; in a diagnostic setting, the value of genetic testing lies in the balance of benefits to risks in more psychological domains.

contextual or implementation issues (e.g., availability of resources) and that clinical utility can also include psychological benefits.

\subsection{Evaluating genetic tests}

Evaluating genetic tests is often methodologically difficult largely due to small patient populations and the resulting dearth of high-quality studies. Adapted from Morrison et al. 2012, the following subsections are generally agreed upon as common characteristics for reviewing genetic tests $[3,4]$.

\subsubsection{Overview of disease and underlying genetics}

- Information on the disease prevalence, treatments, and outcomes of the disease as well as overall cost

- Description of the genetic causes, including inheritance patterns

- Classifying the mutational spectrum, along with the prevalence and penetrance

- Determination if there is any "gold standard" tests to compare to

\subsubsection{Target population and intended use}

- Prevalence for target population involves age, ethnicity, and eligibility for testing 
- Purpose of the test: is it diagnostic, for treatment, prognosis, management, carrier testing, prenatal testing, or other?

\subsubsection{Laboratory information}

- Validation details

$\circ$ Test new or already in use?

- If already in use:

- Number and rate of positive and negative mutations

- Turn-around-time for results

- Similar tests available

- Current testing activity and expected with appropriate funding figures

- Whether there are other laboratories that could offer the test

- Infrastructure requirements

- Quality assurance, maintenance, and improvement programs-both internally and externally

\subsubsection{Economic considerations}

- Cost estimates for the test including equipment, personnel, and consumables/ reagents

- Costs of disease burden with or without treatment

- Costs saved by employing test

\subsubsection{Analytic validity}

- Precision, reliability, accuracy, sensitivity, and specificity of the genetic test, and how these compare with other employed screening and diagnostic tests

\subsubsection{Clinical validity}

- Specificity and sensitivity, positive predictive value, negative predictive value, likelihood ratios, and how these compare with other employed screening and diagnostic tests

\subsubsection{Clinical utility}

- Benefits and risks of the test

- Treatment of the patient 
- Patient's health outcome

- Effect on patient and patient's family members

- Alternative diagnostic tests compare and contrast to genetic testing

\subsubsection{Ethical, legal, and social}

- Details on ethical, legal, and societal issues include support and follow-up

\subsection{ACCE model and beyond}

The CDC furthered the ACCE framework by establishing the Evaluation of Genomic Applications in Practice and Prevention (EGAPP) Initiative. The EGAPP supports the development and implementation of an evidence-based process for evaluating genetic tests and other genomic applications for clinical and public health practice. An independent, nonfederal EGAPP Working Group (EWG), consisting of a multidisciplinary expert panel selects topics of interest, reviews evidence, and recommends courses of action [2]. Key objectives of the EWG are to develop an openly accountable process, reduce conflicts of interest, and provide a connection between well-established evidence and the EWG recommendations [2, 5].

The ACCE model has stood the test of time and has proven to be a basis for the technical appraisal of genetic tests across the globe (Figure 2). The UK Genetic Testing Network and the Andalusian Agency for Health Technology Assessment expanded the ACCE model to guide the introduction of new genetic tests into their

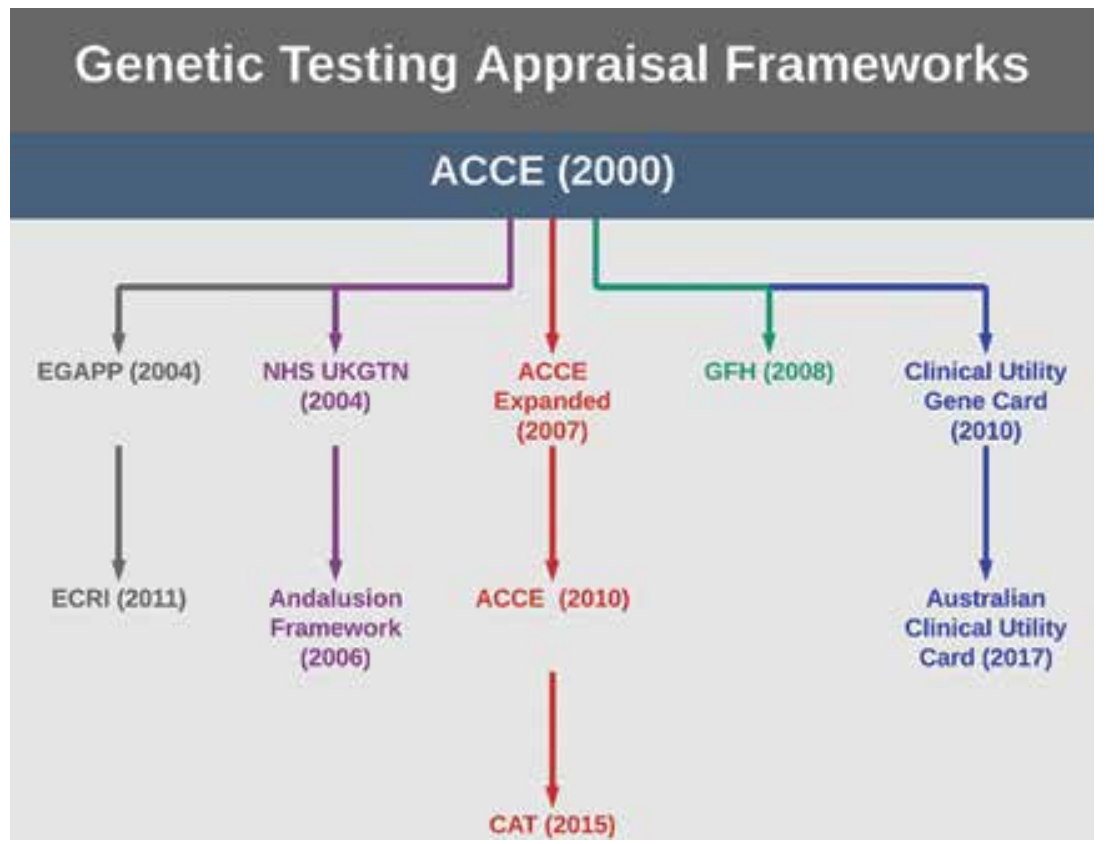

Figure 2.

Genetic testing appraisal frameworks. Testing appraisal frameworks around the globe have largely stemmed from the analytic validity, clinical validity, clinical utility, and ethical, legal and social implications (ACCE) framework announced in 200o. EGAPP, evaluation of genomic applications in practice and prevention; ECRI, Emergency Care Research Institute; NHS UKGTN, National Health Service UK Genetic Testing Network; CAT, companion test assessment; GFH, German Society of Human Genetics. 
public health system, creating the 2004 NHS UKGTN Gene Dossier and the 2006 Andalusian Framework. In 2007, the ACCE model was again modified by adding health quality measures to the evaluation process. The process was made more streamlined, shortening the systematic review process for emerging genetic tests. In 2010, the ACCE model was adapted to particular types of genetic testing through the Complex Disease Framework and the ACHDNC Newborn Screening Framework of the Advisory Committee on Heritable Disorders in Newborns and Children. The ACCE model also spawned two European frameworks: the 2008 GFH Indication Criteria of the German Society of Human Genetics and the 2010 Clinical Utility Gene Card of EuroGentest. The 2015 Companion test Assessment Tool (CAT) build upon the ACCE model to determine which tests needed further evaluation. In 2011, the ECRI Institute utilized the EGAPP process to develop a set of analytical frameworks for various testing scenarios and other stakeholder aspects. Lastly, the EuroGentest inspired the 2017 Australian Clinical Utility Card [5].

We cannot ignore the influence of the stakeholders who will invariably have wildly different opinions as to which outcomes are considered relevant. Thus, the types of outcomes that must be considered in evaluating the utility of a genetic test will also depend on the purpose of the test and the congregation of those who make the final decision. For example, a state-funded public health program will likely focus on the overall impact on morbidity and mortality versus privately funded sectors concentrating on the greater net profit. Coverage decisions by third-party payers may be based in large part on perceptions that test results are useful for timely or accurate diagnoses and clinical management. For a test that is offered to families in a clinical setting on a voluntary basis, the value of information for making career, residential, and reproductive decisions take on greater relevance.

Before a genetic test can be accepted into clinical practice, data must be collected to demonstrate the benefits and risks that accumulate from both positive and negative results [1]. Referring back to the colorectal surgery example above, the term "clinical utility" fits in very well; however, when applied to genetics or genomics medicine, the term may be too limited. The clinical end points are extremely important, but the utility or actionable context must remain broad in genetics to embody an overall net benefit. Genetic testing is particularly useful in the psychosocial, ethical, legal, and social (ELS) realms as well as in many diagnostic cases (Figure 1). By including clinical and ELS together in the concept, improvements in health outcomes such as enhancements in morbidity, mortality, and in disability become strong primary end points when assessing the utility of genetic testing.

\section{Genetic epidemiology: population and family-based studies}

The process of genetic epidemiology has flowed sequentially from observing phenotypic differences between populations to demonstrating that diseases can run in families, to examining feasible genetic susceptibility models, to tracking cosegregating genetic markers with disease in families, to narrowing the region of candidate genes, to association analyses with candidate genes, to cloning and mutation identification, to functional and structural characterization of a gene, and, ultimately, to extending the phenotype characterization even further based on the genotype identified (Figure 3) [6].

Population and family-based studies are at the heart of genetic epidemiology. Population-based association studies are generally regarded as more statistically powerful than family-based studies, as they tend to have more subjects and are overall easier to execute [6]. Family-based designs are influential methods that use the proband as well as their relatives to assess the genetic and molecular 


\section{Genetic Epidemiological Historical Progression}

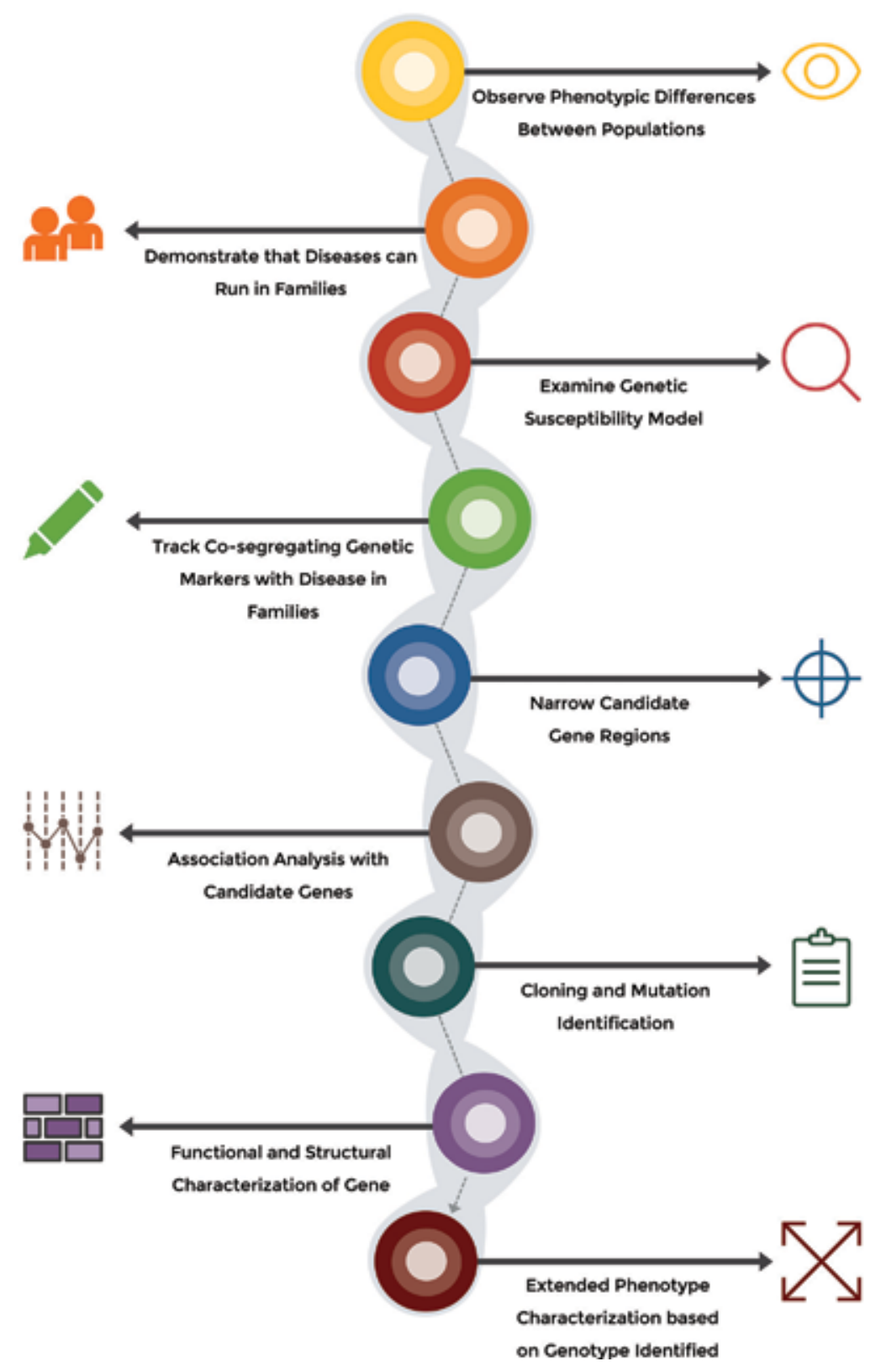

Figure 3.

Genetic epidemiological historical progression.

epidemiology of disease (Figure 4). The various types of studies available include familial aggregation, twins, segregation, linkage, and association.

Linkage and association studies directly evaluate genetic markers and require the collection of DNA from the study subjects-as opposed to twin studies, segregation studies, and familial aggregations studies. Family-based studies have been the long-standing primary approach to detect disease-causing genes.

Segregation and linkage studies are highly valuable methods for assisting in 


\section{Population and Family Studies}

\section{A Closer Look at the Essential Elements of Each}
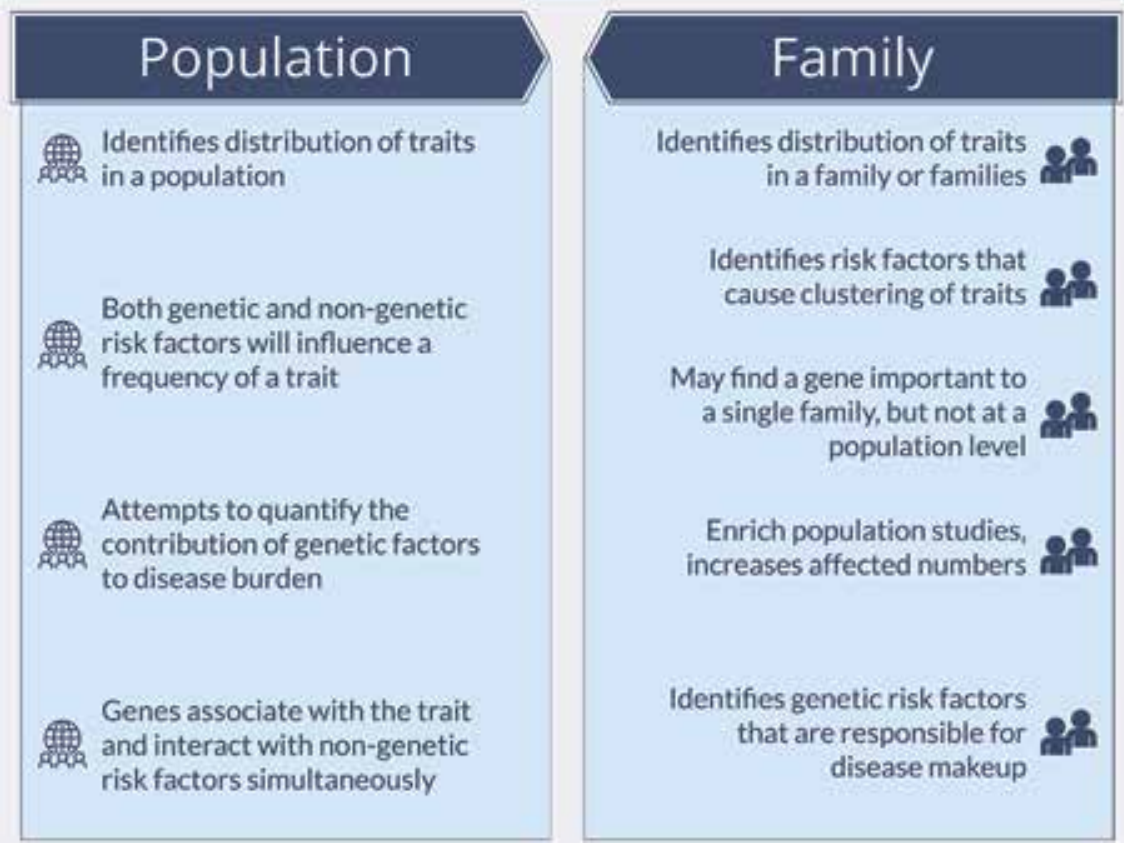

Figure 4.

A closer look at family-based and population studies.

cloning highly penetrant rare disease-causing genes. Family-based association studies strengths lie in their ability to control for confounding bias due to population stratification-albeit they do so at a loss of power $[1,5,6]$.

Population stratification is when contrived associations can be detected if cases and controls come from different source populations that have systematic differences in ancestral allele frequencies. A great advantage of employing family-based study designs is that population stratification can be circumvented. By studying parents and their offspring/siblings, cases and controls within each family are virtually guaranteed to arise from the same sample source or population. Due to the increasing efficacy of identification of association with disease, the importance of family-based studies has seemingly subsided; however, it is worth pressing that family-based studies are arguably more important than they have ever been as they are still the only way to truly link a causative variant to disease $[1,5,6]$.

Family-based studies can help determine whether a disease or trait is genetically influential by studying familial aggregation. Results can be furthered with a segregation analysis to identify the mode of inheritance. The results from the segregation analysis can add power to a linkage analysis, which searches across the entire genome in an attempt to locate regions containing causal genes $[1,5,6]$.

Segregation analysis is a method of establishing the genetic inheritance of disease and is performed exclusively with family data. This approach assists in 
determining if a disease segregates with a variant in a single gene; in addition to this, the mode of inheritance can also be ascertained. Very large pedigrees and families with a plethora of affected individuals are exceptionally informative for identifying specific genes $[1,5,6]$.

Once a family is collected, and studied, in a segregation analysis, that family is generally made available for further analyses (e.g., linkage). Linkage occurs when two loci/alleles on the same chromosome are inherited together. Since recombination during meiosis can occur virtually anywhere in the genome it stands to reason that the closer two loci are to each other the less likely they will be separated after a recombining event (i.e., the more likely they are to stay together after recombination), that is, it says they are "linked." Linkage analyses utilize this phenomenon by investigating co-segregating genetic markers along with a disease trait seen within the family (or families) - the trait can be either qualitative or quantitative. If the markers and traits are observed to co-segregate within families, it can be logically inferred that the disease-causing variants are within close proximity to the markers $[1,5,6]$.

This point reveals that linkage is "intrafamilial," whereby the co-segregating marker allele may very well be different in different families. Families are generally recruited into linkage studies on the basis of having at least one identified affected individual, and the families are either quite large or have affected siblings. Generally, the markers are spaced evenly over the entire genome, and linkage can be performed by utilizing these markers.

\section{Breast and ovarian cancer: the journey of finding $B R C A 1$ and $B R C A 2$}

Establishing penetrance is an arduous undertaking even for some of the most well-studied genes (e.g., with $B R C A 1$ and $B R C A 2$ ) simply because no two genetic studies have yielded the same findings. Many of the data and results discrepancies can be linked to differences in the populations studied and to the methodologies employed. It is vanishingly rare, if not impossible, for these studies to have similar methodologies to allow for perfect reproduction of results. The range of penetrance found for the BRCA variants and genes has guided the clinical recommendations for breast and ovarian cancer surveillance and prevention and has provided a sort of genetic "gold standard" by which all other genes are now compared and contrasted against $[7,8]$.

A strong family history of breast cancer is associated with an early age of onset, the addition of ovarian cancer, bilateral tumors, and a rarely affected male. BRCA1 (and similarly for $B R C A 2$ ) has been identified through the study of women who have presented with a strong family history of breast and ovarian cancer (Figure 5). In 1988, more than 1500 families with multiple cases of breast and ovarian cancer were studied; the data generated was subjected to a segregation analysis. The results illuminated that roughly $5 \%$ of cases, particularly those with early-onset disease, could be heritable in a Mendelian fashion. Selected families, those with nearMendelian pedigree patterns, were aggregated for linkage analysis. A major susceptibility locus, BRCA1 (OMIM 113705), was mapped to 17q21 in 1990. 17q-linked families that were above 45 years of age at diagnosis were given negative LOD scores.

In 1994, a linkage analysis performed on 15 large families with breast cancer that were also determined to not be linked to $17 \mathrm{q}$ helped identify the BRCA2 locus located on 13q12 (OMIM 600185). Later that year BRCA1 was cloned, and in 1995 $B R C A 2$ was cloned. $B R C A 1$ variants accounted for a very large proportion of 


\section{Identification of the BRCAl Gene}

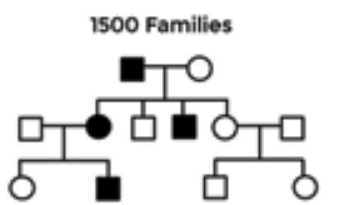

\section{Segregation} Analysis

Cenetic Susceptibility Model

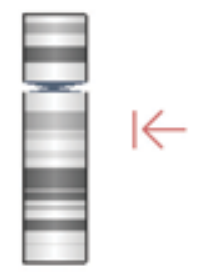

LOD-Score Analysis
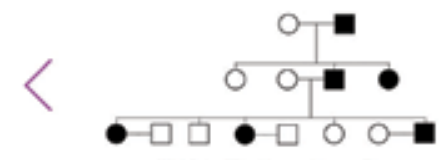

23 Multi-Case Families

Locus at 17q21

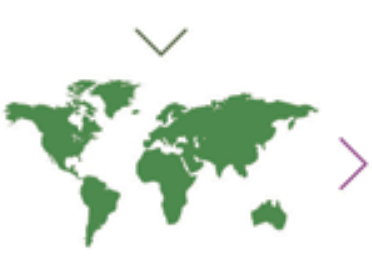

LOD-Score Analysis

214 International Multi-Case Families

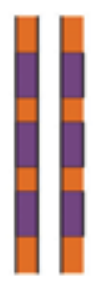

Candidate Region

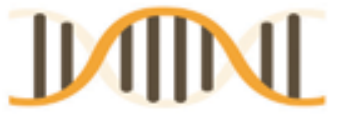

BRCAI Cene Identified

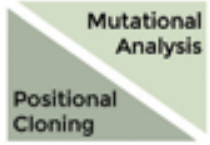

Figure 5 .

The progression of discovering the BRCA1 gene.

families with both breast and ovarian cancers, while male breast cancer was predominately observed in $B R C A 2$ variant families [9].

$B R C A 1$ and $B R C A 2$ were identified by focusing on a small number of specific families. Other candidate genes were established from focused studies.

- In 2004, the variant c.1100de1C in the CHEK2 gene was observed in 201 cases (1.9\%) and 64 controls $(0.7 \%)$ in 10,860 breast cancer cases and 9065 controls from 10 case-control studies in 5 countries (estimated odds ratio (OR) 2.34; 95\% CI 1.72-3.20; $\mathrm{P}=0.0000001$ ) [10].

- In 2006, the $A T M$ gene was screened in individuals from specific families, and 12 mutations were found in affected individuals and in 2 controls $(P=0.0047)$ from 443 familial breast cancer pedigrees and 521 controls (estimated relative risk of 2.37 (95\% CI 1.51-3.78, $\mathrm{P}=0.0003$ ) [11]. 
- BRIP1 was initially described as a breast cancer predisposition gene in 2006. The analysis of 1212 women with familial breast cancer along with 2081 controls yielded mutations in 9 cases and in 2 controls (estimated relative risk of $2.0 ; 95 \% \mathrm{CI}=1.2-3.2 ; \mathrm{P}=0.012)$ [12].

- PALB2 mutations were found in 10 cases of 923 individuals with familial breast cancer, and no mutations were found in 1084 controls $(P=0.0004)$ (estimated odd ratio of 2.3; 95\% CI = 1.4-3.9; $\mathrm{P}=0.0025$ ) [13].

These factors are the most relevant in families where the disease and the variant are actually segregating together, but at a population level, their overall implication is surprisingly small. For instance, CHEK2:c.1100de1C, at a population level, is seen in only $1.9 \%$ of cases [14].

\section{Less penetrant genes: $P A L B 2, B R I P 1$, and RECQL}

Traditionally, epidemiological studies tend to emphasize the inclination that the greatest benefits to the population are found in interventions that decrease risk factors for the bulk of the population, not in targeting a small number of individuals at the extreme ends of the risk spectrum. As we can see from the sample multigene panel for hereditary breast cancer the genes selected for testing range from quite influential (e.g., BRCA1 and BRCA2) to marginally influential (e.g., STK11)

(Table 1). However, it is quite interesting to explore the data for lower-risk genes such as PALB2 and BRIP1 and also for genes that are suspected of having involvement in breast or ovarian cancer, but the data is not quite yet congruent with the theory (e.g., $R E C Q L$ ).

Less penetrant genetic loci are mainly represented by the single-nucleotide polymorphisms (SNPs) or by the variants of uncertain significance discovered through genome-wide association studies. Variants associated with a minor increased risk, unlike high-risk mutations, can only account for a small portion of cancers seen in family histories of carriers. Thus, the cumulative risk for carriers with a positive family history will largely depend on the risk levels attributed to both their family history for that cancer and the risk induced by the variant itself. For example, if a carrier of a variant associated with an increased odds ratio of cancer also has a family history sufficient to quadruple her risk, her cumulative risk will be about that of a woman with a $4 \mathrm{x}$ OR increased risk [7].

Mutations in ATM, PALB2, and CHEK2:c.1100delC, in conjunction with a strong family history, are very likely to be associated with a high absolute risk of breast cancer [17]. It is important to note that the family history creates a context whereby it changes the penetrance of these mutations. This interpretation is clinically important and would justify testing for these mutations in multi-case breast cancer families such as those seen by typical cancer family genetics services.

Genetic risk factors, which are familial by their very definition, will be more frequent in women with positive family histories involving multiple breast cancers through their direct association with breast cancer as a disease entity and with their direct association with the familial aspect of breast cancer. This can be illustrated in a simple example where we consider a rare mutation whose presence doubles the risk of breast cancer relative to the general population: it will be roughly four times more common in women who are affected and who have an affected first-degree relative, which will square the ratio [17]. 


\begin{tabular}{|c|c|}
\hline \multicolumn{2}{|c|}{ Sample multigene hereditary breast cancer panel } \\
\hline Gene & Notes \\
\hline ATM c.7271 T > G & - \\
\hline $\begin{array}{l}\text { other } A T M \\
\text { mutations }\end{array}$ & $\begin{array}{l}\text { Lack of data regarding penetrance and surveillance except for c. } 7171 \mathrm{~T}>\mathrm{G} \\
\text { mutation. If mutation has been identified, a careful assessment of residual risk for } \\
\text { relatives who are noncarriers is needed }\end{array}$ \\
\hline BARD1 & - \\
\hline$B R C A 1$ & - \\
\hline$B R C A 2$ & - \\
\hline$B R I P 1$ & - \\
\hline CDH1 & $\begin{array}{l}\text { Increased risk of lobular breast cancer. Gastric cancer risk is unknown when } \\
\text { mutations are identified in absence of a positive family history of gastric cancer }\end{array}$ \\
\hline $\begin{array}{l}\text { CHEK2 } \\
\text { c.1100delC }\end{array}$ & Mutations are rare, but high penetrance in some families \\
\hline $\begin{array}{l}\text { other } C H E K 2 \\
\text { mutations }\end{array}$ & Lack of penetrance data except for in specific mutations \\
\hline$N B N$ & - \\
\hline NF1 & $\begin{array}{l}\text { Can identify mutation carriers by clinical phenotype and then perform gene } \\
\text { specific test }\end{array}$ \\
\hline PALB2 & Mutations are rare, but high penetrance in some families \\
\hline $\begin{array}{l}\text { other } P A L B 2 \\
\text { mutations }\end{array}$ & - \\
\hline PTEN & Can usually be identified by clinical phenotype \\
\hline RAD50 & - \\
\hline STK11 & Can usually be identified by clinical phenotype. Low penetrance in breast cancer \\
\hline TP53 & $\begin{array}{l}\text { Breast cancer risk management inferred from other genes. High penetrance for } \\
\text { breast cancer, but mutations are rare }\end{array}$ \\
\hline apted from: Invitae a & and eviQ $[15,16]$. \\
\hline
\end{tabular}

Table 1.

Sample multigene panel offered for hereditary breast cancer.

\subsection{PALB2}

The Finnish founder mutation was found in 0.9\% (18 of 1918) of cases without selecting for or emphasizing family history. Likewise, a French-Canadian founder mutation was found in $0.6 \%$ ( 2 of 356 ) of cases also without selecting for or emphasizing family history selected. The numbers of the PALB2 founder mutation carriers were too small to make precise risk inferences, but modified segregation analyses of data from the families of case-carriers were used to estimate risk for carrier families, which has demonstrated the importance of these founder mutations in the risk of developing breast cancer [13, 14, 18, 19].

Blanco et al. found that the frequency of $P A L B 2$ mutations was $\sim 1.5 \%$ after investigating the incidence of mutations in $P A L B 2$ patients with breast cancer that were also negative for any variants in $B R C A 1$ and $B R C A 2+/-$ a family history of pancreatic cancer; previous studies had the mutation rate for similar cohorts range from 0 to $4.8 \%$. Dansonka-Mieszkowska et al. conducted similar research among Polish women; their study showed a minor but significant PALB2 mutation presence at $\sim 0.6 \%[13,14,18,19]$. 
Likewise, Bogdanov et al. conducted a study on the occurrence of $P A L B 2$ mutations among Russian and German women and reported a mutation rate of $\sim 2 \%$. In 2014, Antoniou et al. tested 362 women from 154 families and found that the risk of breast cancer in women 40 years of age or younger with $P A L B 2$ mutation was $\sim 9 \mathrm{x}$ greater, $\sim 8 \mathrm{x}$ greater in patients aged $40-60$ years, and $\sim 5 \mathrm{x}$ greater in patients 60 years and older when compared to the general population. The absolute risk of breast cancer in women with PALB2 mutations under 70 years of age ranges from 33 to $58 \%$ for women without and with a positive family history of breast cancer, respectively. Interestingly, Hartley et al. conducted a study that confirmed that as the number of cases of breast cancer in a family increases, the likelihood of PALB2 mutations increases as well. Women with $3+$ positive cases of familial breast cancer have a $2.6 \%$ greater likelihood of having a PALB2 mutation than those without multiple cases $[13,14,18,19]$.

Southley et al. studied Australian women to determine the occurrence rate and penetrance of $P A L B 2$ mutations. The study found that the women with breast cancer and a positive family history of having PALB2 mutations had PALB2 mutations present in $1 \%$ of patients. The study identified that the women with breast cancer and no family history of PALB2 mutations had PALB2 mutations present in only $\sim 0.4 \%$ of patients. There were no PALB2 mutations detected in the control/ healthy population of women. Heikkinen et al. studied southern Finnish women and found PALB2 mutations in $2 \%$ of patients with a positive familial history of breast cancer and also in $0.6 \%$ of women with a sporadic breast cancer presentation $[13,14,18,19]$.

In 2016, a seminal paper by Thompson et al. examined 2000 predominantly breast cancer-affected women with a strong family history that were also BRCA1 and $B R C A 2$ variant-negative and compared them to 1997 controls. They observed that a significant proportion of mutations were only in PALB2 (26 cases vs. 4 controls) and in TP53 (5 cases vs. none in controls), whereas no mutations were identified in STK11 [14]. PALB2 is a great example of how penetrance estimates can depend on the population, family history, and age at onset as well as other considerations [17].

\subsection{BRIP1}

BRIP1 was initially described as a breast cancer predisposition gene in 2006. The analysis of 1212 women with familial breast cancer along with 2081 controls yielded mutations in 9 cases and in 2 controls (estimated relative risk of 2.0; 95\% $\mathrm{CI}=1.2-3.2 ; \mathrm{P}=0.012$ ). However, recently BRIP1's association with breast cancer has grown suspect, while its association with ovarian cancer has risen sharply. $B R I P 1$ mutations confer a high ovarian risk in familial index patients $(\mathrm{OR}=20.97$, $95 \% \mathrm{CI}=12.02-36.57 ; \mathrm{P}<0.0001)$ and in the subgroup of patients with late onset ovarian cancer $(\mathrm{OR}=29.91,95 \% \mathrm{CI}=14.99-59.66 ; \mathrm{P}<0.0001)$ [12].

\subsection{RECQL}

In a screen of 144 Polish and 51 French-Canadian women with early-onset familial breast cancer, $2.6 \%$ possessed truncating mutations in RECQL. Validation studies that reviewed the RECQL variant c.1667_1667C3delAGTA in over 13,000 breast cancer patients with 4702 Polish controls showed the RECQL mutation appeared in $0.23 \%$ of cases and in $0.04 \%$ in controls. Likewise, the RECQL variant c.634C > T (p. Arg215*) seen in the French-Canadian population was further screened in 538 patients and 7136 newborn controls and was detected in 5 patients and in one control-a nearly 50x increase in frequency in affected versus 
unaffected individuals. Studies of patients in northern China revealed a pathogenic RECQL mutation in $2.0 \%$ of the 448 familial breast cancer patients compared to the $0.06 \%$ seen in 1588 control subjects [20]. By whole exome sequencing 0 early-onset familial breast cancer patients without $B R C A 1 / 2$ mutations and by screening the RECQL gene in an additional 439 unrelated familial breast cancer patients, 9 index cases were found to carry a pathogenic mutation in the RECQL gene among the 448 BRCA-negative familial breast cancer patients. It was determined that the pathogenic mutation rate of the RECQL gene in familial breast cancer in BRCA1-/BRCA2-negative breast cancer patients was $2.0 \%$. Further to these results, no loss of heterozygosity was found in the RECQL mutation carriers, suggesting that $R E C Q L$-associated tumorigenesis is likely through classical haploinsufficiency [21].

In 2018, Li et al. sequenced all the exons of RECQL and at least $10 \mathrm{bp}$ of the exon-intron flanking regions in 9112 subjects from Australia. The case subjects were females diagnosed with breast or ovarian cancer from 4536 families with a negative result after BRCA1 and BRCA2 mutation testing. The controls were 4576 women who were above 40 years of age and were cancer-free as of May 2016. Thirteen loss-of-function mutations in the cases and 25 in the controls were identified $(0.29$ versus $0.55 \%$, odds ratio $0.52,95 \%$ confidence interval $0.25-1.06$, $\mathrm{P}=0.072$ by two-tailed Fisher's exact test) [22]. Missense variants observed between cases and controls were not statistically significant (54 cases, 1.19\%, versus 37 controls, $0.81 \% ; \mathrm{P}=0.073$ ) [22]. It is generally accepted that a predisposition gene is considered actionable only if the $90 \%$ confidence limit of the estimated relative risk is greater than four [22]; therefore, RECQL, can be excluded based on these findings.

\subsection{Lack of data and the impact of finding a variant of unknown significance}

Despite the intense and widespread shared enthusiasm to reduce the risk of predictable cancers, the adoption of the more recent breast cancer predisposition genes, such as $P A L B 2$, has been sluggish. This has been largely due to the communal appreciation that following a variant of unknown significance result, the complexity of interpretation may lead to a subsequent clinical utility hindrance. An additional 3.9\% of patients tested by multiple gene panels had pathogenic mutations identified in other breast cancer predisposition genes, namely, in PALB2, CHEK2, and ATM; however, many of these multigene panel tests also identified many variants of uncertain significance, where the classification is either uncertain or simply just not possible-and this information cannot safely be utilized clinically [19].

Indeed, this consideration is shared in recent literature and has been extended by Thompson et al. where the authors examined various genes that are common on hereditary breast cancer panels. They observed that the frequency of mutations in most breast cancer panel genes is quite low, or even, in most cases, similar to the frequency of mutations observed in cancer-free population controls. They concluded that panels have the potential to provide clinical misinformation and harm at the individual level if the data is not interpreted with extreme caution [14]. This lack of evidence for new genetic players is not limited to breast and ovarian cancer, but it also plagues many other genetic diseases and also afflicts a great number of other multigene panels [19].

Due to this lack of supportive data, international large-scale studies into the genes included in these multigene panels are absolutely critical to increase the utility of the information yielded and also to ensure that the new genetic information presented is both safe and useful in a clinical setting. 


\section{Conclusions}

Keeping in-line with global regulation entities such as CAT, EGAPP, NHS UKGTN, and the ACCE backbone discussed above, the recent initiative eviQ provides a variety of guidelines for cancer genetics investigations. EviQ is part of the Cancer Institute NSW (New South Wales) and provides evidence-based information to support health professionals in the delivery of cancer treatments available at the time treatment decisions are being made. We can see from the eviQ's general practitioner referral guidelines for cancer genetics assessment that generally, even in oncology, genetics plays a large part in the diagnostics of disease [23]. We can also note that there must be a strong clinical suspicion of the diagnosis involving a genetic element (e.g., quite young, strong family history, hailing from a region with restricted gene flow, etc.) to warrant testing and for it to be useful.

The clinical utility of genetics is highly variable and dependent on the gene or disorder involved, but genomics medicine appears to be very good at revealing a diagnosis, and, at times, it can help explain why the phenotype is the way it is. In oncology, genetic testing plays an integral role in disease management by influencing treatment options or by being a major inclusion component for clinical trials. Where genetic testing is taking off and, perhaps, where its true potential lies is in its ability to offer predictive and preventative medicine, particularly for families, as opposed to adhering to a purely reactive approach that is typically employed in mainstream medicine.

Genomics is by no means irrelevant; it is revealing much about human disease and pathophysiology, but barring the current leaps and bounds observed in oncology, genomics medicine is still in an informational gathering phase-albeit, it is doing so at an alarming and unparalleled rate. It will take a great deal more data, analysis, and time before it will be considered true mainstream medicine, but there is no doubt that genomics is the future of medicine.

\section{Conflict of interest}

The authors declare no conflict of interest.

\section{Author details}

Tom Nolis and Rodney J. Scott*

NSW Health Pathology North, Hunter Medical Research Institute, Newcastle, NSW, Australia

*Address all correspondence to: rodney.scott@newcastle.edu.au

\section{IntechOpen}

(C) 2018 The Author(s). Licensee IntechOpen. This chapter is distributed under the terms of the Creative Commons Attribution License (http://creativecommons.org/licenses/ by/3.0), which permits unrestricted use, distribution, and reproduction in any medium, provided the original work is properly cited. (c) BY 


\section{References}

[1] Grosse SD, Khoury MJ. What is the clinical utility of genetic testing? Genetics in Medicine. 2006;8(7): 448-450

[2] Teutsch SM, Bradley LA, Palomaki GE, Haddow JE, Piper M, Calonge N, et al. The evaluation of genomic applications in practice and prevention (EGAPP) initiative: Methods of the EGAPP working group. Genetics in Medicine. 2009;11(1):3-14

[3] Morrison A, Boudreau R. Evaluation Frameworks for Genetic Tests

[Environmental Scan issue 37]. Ottawa: Canadian Agency for Drugs and Technologies in Health; 2012

[4] Murad MH, Montori VM, Ioannidis JPA, Jaeschke R, Devereaux PJ, Prasad $\mathrm{K}$, et al. How to read a systematic review and meta-analysis and apply the results to patient care: Users' guides to the medical literature. JAMA - The Journal of the American Medical Association. 2014;312(2):171-179

[5] Pitini E, De Vito C, Marzuillo C, D'Andrea E, Rosso A, Federici A, et al. How is genetic testing evaluated? A systematic review of the literature. European Journal of Human Genetics. 2018;26(5):605-615. Available from: http://dx.doi.org/10.1038/s41431-0180095-5

[6] Fardo DW, Charnigo R. Families or unrelated: The evolving debate in genetic association studies. Journal of Biometrics and Biostatistics. 2012;3(4): 10-11. Available from: http://www. omicsonline.org/2155-6180/2155-61803-e108.digital/2155-6180-3-e108.html

[7] Lindor NM, Hopper J, Dowty J. Estimating cumulative risks for breast cancer for carriers of variants in uncommon genes. Familial Cancer. 2016;15(3):367-370
[8] Guidugli L, Shimelis H, Masica DL, Pankratz VS, Lipton GB, Singh N, et al. Assessment of the clinical relevance of BRCA2 missense variants by functional and computational approaches.

American Journal of Human Genetics. 2018:233-248

[9] Miki Y, Swensen J, Shattuck-eidens D, Futreal PA, Harshman K, Tavtigian $\mathrm{S}$, et al. Strong candidate for the breast and ovarian cancer susceptibility gene BRCA1. Science (80- ). 1994;266

(October):66-71

[10] Causeway W. CHEK2*1100delC and susceptibility to breast cancer: A collaborative analysis involving 10,860 breast cancer cases and 9,065 controls from 10 studies. American Journal of Human Genetics. 2004;74(6):1175-1182. Available from: http://linkinghub. elsevier.com/retrieve/pii/ S0002929707627049

[11] Renwick A, Thompson D, Seal S, Kelly P, Chagtai T, Ahmed M, et al. ATM mutations that cause ataxiatelangiectasia are breast cancer susceptibility alleles. Nature Genetics. 2006;38:873. Available from: http://dx. doi.org/10.1038/ng1837

[12] Weber-Lassalle N, Hauke J, Ramser J, Richters L, Groß E, Blümcke B, et al. BRIP1 loss-of-function mutations confer high risk for familial ovarian cancer, but not familial breast cancer. Breast Cancer Research. 2018;20(1):1-6

[13] Rahman N, Seal S, Thompson D, Kelly P, Renwick A, Elliott A, et al. PALB2, which encodes a BRCA2interacting protein, is a breast cancer susceptibility gene. Nature Genetics. $2007 \mathrm{Feb}$;39(2):165-167. Available from: http://www.nature.com/articles/ng1959

[14] Thompson ER, Rowley SM, Li N, McInerny S, Devereux L, Wong-Brown 
MW, et al. Panel testing for familial breast cancer: Calibrating the tension between research and clinical care. Journal of Clinical Oncology. 2016; 34(13):1455-1459

[15] Invitae. Invitae Breast Cancer Panel [Internet]. 2018 Available from: https:// www.invitae.com/en/physician/tests/ 01202/ [Accessed: 2018-07-16]

[16] Clinical Resource: Panel Testing for Familial Breast Cancer 2018 V.1, eviQ Cancer Treatments Online, Cancer Institute NSW, viewed 16th July 2018, https://www.eviq.org.au/cancer-genetics/ genetic-testing-using-cancer-genepanels/3413-panel-testing-for-famil.

[17] Byrnes GB, Southey MC, Hopper JL. Are the so-called low penetrance breast cancer genes, ATM, BRIP1, PALB2 and CHEK2, high risk for women with strong family histories? Breast Cancer Research. 2008;10(3):208. Available from: http://breast-cancer-research. biomedcentral.com/articles/10.1186/ bcr2009

[18] D MWA, E MJ. The risk of breast cancer due to PALB2 gene mutations. Advances in Clinical and Experimental Medicine. 2017;26(2):339-342

[19] Winship I, Southey MC. Gene panel testing for hereditary breast cancer. The Medical Journal of Australia. 2016; 204(5):188-190.e1

[20] Banerjee T, Brosh RMJ. RECQL: A new breast cancer susceptibility gene. Cell Cycle. 2015;14(22): 3540-3543

[21] Sun J, Wang Y, Xia Y, Xu Y, Ouyang $\mathrm{T}$, Li J, et al. Mutations in RECQL gene are associated with predisposition to breast cancer. PLoS Genetics. 2015; 11(5):4-15

[22] Li N, Rowley SM, Goode DL, Amarasinghe KC, McInerny S,
Devereux L, et al. Mutations in RECQL are not associated with breast cancer risk in an Australian population. Nature Genetics. 2018;89:1. Available from: http://www.nature.com/articles/ s41588-018-0206-9

[23] Clinical Resource: General Practitioner Referral Guidelines for Cancer Genetics Assessment 2017 V.4, eviQ Cancer Treatments Online, Cancer Institute NSW, viewed 16th July 2018, https://www.eviq.org.au/footer-pages/ faqs/protocols-and-documents 


\section{Edited by Israel Gomy}

The field of medical genetics and genomics has been constantly revolutionized by new breakthroughs, which bring more knowledge into the etiology and help improve the health care of individuals with either rare or common diseases. Nevertheless, as technologies evolve, novel challenges emerge, both technically and ethically, so they must be prudentially addressed. Among the myriad applications of genomics in medicine, this book depicts a glimpse of the advances achieved that have been leading us to the personalized/precision medicine era.

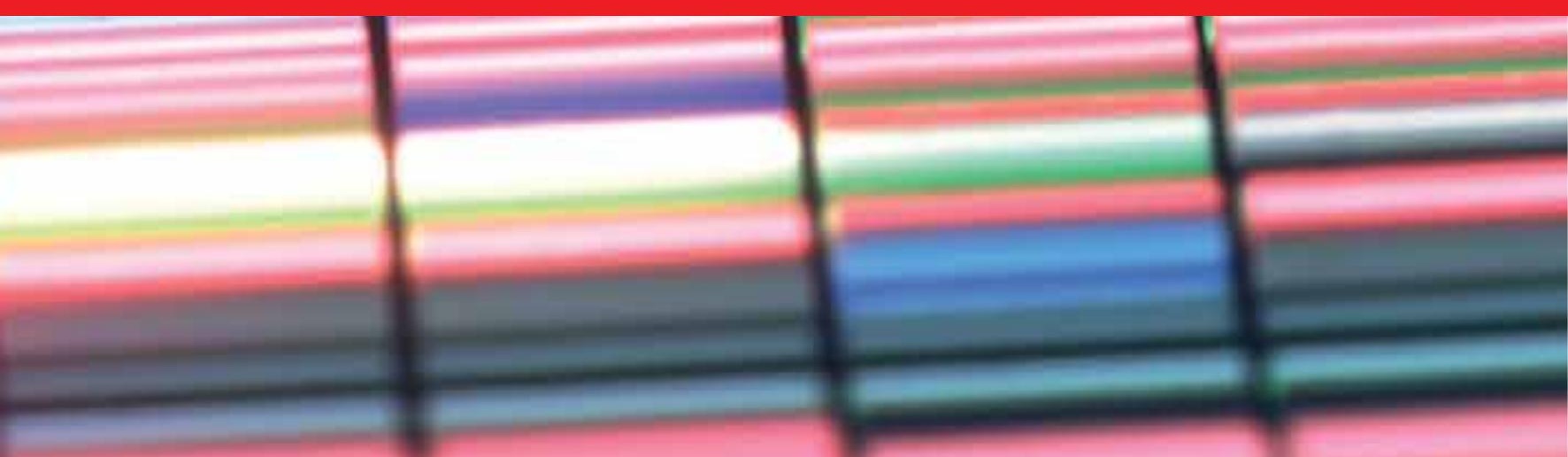

